\title{
The atmospheric chemistry general circulation model ECHAM5/MESSy1: consistent simulation of ozone from the surface to the mesosphere
}

\author{
P. Jöckel ${ }^{1}$, H. Tost ${ }^{1}$, A. Pozzer ${ }^{1}$, C. Brühl ${ }^{1}$, J. Buchholz ${ }^{1}$, L. Ganzeveld ${ }^{1}$, P. Hoor ${ }^{1}$, A. Kerkweg ${ }^{1}$, M. G. Lawrence ${ }^{1}$, \\ R. Sander ${ }^{1}$, B. Steil ${ }^{1}$, G. Stiller ${ }^{2}$, M. Tanarhte ${ }^{1}$, D. Taraborrelli ${ }^{1}$, J. van Aardenne ${ }^{1,{ }^{*}}$, and J. Lelieveld ${ }^{1}$ \\ ${ }^{1}$ Max Planck Institute for Chemistry, Atmospheric Chemistry Department, P.O. Box 3060, 55020 Mainz, Germany \\ ${ }^{2}$ Institute for Meteorology and Climate Research, Forschungszentrum Karlsruhe, P.O. Box 3640, 76021 Karlsruhe, Germany \\ *now at: European Commission, DG Joint Research Centre, Ispra, Italy
}

Received: 23 June 2006 - Published in Atmos. Chem. Phys. Discuss.: 25 July 2006

Revised: 1 November 2006 - Accepted: 3 November 2006 - Published: 7 November 2006

\begin{abstract}
The new Modular Earth Submodel System (MESSy) describes atmospheric chemistry and meteorological processes in a modular framework, following strict coding standards. It has been coupled to the ECHAM5 general circulation model, which has been slightly modified for this purpose. A 90-layer model setup up to $0.01 \mathrm{hPa}$ was used at spectral T42 resolution to simulate the lower and middle atmosphere. With the high vertical resolution the model simulates the Quasi-Biennial Oscillation. The model meteorology has been tested to check the influence of the changes to ECHAM5 and the radiation interactions with the new representation of atmospheric composition. In the simulations presented here a Newtonian relaxation technique was applied in the tropospheric part of the domain to weakly nudge the model towards the analysed meteorology during the period 1998-2005. This allows an efficient and direct evaluation with satellite and in-situ data. It is shown that the tropospheric wave forcing of the stratosphere in the model suffices to reproduce major stratospheric warming events leading e.g. to the vortex split over Antarctica in 2002. Characteristic features such as dehydration and denitrification caused by the sedimentation of polar stratospheric cloud particles and ozone depletion during winter and spring are simulated well, although ozone loss in the lower polar stratosphere is slightly underestimated. The model realistically simulates stratosphere-troposphere exchange processes as indicated by comparisons with satellite and in situ measurements. The evaluation of tropospheric chemistry presented here focuses on the distributions of ozone, hydroxyl radicals, carbon monoxide and reactive nitrogen compounds. In spite of minor shortcomings, mostly related to the relatively
\end{abstract}

Correspondence to: P. Jöckel

(joeckel@mpch-mainz.mpg.de) coarse $\mathrm{T} 42$ resolution and the neglect of inter-annual changes in biomass burning emissions, the main characteristics of the trace gas distributions are generally reproduced well. The MESSy submodels and the ECHAM5/MESSy1 model output are available through the internet on request.

\section{Introduction}

Ozone plays a key role in atmospheric chemical and radiation processes and for the existence of the stratosphere. The meridional gradients in solar radiation absorption by ozone locally modify the wave driven stratospheric circulation, and ozone photochemistry drives oxidation mechanisms in both the stratosphere and troposphere.

In the past, atmospheric chemistry general circulation models (AC-GCMs) generally focused either on the lower or the middle atmosphere, addressing e.g. global photooxidant formation or ozone depletion, respectively (Roelofs and Lelieveld, 2000; Steil et al., 2003). However, it is becoming increasingly evident that the understanding of links between these vertical layers up to the mesosphere may be central in improving our ability to model atmospheric composition, weather and climate; overviews of these issues and of current chemistry climate model developments are provided by Pawson et al. (2000); Austin et al. (2003); Eyring et al. (2006).

The intricate coupling of numerical schemes for different parts of the atmosphere and the replacement of prescribed boundary conditions by process descriptions introduces additional feedback mechanisms, while the options to tune the models towards the observed state of the atmosphere decrease. Thus, increasing consistency is accompanied by

Published by Copernicus GmbH on behalf of the European Geosciences Union. 
increasing complexity. But this increasing complexity of models can impede the error analyses and increase the vulnerability to numerical problems. In order to keep this continuously growing complexity towards Earth system models controllable, advanced methodologies for an efficient implementation are clearly required. We followed one of these potential methods, namely the rigorous modularisation of process descriptions explained by Jöckel et al. (2005), who discussed the advantages and consequences, and compared it with alternative approaches. We developed many new or improved atmospheric chemistry and dynamics related modules (see Appendices B and C) for the Modular Earth Submodel System (MESSy) ${ }^{1}$ and linked it to the 5th generation European Centre Hamburg GCM, ECHAM5 (Roeckner et al., 2003, 2004). The resulting model system ECHAM5/MESSy1 represents a new coupled lowermiddle atmospheric chemistry general circulation model (AC-GCM). It can be used to simulate both the weather and climate, the latter being the statistical representation of the former. However, before it can be applied to perform coupled chemistry-climate simulations (then usually referred to as a chemistry-climate model (CCM)), it needs to be determined if the model represents the current dynamical and chemical state of the atmosphere as constrained by known boundary conditions.

To show this is the focus of the present study. More precisely, we present the first comprehensive use of ECHAM5/MESSy1 to simulate the chemical weather, focusing on tropospheric and stratospheric ozone during the period 1998-2005 based on a trace gas emission dataset representative of the year 2000 (van Aardenne et al., 2005; Ganzeveld et al., 2006).

Our work takes advantage of the recent extensive evaluation of the GCM ECHAM5 (see Sect. 2 below). To simulate realistic synoptic conditions, we applied a weak "nudging" toward realistic meteorology (over the period of interest) by the assimilation of data from the European Centre for Medium-range Weather Forecasting (ECMWF) through the Newtonian relaxation of four prognostic model variables: temperature, divergence, vorticity and the logarithm of surface pressure (van Aalst et al., 2004). Apart from the prescribed sea surface temperature (SST) and the nudged surface pressure, the nudging is only applied in the free troposphere, tapering off towards the surface and lower stratosphere, so that the stratospheric dynamics are calculated freely and possible inconsistencies between the boundary layer representations of the ECMWF and ECHAM5 models are avoided. But also in the free troposphere, the nudging is weak enough to not disturb the self-consistent model physics.

Thus, this approach allows a direct comparison of the model output with measurement data (without constraining the model physics), and therefore an efficient model evaluation. For the evaluation we compare the model results with in

\footnotetext{
${ }^{1}$ http://www.messy-interface.org
}

situ and satellite measurements, with an emphasis on meteorological and transport characteristics of the coupled model. The tested meteorological parameters include temperature and moisture to ensure that the new modules do not deteriorate the ECHAM5 simulations of dynamical and physical processes that influence the chemical weather. We furthermore focus on chemical parameters for which extensive datasets are available, with an emphasis on tracer transport and gas-phase chemistry. For the stratosphere we used newly available comprehensive satellite data. Our analyses cover the full 8 year period, discuss seasonal averages and highlight a specific event, namely the 2002 southern hemispheric vortex split. Follow-up articles will address in more detail the atmospheric multiphase chemical processes involved, and the combined set of articles will be submitted to this special issue of Atmospheric Chemistry and Physics.

The high complexity applied in this study requires a relatively large computational effort, though in the presented setup the model can serve as a reference model for key processes in the upper troposphere/lower stratosphere which are critical for chemistry climate feedbacks. Nevertheless, it is also possible to simulate several decades, also without nudging of tropospheric meteorology.

The present study thus provides a benchmark for more efficient simulations in which some of the CPU time demanding routines may be switched off or reduced (e.g., the comprehensiveness of the chemistry), or replaced by alternative approaches. This possibility is one of the advantages achieved through the modularisation of MESSy. Moreover, the results of the simulations will be available through the internet ${ }^{2}$, so that subsequent model changes can be documented in terms of technical changes and scientific improvements.

After a brief description of the model system and the simulation setup (Sect. 2), we first evaluate basic characteristics of the simulated meteorology (Sect. 3) in the troposphere (Sect. 3.1) and the middle atmosphere (Sect. 3.2). This is followed by an analysis of the simulated ozone, first from a global perspective (Sect. 4). Then, we compare in more detail the simulated ozone chemistry (including other important chemical compounds) in the troposphere (Sect. 5) and in the middle atmosphere (Sect. 6) with observations. Finally, we briefly discuss our evaluation method (Sect. 7), summarise the overall model characteristics (Sect. 8) and end with an outlook.

\section{Model description and setup}

\subsection{The model structure and feedbacks}

ECHAM5/MESSy1 (further denoted as E5/M1) is the first implementation of an AC-GCM following the MESSy standard (Jöckel et al., 2005). Version 5.3.01 of ECHAM5 (Roeckner et al., 2003, 2006; Manzini et al., 2006; Roesch

\footnotetext{
${ }^{2}$ http://www.messy-interface.org
} 
and Roeckner, 2006; Wild and Roeckner, 2006; Hagemann et al., 2006) serves as the basemodel layer. The modifications and additions applied to ECHAM5 are listed in Appendix A. Via the MESSy interface structure a number of MESSy submodels are coupled to the system. These are listed in Appendix B including more details about the model setup. Additional and alternative submodels are also included in MESSy version 1.1 which are not applied in the present study. These are listed in Appendix C. The coupling among the various submodels and to the basemodel is sketched in Fig. 1. The following processes provide a coupling between chemistry and dynamics:

- Radiative temperature tendencies are calculated (submodel RAD4ALL) depending on the tracers $\mathrm{CO}_{2}, \mathrm{CH}_{4}$, $\mathrm{O}_{3}, \mathrm{~N}_{2} \mathrm{O}, \mathrm{CFCl}_{3}$ and $\mathrm{CF}_{2} \mathrm{Cl}_{2}$, and depending on the cloud cover (calculated by CLOUD), the water vapour, the cloud water content, and cloud ice.

- The chemical $\mathrm{H}_{2} \mathrm{O}$ tendency (calculated by the submodel MECCA) is fed back to the specific humidity of the basemodel (by the submodel $\mathrm{H} 2 \mathrm{O}$ ).

- The partitioning of total water into water vapour, liquid water, and ice, within and outside the PSC regions is calculated (by the submodels PSC and HETCHEM, respectively).

- Cloud droplet formation changes the partitioning of total water into vapour, liquid and ice (submodel CLOUD).

- Water vapour, liquid water, and ice are transported by convection (submodel CONVECT).

The chemical mechanism comprises 104 gas phase species and 245 reactions including heterogeneous reactions on sulfate aerosol and PSC-particles calculated by the submodel MECCA, and 6 additional species and 41 reactions for liquid phase chemistry in clouds and precipitation calculated by the submodel SCAV (see Appendix B and the electronic supplement http://www.atmos-chem-phys.net/6/5067/2006/ acp-6-5067-2006-supplement.zip for details). The chemical mechanism has been integrated in the entire model domain, i.e., consistently from the surface to the mesosphere. It is important to highlight that no arbitrary or artificial "intermediate boundary conditions" (for instance at the tropopause or between layers) are prescribed. This means that in particular the stratosphere-to-troposphere transport of ozone is simulated self-consistently, i.e., with only one ozone tracer. Chemical species are advected by the algorithm of Lin and Rood (1996), which is part of ECHAM5.

\subsection{Chemical boundary conditions}

Emissions of dimethyl sulfide (DMS) from the ocean, isoprene from plants, and NO from soils have been calcu- lated online (see Appendix B, submodel ONLEM). Emissions of $\mathrm{NO}, \mathrm{CO}, \mathrm{C}_{2} \mathrm{H}_{4}, \mathrm{C}_{2} \mathrm{H}_{6}, \mathrm{C}_{3} \mathrm{H}_{6}, \mathrm{C}_{3} \mathrm{H}_{8}, \mathrm{C}_{4} \mathrm{H}_{10}$, $\mathrm{CH}_{3} \mathrm{CHO}, \mathrm{CH}_{3} \mathrm{COCH}_{3}, \mathrm{CH}_{3} \mathrm{COOH}, \mathrm{CH}_{3} \mathrm{OH}, \mathrm{HCHO}$, $\mathrm{HCOOH}$, methyl ethyl ketone (MEK), $\mathrm{SO}_{2}$, and $\mathrm{NH}_{3}$ are distributed as multi-layer emissions onto 6 levels (45, 140, 240, 400, 600, $800 \mathrm{~m}$, see Appendix B, submodel OFFLEM). These emissions comprise the anthropogenic emissions from the EDGAR3.2FT 2000 ("fast-track") ${ }^{3}$ database and additional biogenic emissions as described in Ganzeveld et al. (2006). The aircraft NO emissions (1995) (Schmitt and Brunner, 1997) are distributed as volume emissions. In addition, the lower boundary conditions of $\mathrm{N}_{2} \mathrm{O}, \mathrm{CH}_{4}$, $\mathrm{CFCl}_{3}, \mathrm{CF}_{2} \mathrm{Cl}_{2}, \mathrm{CH}_{3} \mathrm{CCl}_{3}, \mathrm{CCl}_{4}, \mathrm{CH}_{3} \mathrm{Cl}, \mathrm{CH}_{3} \mathrm{Br}, \mathrm{CF}_{2} \mathrm{ClBr}$, $\mathrm{CF}_{3} \mathrm{Br}, \mathrm{H}_{2}, \mathrm{CO}_{2}$, and $\mathrm{SF}_{6}$ are prescribed from observed (time-dependent) mixing ratios using the AGAGE database (Prinn et al., 2000, see also Appendix B, TNUDGE). As in Steil et al. (2003) other source gases contributing to stratospheric chlorine, such as $\mathrm{C}_{2} \mathrm{~F}_{3} \mathrm{Cl}_{3}, \mathrm{CHF}_{2} \mathrm{Cl}$ and $\mathrm{C}_{2} \mathrm{H}_{3} \mathrm{FCl}_{2}$, are added to $\mathrm{CF}_{2} \mathrm{Cl}_{2}$ taking into account their chlorine atom number.

\subsection{Model setup}

The reference simulation (further denoted as S1) has been performed for the period January, 1998, to October, 2005, in T42L90MA resolution (MAECHAM5, Giorgetta et al., $2002,2006)$, i.e., with a triangular truncation at wave number 42 for the spectral core of ECHAM5, and with $90 \mathrm{lev}$ els on a hybrid-pressure grid in the vertical, reaching up to $0.01 \mathrm{hPa}$ (middle of uppermost layer). The vertical resolution near the tropopause is about $500 \mathrm{~m}$. As upper boundary condition the flux of constituents is set to zero. The chosen spectral resolution of T42 corresponds to a quadratic Gaussian grid of approximately $2.8^{\circ} \times 2.8^{\circ}$ in latitude and longitude, respectively. The model time step is $900 \mathrm{~s}$. Output has been archived as 5-hourly instantaneous fields to capture an hourly resolved diurnal cycle within 5 days of integration and to avoid aliasing effects from the diurnal cycle when model data are subsampled offline. The high vertical resolution has been chosen for three main reasons: First, the representation of advective transport is very sensitive to the vertical resolution. With a high resolution we minimise numerical inconsistencies in regions of steep gradients (e.g., $\mathrm{O}_{3}$ at the tropopause) and we expect a much improved representation of stratosphere-to-troposphere exchange compared to other models. Second, a prognostic model should represent the key dynamical features of the atmosphere, such as the Quasi-Biennial Oscillation (QBO) in the middle atmosphere. A lower vertical resolution limits wave propagation and does not allow a self-consistent simulation of the QBO, as shown by Giorgetta et al. (2006). With the high resolution we are therefore able to simulate the QBO transport effects

\footnotetext{
${ }^{3}$ http://www.mnp.nl/edgar/model/v32ft2000edgar/ docv32ft2000
} 


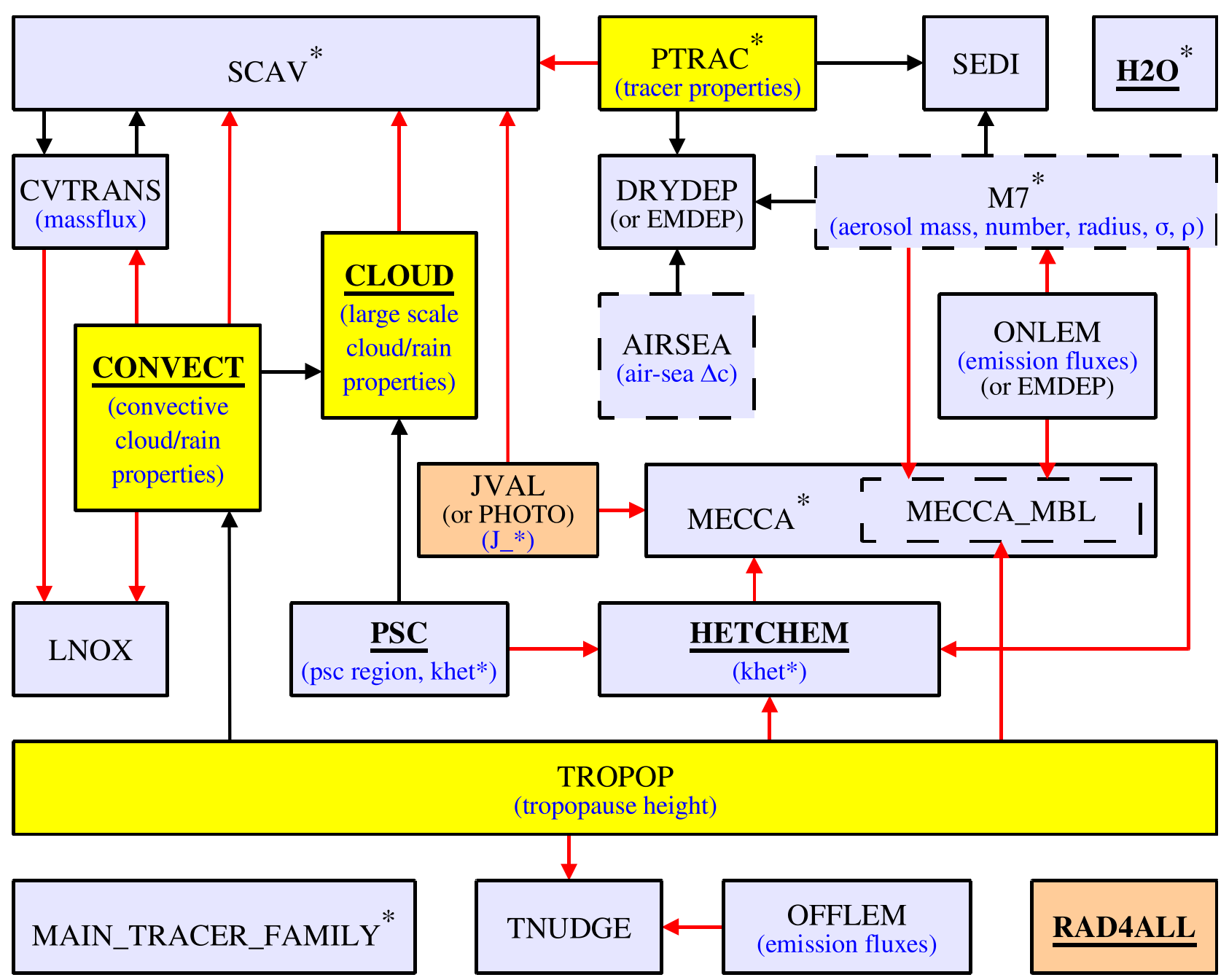

Fig. 1. Diagram of the coupling between submodels. The names of the submodels are shown in black, uppercase letters. The physical and chemical properties that are produced by the submodels are shown in parentheses in blue. These properties are exported to other submodels, as indicated by the arrows. Red arrows denote connections that can be controlled via namelists. Submodels in dashed boxes are switched off in the current model simulation. The colour of the boxes shows the effect on tracers. Yellow submodels do not change the tracer tendencies directly. Orange submodels use tracer values but do not change them. Blue submodels use tracers and also change their tendencies. Submodels with an asterisk define new tracers. Most submodels import data (e.g., temperature, humidity, pressure) from the ECHAM5 basemodel via the basemodel interface layer. Those with feedbacks to the basemodel are underlined (see text).

on chemistry directly. Finally, with a high vertical resolution we expect a much improved representation of the upper troposphere/lower stratosphere (UTLS), a region which is critical for the coupling between the lower and middle atmosphere and which is sensitive w.r.t. climate change.

To represent the observed meteorology in the troposphere, ECHAM5 has been nudged (Jeuken et al., 1996; Lelieveld et al., 2006 ${ }^{4}$ ) towards analysis data from the European Cen-

\footnotetext{
${ }^{4}$ Lelieveld, J., Brühl, C., Jöckel, P., Steil, B., Crutzen, P. J., Fischer, H., Giorgetta, M. A., Hoor, P., Lawrence, M. G., Milz, M., Sausen, R., Stiller, G. P., and Tost, H.: Stratospheric dryness, Atmos. Chem. Phys. Discuss., submitted, 2006.
}

tre for Medium-range Weather Forecasting (ECMWF) operational forecast model. The nudging (relaxation e-folding time in parentheses) of temperature $(12 \mathrm{~h})$, surface pressure $(12 \mathrm{~h})$, divergence $(48 \mathrm{~h})$, and vorticity $(6 \mathrm{~h})$ in spectral representation was applied between model levels $63(\approx 97 \mathrm{hPa})$ and $84(\approx 706 \mathrm{hPa})$, with additional transition zones (intermediate stepwise reduced nudging coefficients) between levels $58(\approx 62 \mathrm{hPa})$ and $62(\approx 89 \mathrm{hPa})$, and $85(\approx 775 \mathrm{hPa})$ and $87(\approx 909 \mathrm{hPa})$.

Since the applied nudging technique is crucial for our chosen evaluation method, we tested the sensitivity of the results w.r.t. the chosen nudging height. Moreover, various 
short test simulations (not presented) indicated that a reduced gravity wave forcing in combination with a reduced nudging height (i.e., a free running lowermost stratosphere) improves the representation of the Brewer-Dobson circulation. Therefore, in addition to the reference simulation S1 described so far, a consecutive series of sensitivity simulations (further denoted as S2) encompassing the period 2002 to 2005 with the following changes has been performed: Starting from January 2002 of the S1 simulation, the nudging has been reduced in the vertical down to level 71, i.e., to approximately $204 \mathrm{hPa}$, with a transition zone from level 65 $(\approx 116 \mathrm{hPa})$ to $70(\approx 185 \mathrm{hPa})$. From March 2003 onward, the gravity wave forcing (Hines, 1997a,b; Manzini and McFarlane, 1998) has been reduced by decreasing the root mean square gravity wave wind speed at the launching height from $1 \mathrm{~m} / \mathrm{s}$ to $0.9 \mathrm{~m} / \mathrm{s}$ (Giorgetta et al., 2006). From July 2004 onward, the time step has been reduced to $600 \mathrm{~s}$ to prevent occasional problems with the CFL-criterion (Courant et al., 1928) at the poles. Finally, in September/October 2005 the QBO nudging (discussed below) has been switched on again.

\subsection{Used hardware}

The simulations have been performed on the IBM pSeries "Regatta" system based on Power 4 processor technology at the Max Planck "Rechenzentrum Garching" (RZG). We used 16 compute nodes with 256 CPUs in total. One month simulation time required a wall-clock time of approximately $6 \mathrm{~h}$. Further optimisations of the performance are in progress.

\section{Meteorology}

\subsection{The tropospheric hydrological cycle}

An accurate representation of the hydrological cycle is crucial for the accurate modeling of both the meteorology and the chemistry in an AC-GCM. Hagemann et al. (2006) have performed a detailed evaluation of the hydrological cycle of ECHAM5 using free-running simulations at different resolutions and observed climatologies of precipitation, evaporation and river runoff. The T42L90MA resolution used here was not considered by Hagemann et al. (2006), nor did they perform nudged simulations. For a realistic representation of the chemical composition, in particular two parameters of the hydrological cycle are crucial: the water vapour column (WVC) and the precipitation establish the links between the hydrological cycle and $\mathrm{HO}_{\mathrm{x}}\left(\mathrm{H}, \mathrm{OH}, \mathrm{HO}_{2}\right)$ chemistry, dry and wet deposition, and emissions. In our original manuscript (Jöckel et al., 2006) we show in detail that the modifications introduced by the MESSy system and the coupling between chemistry and climate, as well as by the application of the T42L90MA resolution and nudging, the simulation produces a hydrological cycle consistent with observations. The results are not significantly different from those of Hagemann et al. (2006) and therefore not shown here.

\subsection{Middle atmosphere}

The simulated dynamics of the middle atmosphere essentially results from the model integration alone. The assimilation of the weather in the troposphere includes waves that propagate vertically and dissipate in the middle atmosphere, driving zonal and meridional circulations together with breaking gravity waves and radiation. Phenomena in the stratosphere and mesosphere that are sensitive to such wave forcing are therefore indirectly controled by the assimilation in the troposphere. Examples are sudden or major warmings. This does not imply that the stratosphere is a slave to the tropospheric waves only, since wave propagation from the troposphere to the stratosphere also depends on the state of the stratosphere. Therefore, we do not expect the simulated stratosphere to always follow the observations everywhere, but rather that the major phenomena that depend on vertically propagating waves will be simulated realistically. In addition, we expect to reproduce features which are only weakly dependent on the dynamics, for example ozone mixing ratios in regions where radiative and chemical time scales are much shorter than the transport time scale.

\subsubsection{The zonal wind and the Quasi-Biennial Oscillation (QBO)}

The zonal wind in different seasons has been compared with the ERA40-reanalysis in Giorgetta et al. (2006). The patterns in our actual simulations with the coupled system (not shown) are very similar. In the tropics the model selfconsistently calculates the quasi-biennial oscillation (QBO) of the zonal wind from 1999 to 2003 in simulation S1. With the nudging to $\approx 100 \mathrm{hPa}(\mathrm{S} 1)$, after spring 2004 the zonal winds in the lower tropical stratosphere remain in one phase, caused by a blocking layer of westerlies near the tropical tropopause. With nudging only to $200 \mathrm{hPa}$ as in the sensitivity study S2 (from 2000 onward) the tropical zonal winds remain close to the observations until the end of the simulation period in 2005 (Fig. 2). The reduction of the forcing by gravity waves, however, causes a slightly too long period at the end of the simulation (Giorgetta et al., 2006).

\subsubsection{Temperatures compared to satellite data}

The temperatures of the full simulation period have been compared with data from the HALogen Occultation Experiment (HALOE) on the Upper Atmosphere Research Satellite (Russell III et al., 1993) and for a shorter time period with the Michelson Interferometer for Passive Atmospheric Sounding (MIPAS) on the ENVISAT satellite. For a systematic comparison, simulated temperature profiles have been subsampled from the model output at the same location and local time as the satellite observations. This approach is feasible because of the nudged tropospheric forcing. We compared correlations and probability density functions (PDFs) 


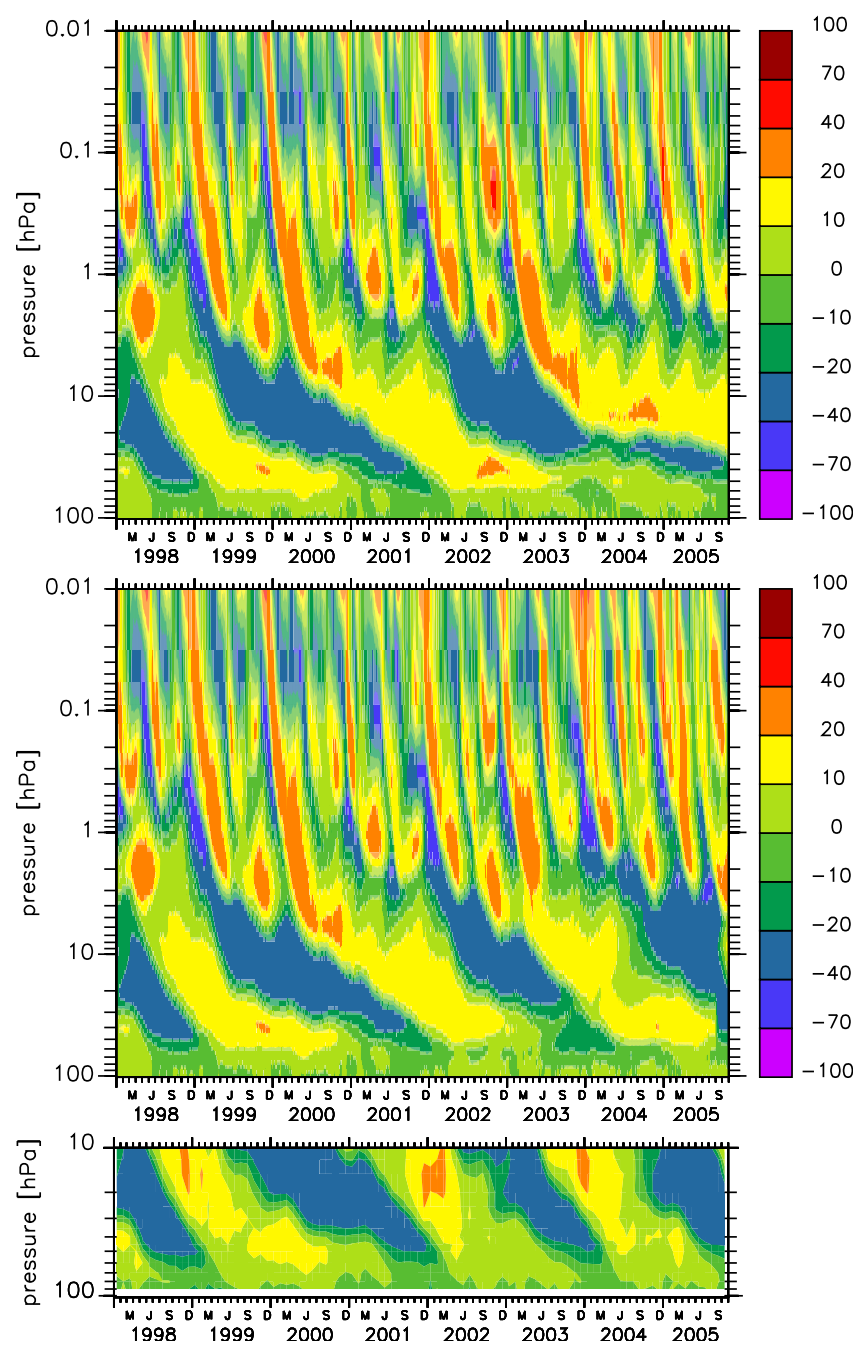

Fig. 2. Tropical zonal wind (in $\mathrm{m} / \mathrm{s}$ ) average between $2^{\circ} \mathrm{S}$ and $2^{\circ} \mathrm{N}$ and its quasi-biennial oscillation (top panel: reference simulation (S1), middle panel: S1 with overlayed sensitivity studies (S2, 2002 onward), lower panel: observations).

for different latitude and altitude regions demonstrating that the simulated stratospheric temperature statistics are close to observations. As an example, Fig. 3 shows a comparison of the simulated temperature with 8 years of HALOE-data at $30 \mathrm{hPa}$ (Hervig et al., 1996) for high southern latitudes, southern tropics and northern mid-latitudes for the simulation S1. The deviations in the tropics are mostly related to the problems with the QBO after 2003 in S1. In the tropics the simulation is $1-2 \mathrm{~K}$ colder than the observations, consistent with a slightly overestimated Brewer-Dobson circulation. In southern high latitudes the bimodal distribution related to the polar vortex is captured. Occasional large deviations can occur because of the relatively coarse horizontal resolution. The same analysis has been performed for the upper stratosphere ( $3 \mathrm{hPa}$, not shown) for which the model results and HALOE observations are even closer because of less influence of the QBO.

MIPAS provides 19 months of profiles of temperatures and several chemical constituents with global coverage during day and night (von Clarmann et al., 2003a). For evaluation we use here the products of a scientific processor by von Clarmann et al. (2003b) and compare averages for the 4 seasons (DJF, MAM, JJA, SON) for the period December 2002 to November 2003 for both simulations (S1, S2). Distributions and differences are shown in Fig. 4. For most regions, the agreement of the average model data with the observations is of the order of the systematic error range of the observations, i.e., within about 1-2 K (Wang et al., 2005). The largest differences between observations and simulations occur in boreal summer. The cold bias in the southern winter lower-middle stratosphere, present in many GCMs (Austin et al., 2003; Eyring et al., 2006), including the previous version of our model (Steil et al., 2003), is strongly reduced. Here S1 is somewhat better; however, in the upper stratosphere there is a much too strong adiabatic heating by descent. Note that in DJF of S2 the gravity wave parameter still has the same value as in simulation S1.

From a comparison of MIPAS and ECMWF temperatures for the period of mid-October to mid-November 2003 (Wang et al., 2005), it can be concluded that E5/M1 results for the stratosphere are similar in quality to the ECMWF data, although we do not assimilate observations, contrary to ECMWF. The ECMWF temperatures show no cold bias below $30 \mathrm{~km}$, whereas our model simulates a slightly too cold tropical stratosphere. Between 30 and $40 \mathrm{~km}$ altitude in the northern hemisphere the ECMWF data become cold biased with a deviation of up to $7 \mathrm{~K}$ at $50 \mathrm{~km}$ in the Arctic, while our model matches the MIPAS temperatures. Above $45 \mathrm{~km}$ the ECMWF temperatures are warm biased by $3-4 \mathrm{~K}$ in low and middle latitudes, whereas our model tends to underestimate temperatures in comparison with MIPAS data by $2-3 \mathrm{~K}$.

The model temperatures in the polar winter and spring lower stratosphere $(<10 \mathrm{hPa})$ compare quite well with MIPAS observations. For the Arctic there is no temperature bias. The mid-winter Antarctic temperatures in the lower stratosphere agree well and in spring the cold bias of $2-3 \mathrm{~K}$ is small. In SH mid-winter above $25 \mathrm{hPa}$ the model temperatures in $\mathrm{S} 2$ are relatively low by $3-7 \mathrm{~K}$ in high latitudes and $2-6 \mathrm{~K}$ high between $40-55^{\circ} \mathrm{S}$. The low bias points to a too weak subsidence in the polar vortex (see below) whereas the warm bias indicates an extension of the vortex too far to the north, which is confirmed by too low $\mathrm{N}_{2} \mathrm{O}$ in the simulation compared to MIPAS measurements (see below). In contrast, $\mathrm{S} 1$ is much too warm at the stratopause near the south pole. The slightly too cold tropical stratosphere and summer upper stratosphere and a too warm winter mesosphere, especially in $\mathrm{S} 1$, indicates deficiencies related to the wave forcing and adiabatic cooling/warming rates. Temperatures are closer to the observations everywhere with only tropospheric nudging (up to $\approx 200 \mathrm{hPa}$ ) and weaker gravity wave forcing in simulation 

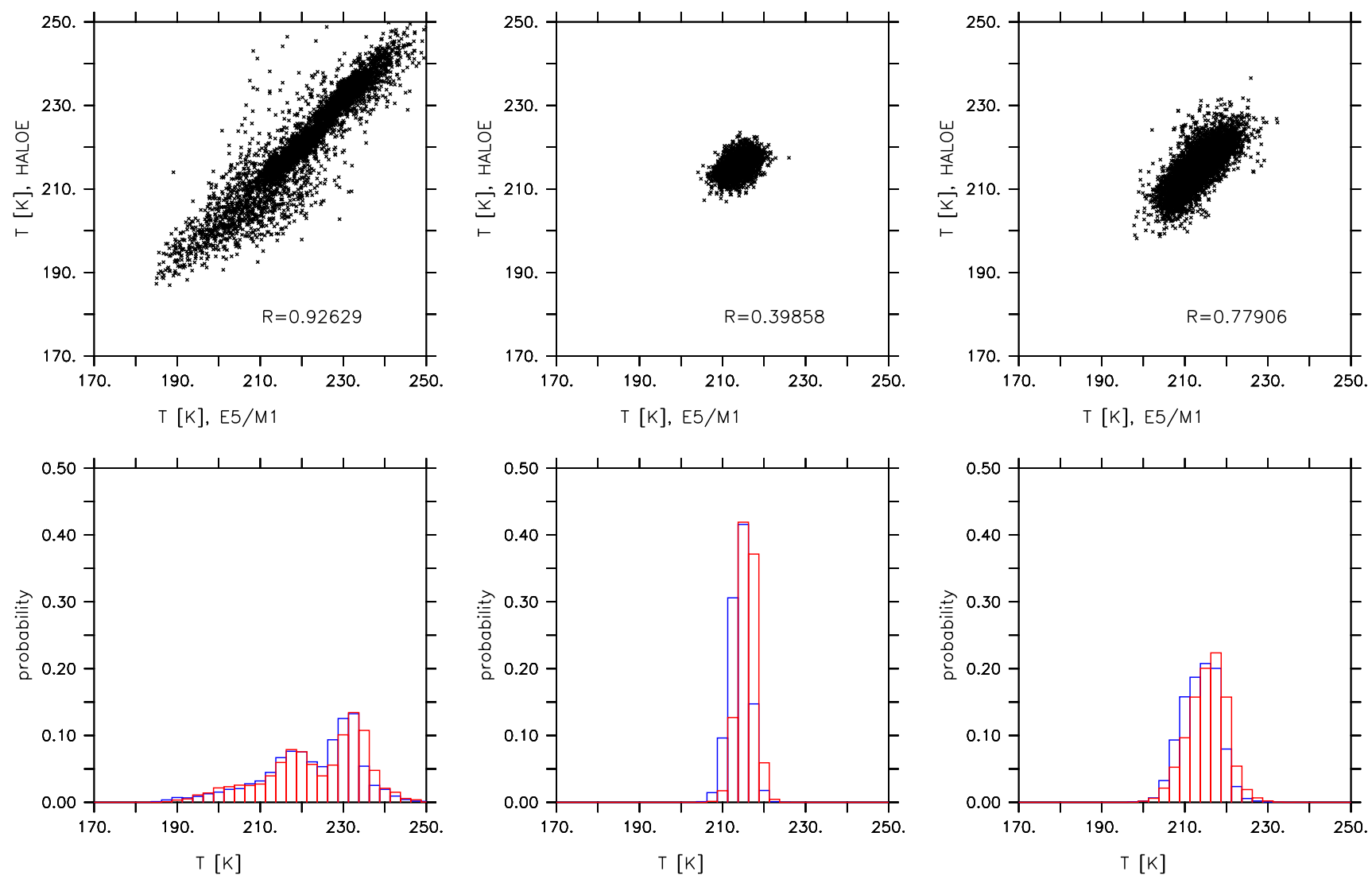

Fig. 3. Point-to-point comparison of simulated (S1) temperature with HALOE-data from February 1998 to September 2005 at $30 \mathrm{hPa}$. The upper panels show the correlations, the lower panels the probability density functions (model: blue; HALOE: red). Left: $90^{\circ} \mathrm{S}$ to $50^{\circ} \mathrm{S}$ (5566 data points), middle: $25^{\circ} \mathrm{S}$ to $0^{\circ} \mathrm{N}$ (4902 data points), right: $25^{\circ} \mathrm{N}$ to $50^{\circ} \mathrm{N}$ (7538 data points)

S2. In S2, the still too cold summer mesosphere can be explained by the neglect of the far UV solar heating in the radiation scheme of ECHAM5.

\subsubsection{The Brewer-Dobson circulation and the transport bar- riers}

Information on the calculated residual tropical upwelling is given in Giorgetta et al. (2006). Since the residual circulation and especially the residual vertical velocity $w^{*}$ derived from ERA40 is too noisy for a useful evaluation, we use long lived tracers observed by satellites to evaluate the mean transport and transport barriers (Hall et al., 1999).

The comparison between model and satellite data for the trace gas $\mathrm{N}_{2} \mathrm{O}$ as an example for a mostly transport controlled long lived source gas has been performed in the same way as for the temperatures in the previous section (Fig. 5). For most regions the agreement between the model and MIPAS is close to the observational uncertainty range of about $7 \%$ for total systematic errors (Glatthor et al., 2005) (the effect of random error is strongly reduced due to the large dataset). The model reproduces the observed distribution in the tropics and the subtropical transport barriers well, including the double peak structure related to the QBO in the middle and upper tropical and subtropical stratosphere, indicating that the upward branch of the Brewer-Dobson circulation is simulated correctly, and better in S2 than in S1, where in the tropics the effect of the mismatch in the QBO phase in SON 2003 (Fig. 2) is visible. The mean circulation and tracer transport is much better than in the previous model version of Steil et al. (2003). This holds also for methane, for which we compared correlations and PDFs of S1 with 8 years of HALOE-data (Fig. 6) and halocarbons (not shown here).

The largest differences occur directly poleward of the subtropical barriers (surf zone) and in the lowermost polar stratosphere in spring and winter. These are partially related to the differences in horizontal and vertical resolution of the satellite and the model data. Note that the MIPAS data is obtained by limb-scan from a polar orbit in the anti flight direction. The resolution is about $30 \mathrm{~km}$ in the zonal, $500 \mathrm{~km}$ in the meridional, and $3 \mathrm{~km}$ in the vertical direction (Endemann et al., 2000). Hence differences in representing mesoscale features such as streamers (e.g., Riese et al., 1999) and even synoptic structures due to planetary waves can be expected. 

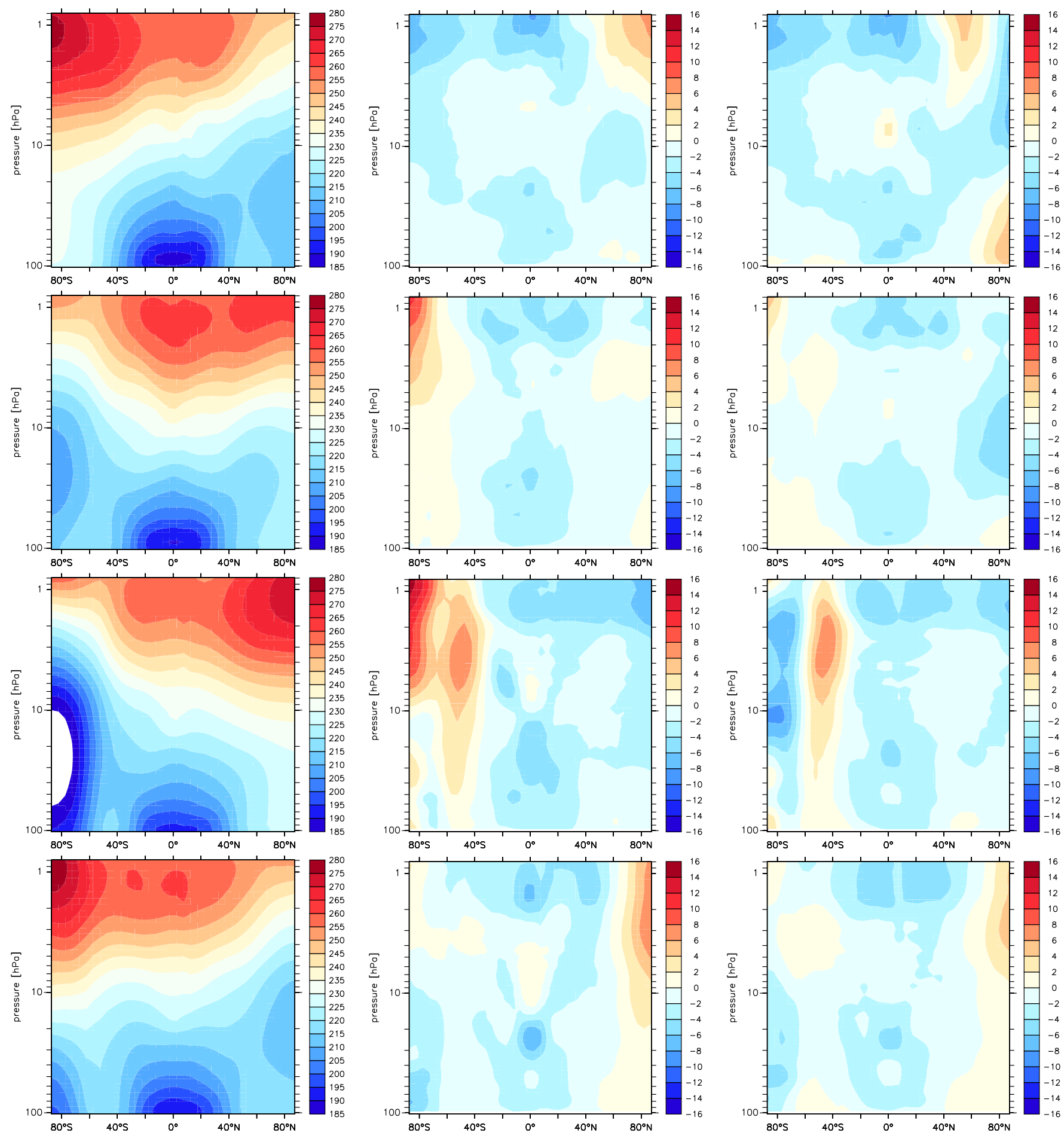

Fig. 4. Zonal averages of the temperature (in K) from the E5/M1 simulations (S2, left) and the difference to observations (S1 minus MIPAS: middle; S2 minus MIPAS: right). The seasons are DJF (2002/2003), MAM, JJA, and SON (2003) from top to bottom. The MIPAS datasets typically represent 15 days with about 14 orbits each. Note that in DJF in S2 only the nudging top height is reduced, i.e., in the upper part the Brewer-Dobson circulation is overestimated in $\mathrm{S} 1$ and $\mathrm{S} 2$.

The gradients at the vortex edges simulated by the model are less steep than observed. In the polar lowermost strato- sphere the database is sparse because of interferences by polar stratospheric clouds and because the data have larger 

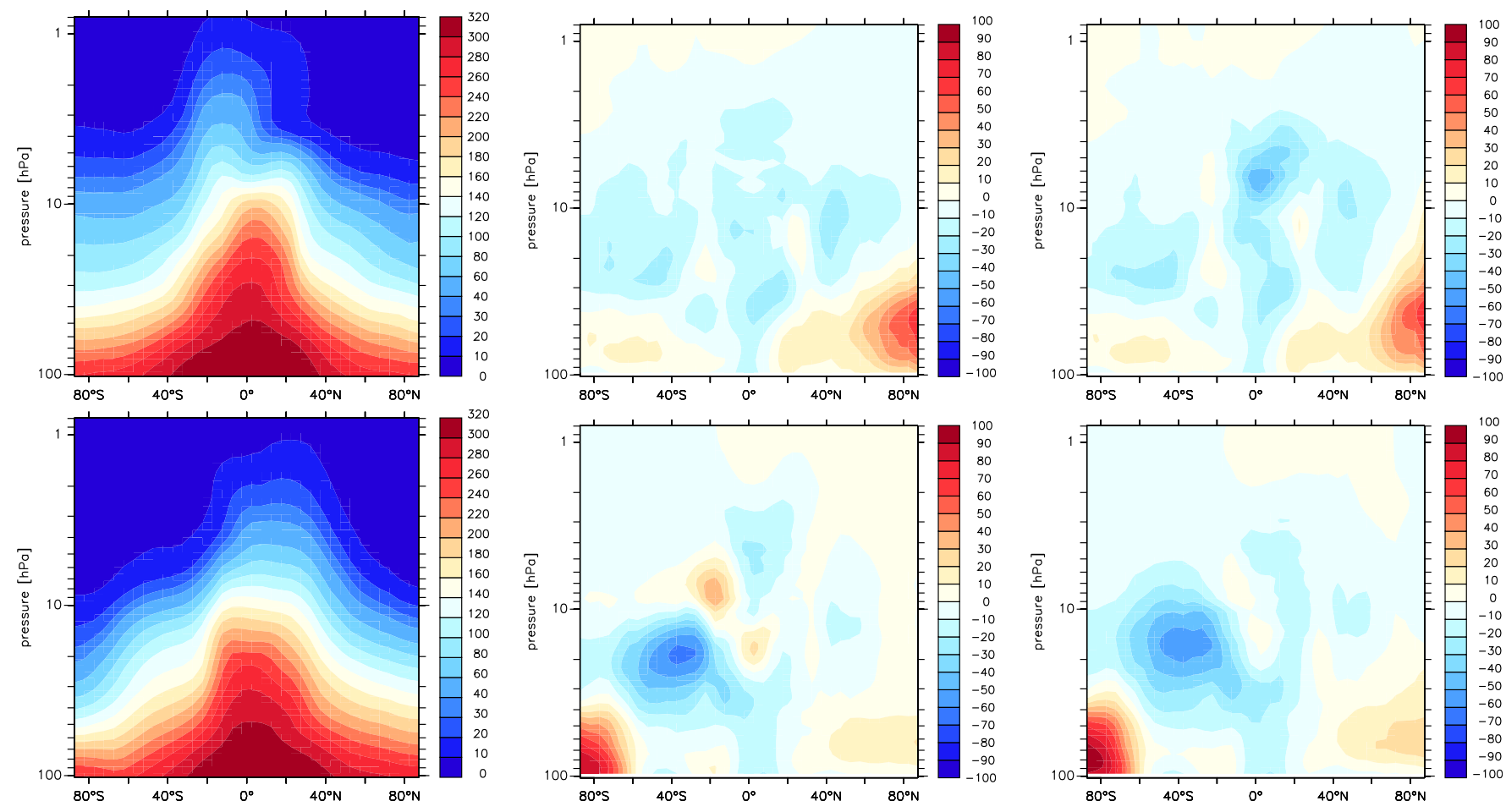

Fig. 5. Zonal averages of simulated (S2, left) nitrous oxide (nmol/mol) and difference (model minus MIPAS) to observations (S1: middle; S2: right). Top: DJF; Bottom: SON. The datasets typically represent 15 days with about 14 orbits each.

uncertainties due to large horizontal gradients, i.e., the differences are only partially significant. Nevertheless, the model generally seems to underestimate the downward transport in the winter lowermost polar stratosphere below about $40 \mathrm{hPa}$ (Fig. 5) in both hemispheres (in simulations $\mathrm{S} 1$ and S2) which causes an underestimate of reactive halogens and ozone depletion there (Sect. 6). At $30 \mathrm{hPa}$ the tracer transport by the mean circulation appears to be simulated well as indicated by the comparison with HALOE observations of methane in Fig. 6.

\subsubsection{The 2002 southern hemispheric major warming in the model and in satellite data}

The lower stratospheric dynamics and the distribution of total ozone as observed by TOMS (Total Ozone Mapping Spectrometer; on the NASA Earthprobe satellite) is to a large extent controlled by planetary waves propagating from the troposphere. Nudging of the tropospheric meteorology enables the model to reproduce the major stratospheric warming in the Austral spring of 2002 and the remarkable vortex split in September 2002 in both simulations (S1 and S2). In a sensitivity study, where we only prescribed the sea surface temperature, the vortex split did not occur. The details in total ozone agree better with TOMS observations in the case of nudging only up to $\approx 200 \mathrm{hPa}$ (simulation S2) instead of $\approx 100 \mathrm{hPa}$ (simulation S1), in contrast to several previous ap- proaches where models were forced at $100 \mathrm{hPa}$ (e.g., Manney et al., 2005). As shown in Fig. 7, the two parts of the vortex are separated too strongly when also the lower stratosphere is nudged, possibly pointing to problems in the ECMWF-data in the Antarctic lower stratosphere.

The model shows a high-ozone bias (further discussed in the following section and in Sect. 6.1), which decreases in the simulation with reduced nudging (S2), but the gradient between the vortex centre and the maximum over McMurdo is about as observed. A detailed comparison of pressure / longitude cross sections at about $63^{\circ} \mathrm{S}$ intersecting the two vortex lobes with MIPAS satellite data for simulation S2 shows that the model reproduces the vertical structure of temperatures and long-lived species (e.g., $\mathrm{N}_{2} \mathrm{O}$ ) within the experimental uncertainties (Fig. 8). We selected the conditions one day before the full vortex split because of better data coverage compared to the conditions 4 days later for which the TOMS comparisons were performed. One has to keep in mind that the comparisons are not done exactly at the same time so that some differences can be caused just by movement of the vortex lobes with their strong gradients. The $\mathrm{N}_{2} \mathrm{O}$ MIPAS-data have gaps around the eastern lobe causing a different shape of the contours due to interpolation (see Sect. 6). 

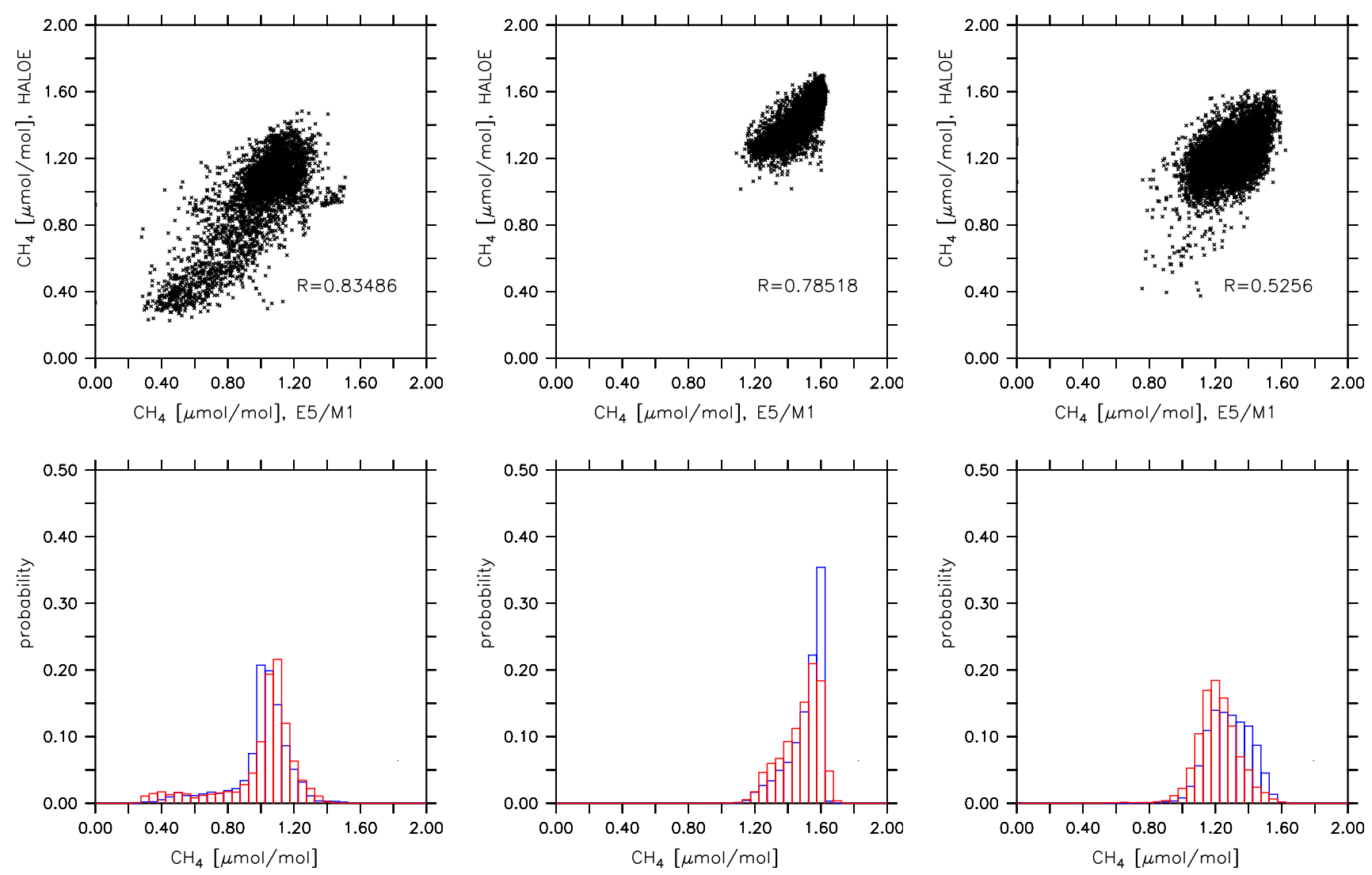

Fig. 6. As Fig. 3 but for $\mathrm{CH}_{4}$.

\section{Global ozone distribution and budgets}

\subsection{Total ozone}

The zonal mean total ozone for the full 8 year period is compared to TOMS observations (V8, see http://jwocky.gsfc. nasa.gov) using ten day averages and shown in Fig. 9. It can be clearly seen that the model reproduces the inter-annual and seasonal variability of observed zonal mean total ozone. In the tropics calculated total ozone is very close to the observations, while in mid-latitudes and high latitudes the simulations are high by up to about $10-15 \%$ due to an overestimate of ozone in the lower stratosphere (see Sect. 6.2). For simulation S2 (2003 to 2005) the bias in middle and high latitudes is typically $20 \mathrm{DU}$ less, i.e., the simulated zonal (and 10-day) averages are within $10 \%$ of the measurements. This is because of a slightly weaker and more realistic Brewer-Dobson circulation. Owing to the nudging of the tropospheric meteorology, most large-scale and regional patterns observed by TOMS are reproduced in the simulations. This includes "mini-holes" in the northern hemisphere, the Antarctic ozone hole, including its remarkable split in September 2002 (see Sect. 3.2.4) and the decline of total ozone in northern high latitudes from spring to fall.

\subsection{Stratospheric and mesospheric chemical ozone budgets}

To derive the ozone budget, we integrated the $\mathrm{O}_{3}$ reaction rates from the MECCA mechanism (see electronic supplement: http://www.atmos-chem-phys.net/6/ 5067/2006/acp-6-5067-2006-supplement.zip) using the 5hourly distributions (model output) of the relevant tracers and the $\mathrm{O}_{2}$ photolysis rate (JVAL) for the stratosphere and the troposphere (see TROPOP for the tropopause definition). For the integration in the stratosphere, we have chosen model level $37(\approx 10 \mathrm{hPa})$ as an upper boundary. Table 1 shows the production from photolysis of oxygen, $\mathrm{NO}+\mathrm{HO}_{2}$ and $\mathrm{NO}+\mathrm{CH}_{3} \mathrm{O}_{2}$, and the loss terms due to different catalytic cycles. In the stratosphere there is a net chemical gain of ozone which is mostly balanced by transport to the troposphere. The individual terms contributing to the chemical ozone budget are about an order of magnitude larger in the upper stratosphere; there is, however, almost photochemical equilibrium, i.e., the large terms are mostly cancelling each other. Therefore, most of the net production and flux to the troposphere is controlled by the layers below $10 \mathrm{hPa}$. Considering the layers above reduces the net gain term by about $10 \%$. The selection of the dynamical tropopause as the lower boundary of the integration domain has only a small 

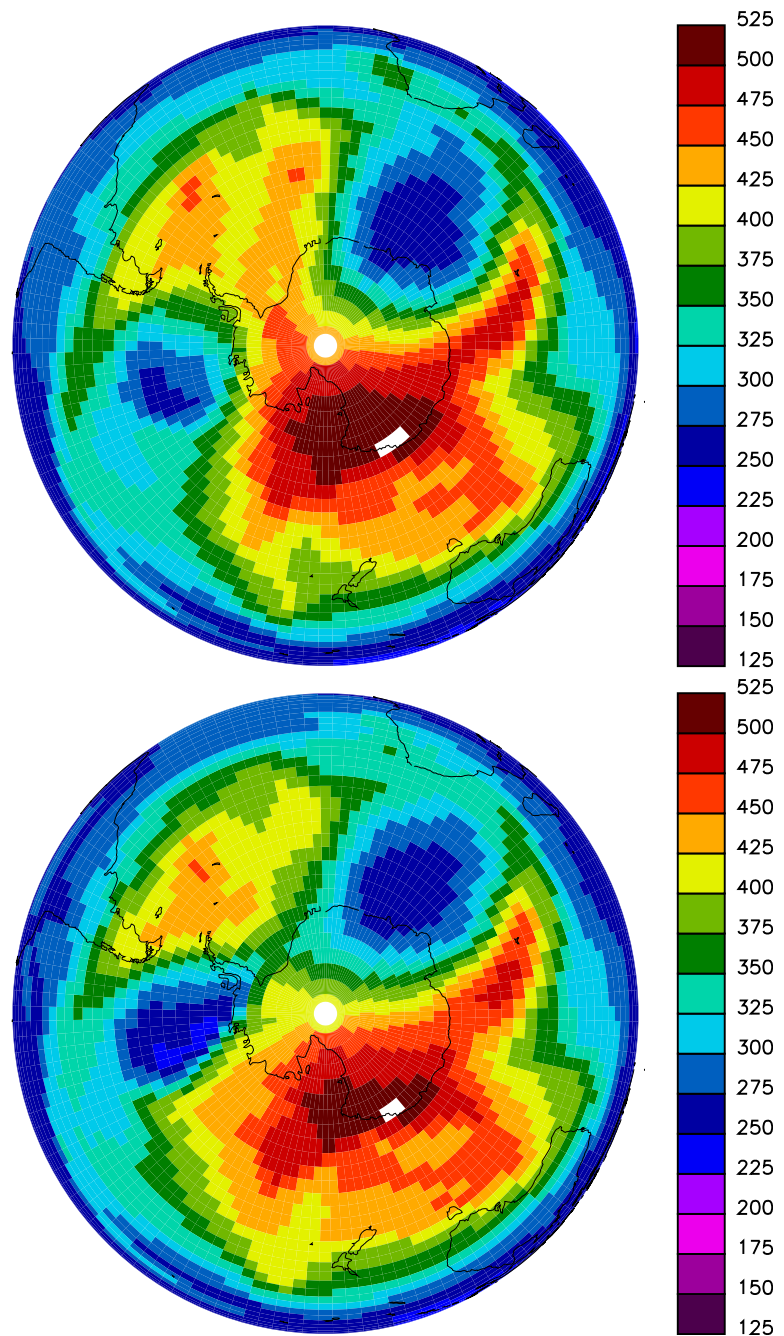

500 475 450 425 400 375 350 325

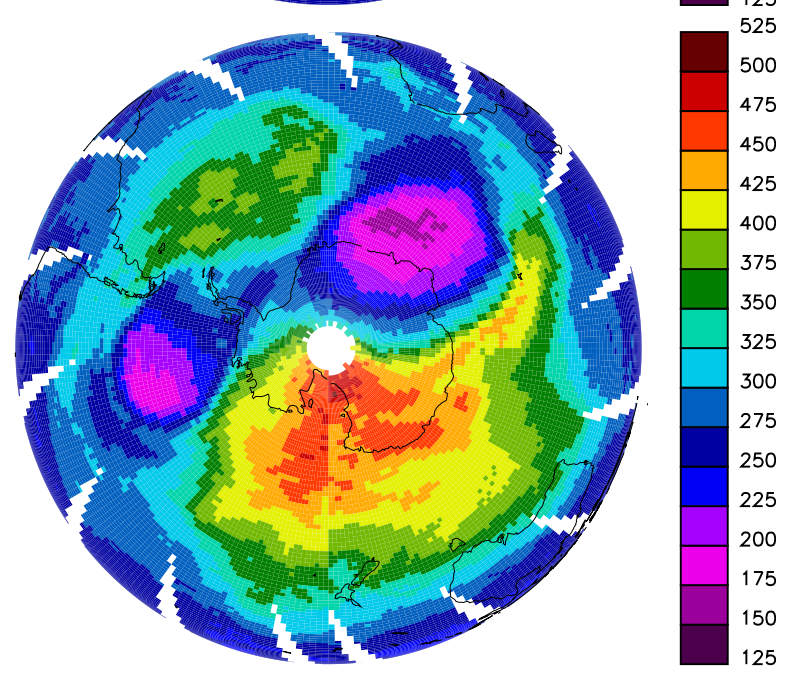

Fig. 7. Total ozone (in DU) on 26 September 2002 as simulated by E5/M1 (S1 in upper, and S2 in middle panel, respectively), and as observed by TOMS (lower panel).
Table 1. Annual stratospheric (tropopause to $10 \mathrm{hPa}$ ) ozone budget (simulation $\mathrm{S} 1$; production $\mathrm{P}$, loss $\mathrm{L}$ ) in $\mathrm{Tg}$ (average \pm inter-annual standard deviation for the years 2000, 2001, 2003 and 2004). Values are rounded to $\mathrm{Tg}$. The loss terms refer to the catalytic cycles involving families of reactive species.

\begin{tabular}{lrrrrrr}
\hline & \multicolumn{2}{c}{$\mathrm{NH}$} & \multicolumn{2}{c}{ SH } & \multicolumn{2}{c}{ Global } \\
\hline P, & 6377 & 97 & 6393 & 101 & 12770 & 176 \\
L, odd oxygen & -579 & 4 & -592 & 8 & -1170 & 9 \\
L, odd nitrogen & -3310 & 92 & -3335 & 89 & -6646 & 165 \\
L, odd hydrogen & -1284 & 20 & -1290 & 22 & -2574 & 41 \\
L, chlorine & -562 & 9 & -656 & 19 & -1219 & 21 \\
L, bromine & -65 & 1 & -102 & 5 & -167 & 6 \\
Pnet & 577 & 18 & 418 & 20 & 995 & 28 \\
\hline
\end{tabular}

influence, and the corresponding fluxes across the $100 \mathrm{hPa}$ level are very similar.

Stratospheric ozone production and loss during summer is dominated by gas phase chemistry. Furthermore the dynamical wave activity is small so that the summer conditions are most suited for evaluation of the scheme for homogeneous chemistry used in the AC-GCM. In high and mid-latitudes ozone decreases from spring to fall due to catalysis by $\mathrm{NO}_{\mathrm{x}}$ under polar daylight conditions in the altitude region between about 10 to $100 \mathrm{hPa}$ (Brühl and Crutzen, 2000; Crutzen and Brühl, 2001). Net chemical ozone production as calculated by the model for the NH-summer (June and August) is depicted in Fig. 10. The results agree well with the corresponding figures in the above papers, where results were constrained by HALOE observations. The net chemical production changes sign at the correct latitudes and altitudes. Above about $2 \mathrm{hPa}$ diurnally averaged ozone is close to photochemical equilibrium. The net gain in the tropics below $10 \mathrm{hPa}$ is balanced by loss to the layers above via the upward motion of the Brewer-Dobson circulation. Fig. 10 also shows the corresponding terms for southern hemispheric summer. The large chemical loss due to reactive nitrogen south of $40^{\circ} \mathrm{S}$ explains the secondary minimum in total ozone there in March. In the winter hemispheres the net production in the upper stratosphere is balanced by the downward motion which also reduces the ozone loss in the middle stratosphere. In the lower high latitude stratosphere, especially in the southern hemisphere, strong chemical ozone loss takes place due to catalytic destruction by halogens, peaking near the terminator.

\subsection{Tropospheric ozone budgets}

The tropospheric chemical ozone budget is derived similarly as the stratospheric budget using the 5 hourly output of the tracers. The dry deposition of $\mathrm{O}_{3}$ was diagnosed from the submodel DRYDEP. From these values the net stratosphere- 

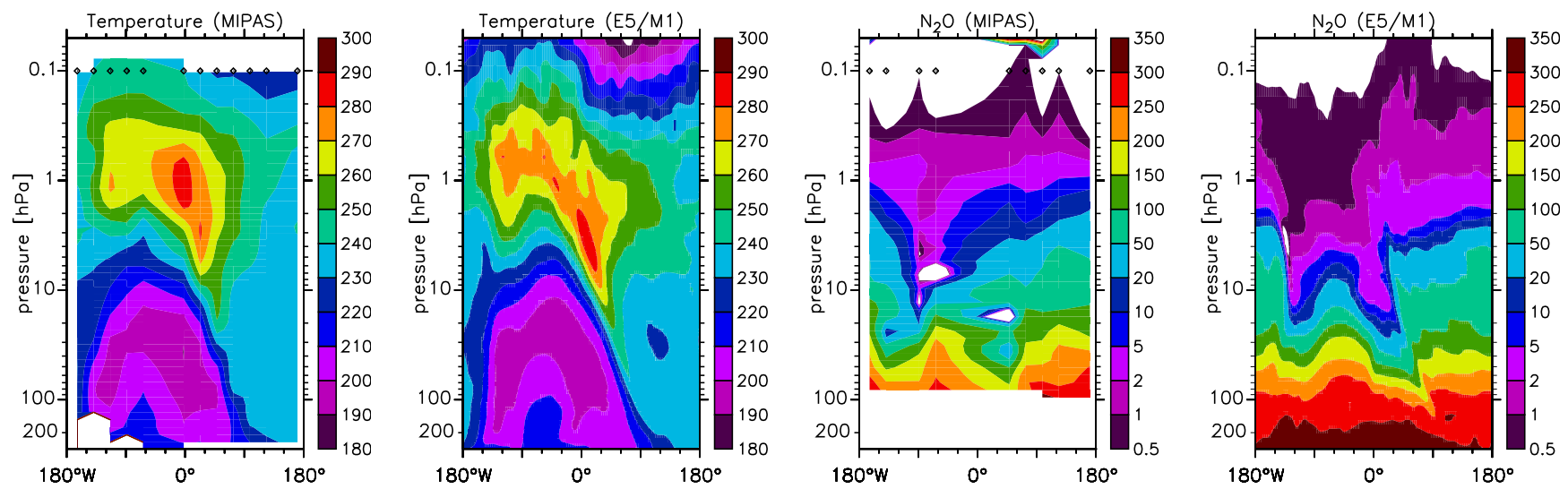

Fig. 8. MIPAS observations and model simulations (E5/M1, S2) of temperature (K) and $\mathrm{N}_{2} \mathrm{O}$ (nmol/mol) for 22 September 2002 , at $63^{\circ} \mathrm{S}$. Diamonds mark longitudes of measurements.

Table 2. Annual tropospheric ozone budget (S1 simulation) in $\mathrm{Tg}$ (average \pm inter-annual standard deviation for the years 2000 to 2004). $\mathrm{RO}_{2}$ comprises $\mathrm{C}_{2} \mathrm{H}_{5} \mathrm{O}_{2}, \mathrm{CH}_{3} \mathrm{C}(\mathrm{O}) \mathrm{OO}, \mathrm{C}_{3} \mathrm{H}_{7} \mathrm{O}_{2}$, $\mathrm{CH}_{3} \mathrm{CH}\left(\mathrm{O}_{2}\right) \mathrm{CH}_{2} \mathrm{OH}, \mathrm{CH}_{3} \mathrm{COCH}_{2} \mathrm{O}_{2}, \mathrm{C}_{4} \mathrm{H}_{9} \mathrm{O}_{2}$, and peroxy radicals resulting from the oxidation of MVK, MEK and isoprene. Values are rounded to $\mathrm{Tg}$.

\begin{tabular}{lrrrrrr}
\hline & $\mathrm{NH}$ & $\mathrm{SH}$ & \multicolumn{2}{c}{ Global } \\
\hline $\mathrm{NO}+\mathrm{HO}_{2}$ & 1884 & 9 & 1244 & 8 & 3129 & 10 \\
$\mathrm{NO}+\mathrm{RO}_{2}$ & 381 & 2 & 201 & 6 & 582 & 5 \\
$\mathrm{NO}+\mathrm{CH}_{3} \mathrm{O}_{2}$ & 685 & 4 & 459 & 3 & 1143 & 4 \\
$\mathrm{P}$ & 2949 & 15 & 1904 & 12 & 4854 & 14 \\
$\mathrm{O}_{3}+\mathrm{OH}$ & -311 & 4 & -221 & 4 & -531 & 2 \\
$\mathrm{O}_{3}+\mathrm{HO}_{2}$ & -823 & 5 & -565 & 10 & -1389 & 6 \\
$\left.\mathrm{H}_{2} \mathrm{O}+\mathrm{O}^{1}{ }^{1} \mathrm{D}\right)$ & -1452 & 24 & -1095 & 7 & -2547 & 24 \\
$\mathrm{~L}$ & -2586 & 29 & -1881 & 17 & -4467 & 28 \\
net & 363 & 27 & 23 & 8 & 386 & 29 \\
dry deposition & -508 & 4 & -272 & 2 & -780 & 4 \\
change in burden & -1 & 7 & 0 & 6 & 0 & 10 \\
$\mathrm{STT}^{\mathrm{a}}$ & 144 & 25 & 249 & 10 & 393 & 25 \\
burden & 171 & 4 & 149 & 4 & 319 & 7 \\
\hline STT of $\mathrm{O}_{3}^{(\mathrm{s})}$ & 676 & 23 & 522 & 10 & 1198 & 28 \\
burden of $\mathrm{O}_{3}^{(\mathrm{s})}$ & 78 & 4 & 59 & 3 & 137 & 5 \\
\hline
\end{tabular}

${ }^{a}$ Net, derived by budget closure, accounts also for upward transport.

to-troposphere (STT) flux of ozone was calculated by closure of the budget, also taking into account the upward flux in the tropics and the (negligible) change of the tropospheric $\mathrm{O}_{3}$ burden. In addition, the chemical mechanism includes a diagnostic tracer for stratospheric ozone $\left(\mathrm{O}_{3}^{(\mathrm{s})}\right)$, which has been "hard-nudged" by TNUDGE to $\mathrm{O}_{3}$ in the stratosphere. In the troposphere, $\mathrm{O}_{3}^{(\mathrm{s})}$ undergoes the same chemical loss reactions as $\mathrm{O}_{3}$, and is also affected by dry deposition. The chemical loss has been "accumulated" over time, and was integrated offline. This chemical loss of $\mathrm{O}_{3}^{(\mathrm{s})}$ plus its dry deposition provides a direct measure of the stratosphere-to-troposphere transport of ozone that has been produced in the stratosphere. The results of our calculations are listed in Table 2.

The results are consistent with the study by Roelofs and Lelieveld (1997) who used ECHAM4 with a simpler chemistry setup constrained by observations in the stratosphere. In a recent multi-model inter-comparison (Stevenson et al., 2006), the net tropospheric ozone production was estimated to be $P=(5110 \pm 606) \mathrm{Tg} / \mathrm{yr}$, with a net loss of $L=(4668 \pm 727) \mathrm{Tg} / \mathrm{yr}$, whereby the range is the multimodel standard deviation. Furthermore, the multi-model ozone dry deposition is $(1003 \pm 200) \mathrm{Tg} / \mathrm{yr}$, and the inferred net stratospheric influx STT $=(552 \pm 168) \mathrm{Tg} / \mathrm{yr}$. These numbers show that the simulated tropospheric ozone budget of E5/M1 agrees well with the multi-model ensemble, whereby the dry deposition and inferred STT are near the lower end of the range in the comparison. The latter underscores the improved representation of the stratosphere-to-troposphere exchange process in E5/M1, since STT is known to be notoriously problematic in past AC-GCMs and transport models. Note that the above mentioned multi-model mean values are based on chemistry transport model simulations, in which stratospheric $\mathrm{O}_{3}$ has been constrained based on observations. In our setup, however, these results are reproduced by an ACGCM without constraining the upper boundary condition.

\section{Tropospheric tracers and chemistry}

\subsection{Carbon monoxide}

Tropospheric chemistry is strongly influenced by carbon monoxide $(\mathrm{CO})$. This is mostly due to the reaction of $\mathrm{CO}$ with the hydroxyl radical $(\mathrm{OH})$, i.e., $\mathrm{CO}+\mathrm{OH} \rightarrow \mathrm{CO}_{2}+\mathrm{H}$. This reaction establishes a sink of $90-95 \%$ for CO (Logan et al., 1981) and of approximately $41 \%$ for $\mathrm{OH}$ (von 
Kuhlmann et al., 2003b) in most of the troposphere. Enhanced $\mathrm{CO}$ levels generally reduce $\mathrm{OH}$ concentrations, influencing the oxidation capacity of the atmosphere.

To evaluate the $\mathrm{CO}$ mixing ratios calculated by E5/M1, we compare the model results to a $\mathrm{CO}$ database provided by the National Oceanic and Atmospheric Administration Climate Monitoring and Diagnostic Laboratory (NOAA/CMDL) ${ }^{5}$ as presented by Novelli et al. (1998). Note that the database currently contains data up to the year 2005. Only monthly averages are compared here.

As shown in Fig. 11, the measured annual cycle, as well as the magnitude of the $\mathrm{CO}$ mixing ratio is well represented by the model for most locations. In many cases the model results agree very well with the observed values, (e.g., at the location of South Hampton, Bermuda (BMW), Tenerife, Canary Islands (IZO) and Mauna Loa, Hawaii (MLO), see Fig. 11). The comparison shows good agreement for the seasonal as well as the overall tendencies over the simulated period. There are also several locations, however, for which the model overestimates $\mathrm{CO}$ mixing ratios (e.g., Wenover, Utah; UTA, Fig. 11). This is mostly an artefact of the coarse model grid, whereby strong gradients near source regions are underestimated, so that these measurements are not representative for the mean $\mathrm{CO}$ in the large grid cells at these locations, especially for the sites where the samples are filtered to be representative of background airmasses.

In very remote regions in the southern hemisphere (Palmer station, Antarctica; PSA, Fig. 11) the model overestimates $\mathrm{CO}$ mixing ratios. The discrepancies are largest in summer, suggestive of a problem with photochemistry. It might be that $\mathrm{OH}$ concentrations in the high latitude southern hemisphere are underestimated, possibly associated with the stratospheric ozone high-bias (Fig. 9), which reduces UV radiation penetration into the troposphere, although it is also conceivable that the $\mathrm{CO}$ source strength in the model is too strong.

In Fig. 12 we compare MOPITT satellite data (Deeter et al., 2004) at $700 \mathrm{hPa}$ with model calculated CO for the year 2003. The left panels show the model results postprocessed with the MOPITT averaging kernel. The right panels show the relative differences, indicating that the model somewhat overestimates CO over central South America in January and in particular over southern Africa in January and July, which suggests that the biomass burning $\mathrm{CO}$ sources in these regions may be overestimated. These results also suggest that especially for Africa the biomass burning emissions early in the year in the model are partly located too far south. The upper right panel of Fig. 12 nevertheless shows that the model results for January agree quite well with MOPITT (light red and blue colours in Fig. 12 are within the measurement uncertainty). This includes the Southern Ocean near Palmer, which indicates that the discrepancy at station PSA (Fig. 11)

\footnotetext{
${ }^{5}$ http://www.cmdl.noaa.gov/ccgg/iadv/dev_sitesummary.php? gas $=$ co\&project $=$ flask
}

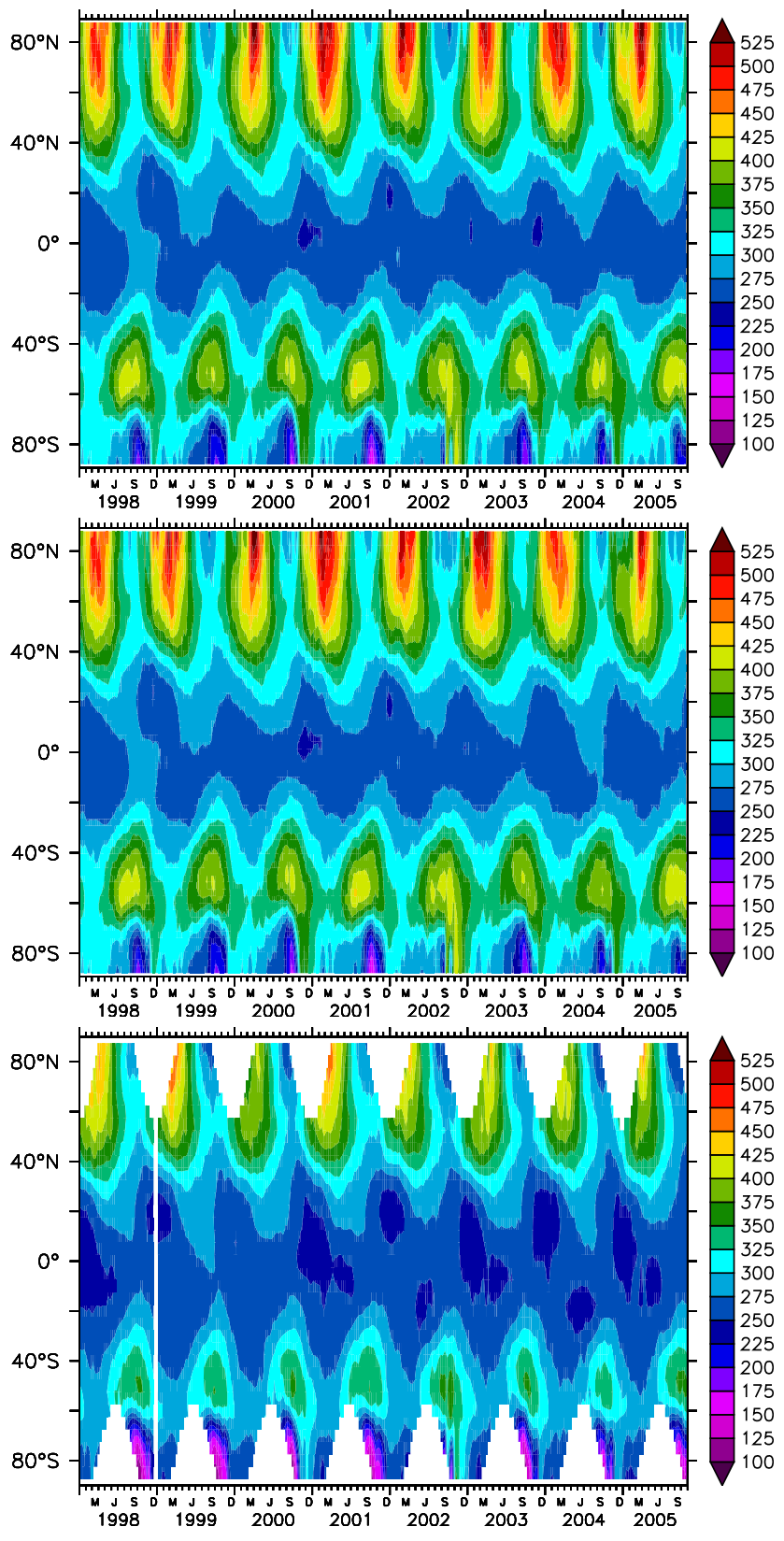

Fig. 9. Total ozone (DU), based on 10-day zonal averages for 8 years (top panel: reference simulation (S1), middle panel: $\mathrm{S} 1$ with overlayed sensitivity studies (S2, 2002 onward), lower panel: TOMS satellite data).

is limited to the surface, possibly related to the representation of the orography and related meteorology.

A more significant issue emerges for simulated $\mathrm{CO}$ at high latitudes in the northern hemisphere in July 2003, as shown in the lower right panel of Fig. 12, which suggests that our model underestimates boreal biomass burning emissions. Indeed, the summer of this year was characterised by dryness and strong burning activity in northwestern North America 

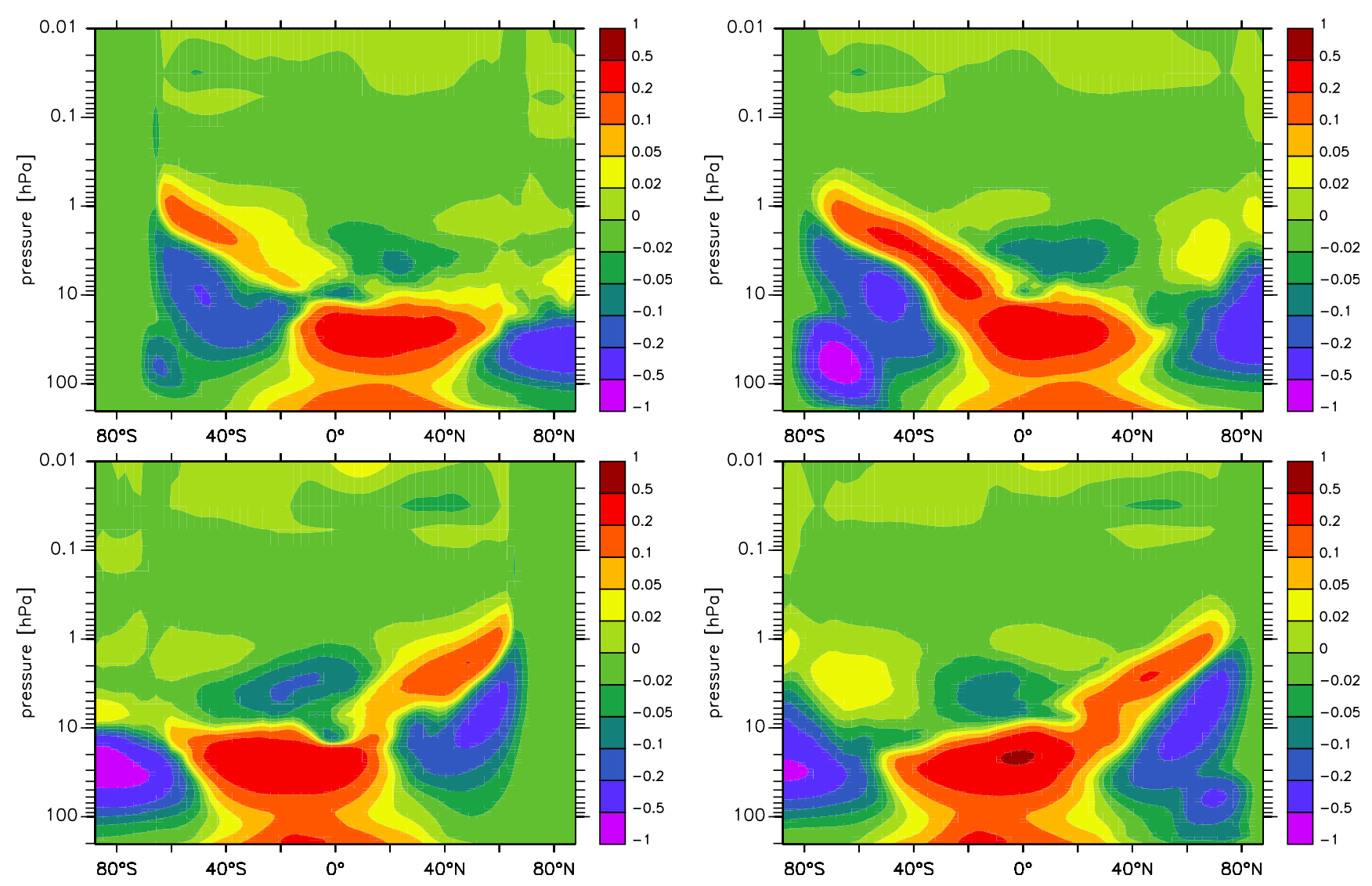

Fig. 10. Net chemical ozone production $\left(P_{\text {net }}=P-L\right)$ with $\mathrm{P}$ being the chemical production from photolysis of molecular oxygen and $L$ being the chemical loss due to the different catalytic cycles (odd nitrogen, oxygen, chlorine, bromine and hydrogen); June (upper left), August (upper right), December (lower left), and February (lower right). Shown are monthly diurnal averages for the year 2000 (S1) in $10^{6}$ molecules $/ \mathrm{cm}^{3} / \mathrm{s}$.

and eastern Siberia. This is confirmed by Fig. 11, which also shows that at high northern latitudes CO was considerably higher than computed in summer, whereas this was not the case for other years. In fact, our model seems to slightly underestimate $\mathrm{CO}$ in winter rather than in summer, possibly associated with anthropogenic emissions in East Asia, and the discrepancy in Fig. 12 for 2003 should be considered as a worst case. All in all, Figs. 11 and 12 indicate that CO distributions and seasonalities are simulated quite realistically. The comparison also underscores that in particular the interannual variability of biomass burning emissions can be substantial, so that the use of the year 2000 emissions for the entire simulation period can give rise to discrepancies for individual years.

\subsection{Reactive Nitrogen: $\mathrm{NO}_{\mathrm{x}}, \mathrm{HNO}_{3}$ and PAN}

Key reactive nitrogen compounds important in tropospheric ozone chemistry are $\mathrm{NO}_{\mathrm{x}}\left(\mathrm{NO}+\mathrm{NO}_{2}\right), \mathrm{HNO}_{3}$ and PAN. $\mathrm{NO}_{\mathrm{x}}$ is important as a catalyst in the photochemical production cycles for $\mathrm{O}_{3}$ in the troposphere. $\mathrm{HNO}_{3}$ and PAN are reaction products and $\mathrm{NO}_{\mathrm{x}}$ reservoir species: $\mathrm{HNO}_{3}$ is highly soluble, and the conversion of $\mathrm{NO}_{\mathrm{x}}$ to $\mathrm{HNO}_{3}$ and subsequent washout or surface deposition represents one of the main losses for reactive nitrogen, while PAN is thermally instable and provides an important source of $\mathrm{NO}_{\mathrm{x}}$ to remote regions in subsiding airmasses.

The 5-year mean surface mixing ratios of $\mathrm{NO}_{\mathrm{x}}$ and $\mathrm{HNO}_{3}$ are plotted in Figs. 13 and 14, respectively. The distributions are generally similar to those computed by other models of similar complexity (e.g., van Noije et al., 2006). The surface distributions show the strong weighting of the $\mathrm{NO}_{\mathrm{x}}$ and $\mathrm{HNO}_{3}$ distribution towards the major source regions, especially the northeastern USA, Europe, and eastern Asia; this is particularly pronounced for $\mathrm{NO}_{\mathrm{x}}$, which results from its relatively short lifetime of about a day in the lower troposphere. Secondary maxima are seen in regions of strong biomass burning and bio-fuel use (South America, central Africa and southern Asia), and the clear influence of oceangoing ship emissions is seen especially in the $\mathrm{NO}_{\mathrm{x}}$ distribution over the Atlantic and Indian Oceans between major ports. 

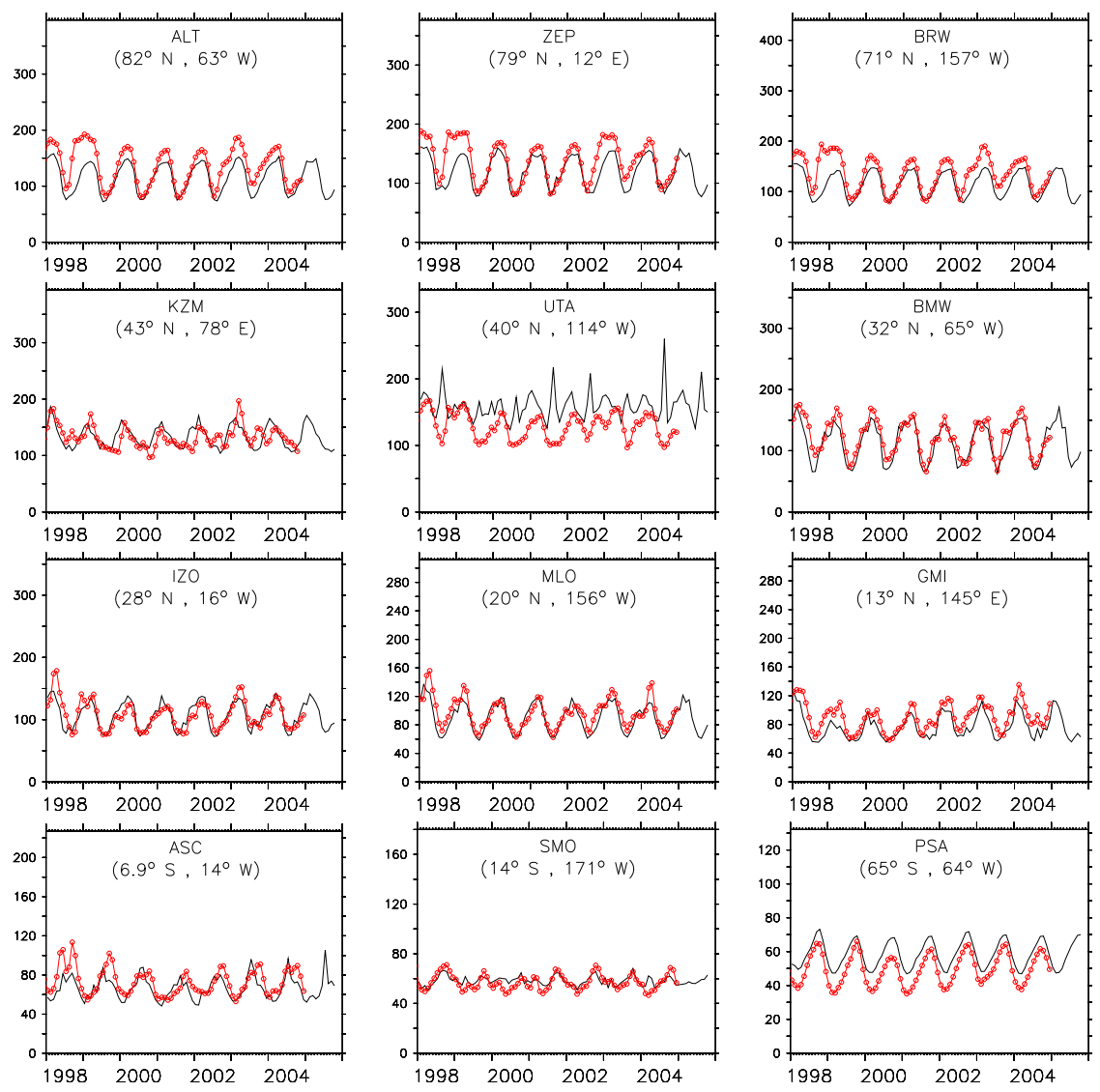

Fig. 11. Comparison of simulated (S1, black) and observed (red) $\mathrm{CO}$ mixing ratios (in nmol/mol) for selected NOAA/CMDL sites (from north to south).

An overview of the annual sources and sinks of reactive nitrogen is given in Table 3; the sources are discussed in more detail in Kerkweg et al. (2006b) and Ganzeveld et al. (2006). On the whole, the listed sources are closely balanced by the budgeted sinks; the difference is due to the small stratosphere-troposphere exchange source of about $0.4 \mathrm{Tg}(\mathrm{N}) / \mathrm{yr}$. The key loss for reactive nitrogen is via $\mathrm{HNO}_{3}$, with about half of the total loss being due to wet deposition of $\mathrm{HNO}_{3}$, and a third of the total due to $\mathrm{HNO}_{3}$ dry deposition. The loss of aerosol nitrate by particle sedimentation contributes a further $15-20 \%$, while the direct loss of $\mathrm{NO}_{\mathrm{x}}$ due to the dry deposition of $\mathrm{NO}_{2}$ contributes less than $10 \%$ to the total budget.

To evaluate the distributions versus observations, we compare to the compiled observations of Emmons et al. $(2000)^{6}$, covering the period 1983 to 2001. For $\mathrm{NO}_{\mathrm{x}}$, we have chosen to only compare to $\mathrm{NO}$ here, rather than $\mathrm{NO}+\mathrm{NO}_{2}$, due to the much greater difficulty in accurately measuring $\mathrm{NO}_{2}$ than NO. NO has a strong diurnal variation with a very low mixing ratio at night (due to conversion to $\mathrm{NO}_{2}$ by reaction with $\mathrm{O}_{3}$ ), and nearly all the measurements in the field
Table 3. Global simulated (S1) tropospheric $\mathrm{NO}_{\mathrm{y}}$ budget (average of 1998 to 2004 and inter-annual standard deviation $\sigma$ ) in $\operatorname{Tg}(\mathrm{N})$ /year. The annual residuals (sources + sinks) are balanced by the stratospheric source.

\begin{tabular}{lrr}
\hline & average & $\sigma$ \\
\hline Sources & & \\
Prescribed Surface Emissions & 43.10 & 0.00 \\
Prescribed Aircraft Emissions & 0.59 & 0.00 \\
Online Emissions & 6.84 & 0.08 \\
Lightning & 2.19 & 0.05 \\
SUM & 52.72 & 0.11 \\
Sinks & & \\
Precipitation Scavenging & -24.32 & 0.20 \\
Dry Deposition: Nitrate & -16.78 & 0.13 \\
Dry Deposition: NO & -3.29 & 0.05 \\
Sedimentation: Aerosol Nitrate & -8.78 & 0.12 \\
SUM & -53.16 & 0.04 \\
Sources+Sinks & -0.44 & 0.13 \\
\hline
\end{tabular}

\footnotetext{
${ }^{6}$ http://gctm.acd.ucar.edu/data/
} 

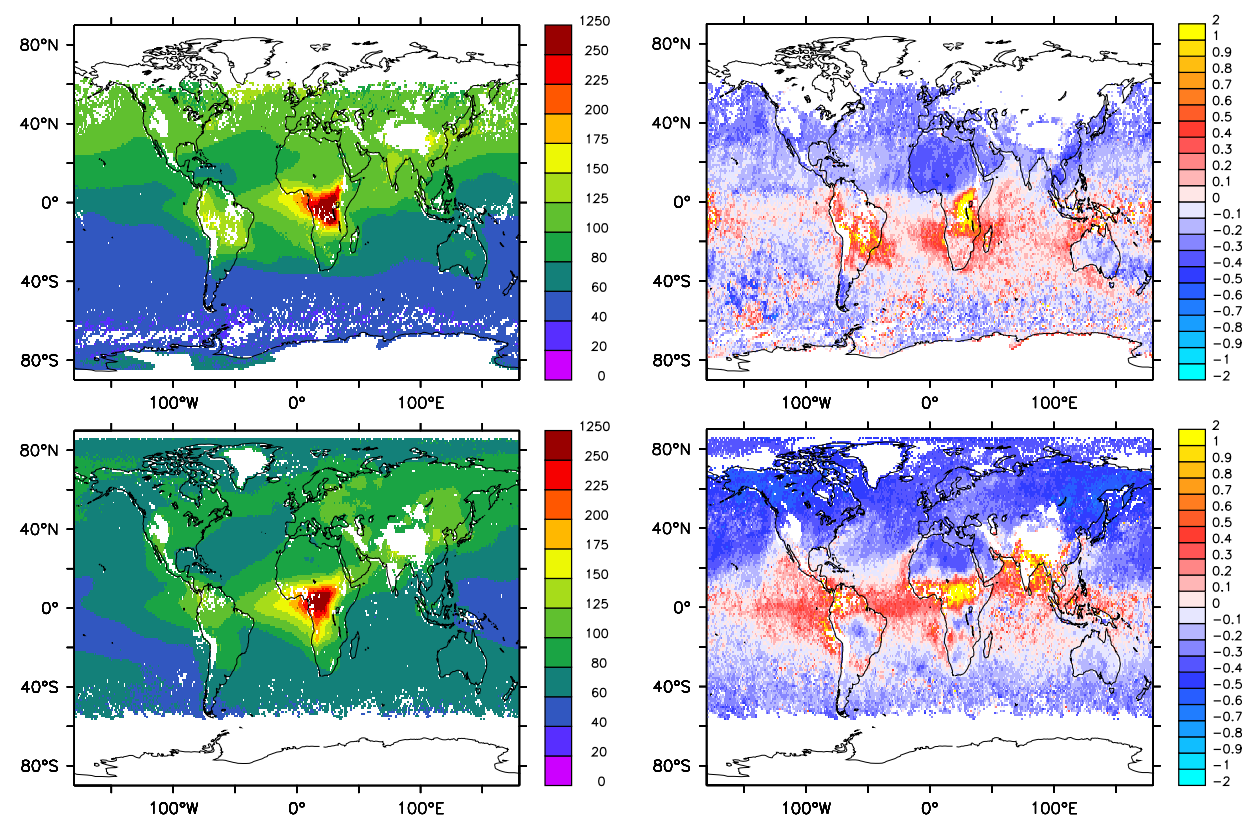

Fig. 12. Left: model calculated (S1) CO (in nmol/mol) at $700 \mathrm{hPa}$ on the MOPITT kernel for January (top) and July (bottom) 2003. Right: relative difference ((E5/M1-MOPITT)/MOPITT) between the model simulation S1 and MOPITT for January (top) and July (bottom) 2003; positive values indicate that E5/M1 is higher and vice versa. Only daylight conditions have been considered.

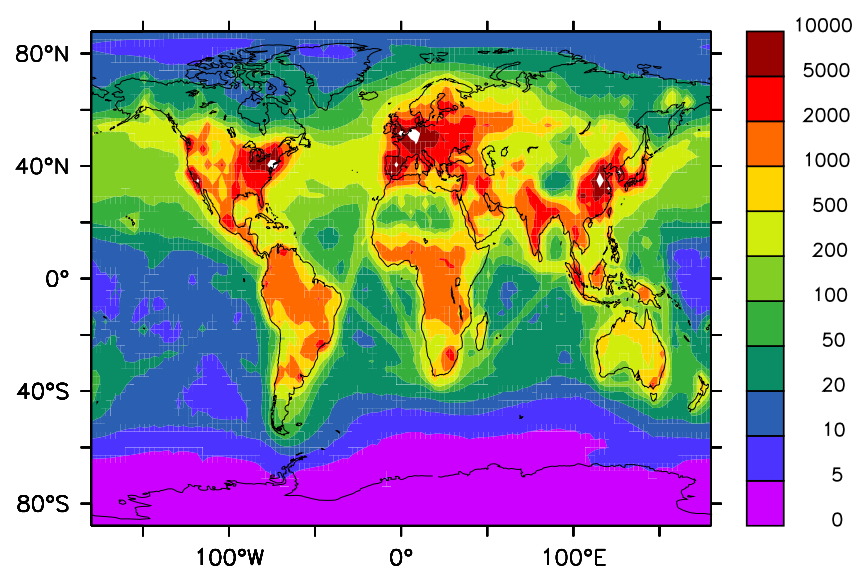

Fig. 13. Simulated (S1) 5-year mean surface $\mathrm{NO}_{\mathrm{x}}$ distribution ( $\mathrm{pmol} / \mathrm{mol})$.

campaign composites were made during daytime. Thus, we have filtered the model output to use daytime-only values in the comparisons for NO.

The comparisons to selected profiles for $\mathrm{NO}, \mathrm{HNO}_{3}$ and PAN are shown in Fig. 15. The same six regions are shown for each gas, for comparability. On the whole, E5/M1 reproduces the vertical structure of NO in the observations very well; out of the entire set of 48 profiles, the majority has a shape which closely resembles the observations, although there are also several which are considerably different. The

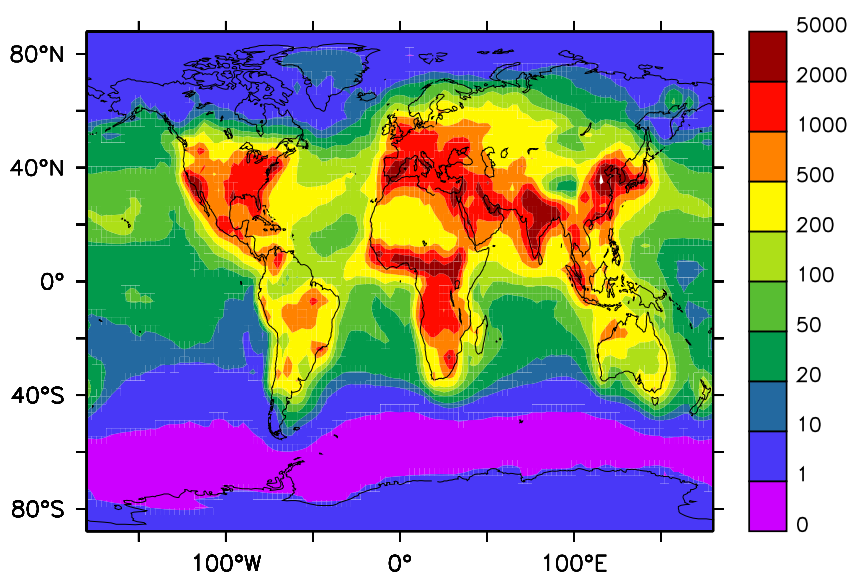

Fig. 14. Simulated (S1) 5-year mean surface $\mathrm{HNO}_{3}$ distribution ( $\mathrm{pmol} / \mathrm{mol})$.

profiles have been selected to show examples of both cases. The model has a slight tendency to underestimate the observed mixing ratios in the individual profiles. The overall regression for the 5 years of data (i.e., using each year as an individual data point) is: $R^{2}=0.32$ with a slope of 0.58 and an intercept of $7.1 \mathrm{pmol} / \mathrm{mol}$. The correlation is rather good for a comparison of this nature; for comparison, the model MATCH-MPIC, which has been widely used and accepted as applicable for detailed individual field campaign analysis 

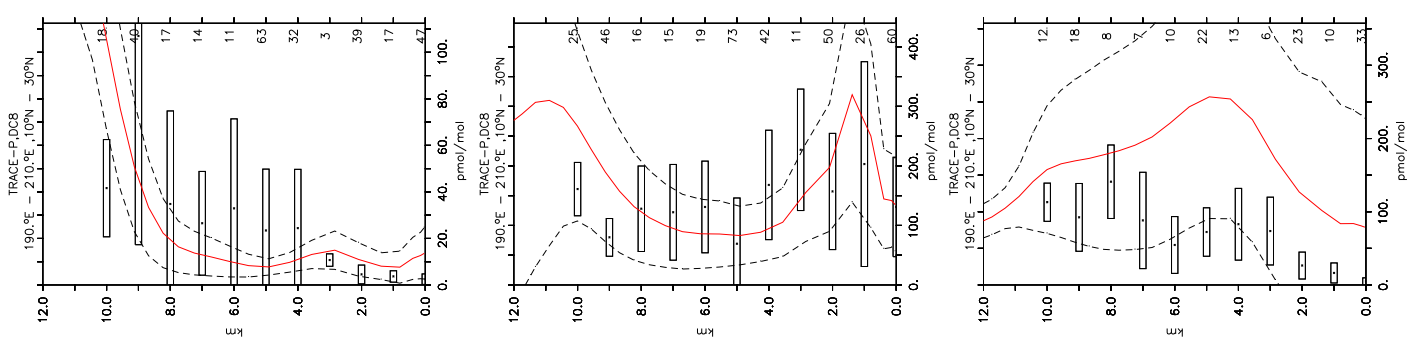

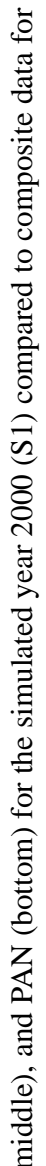
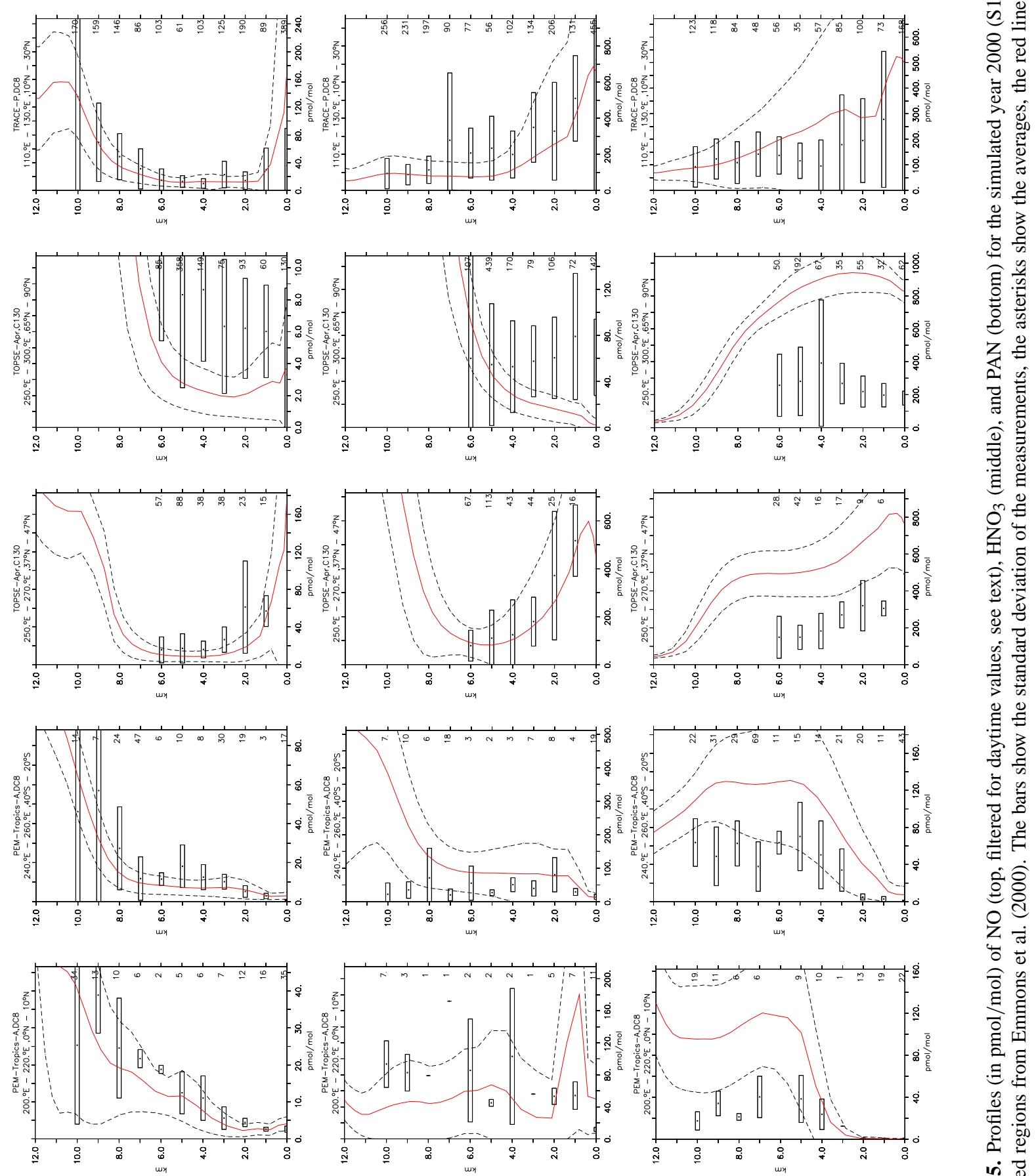

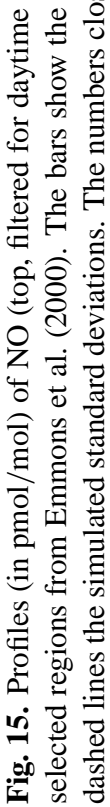




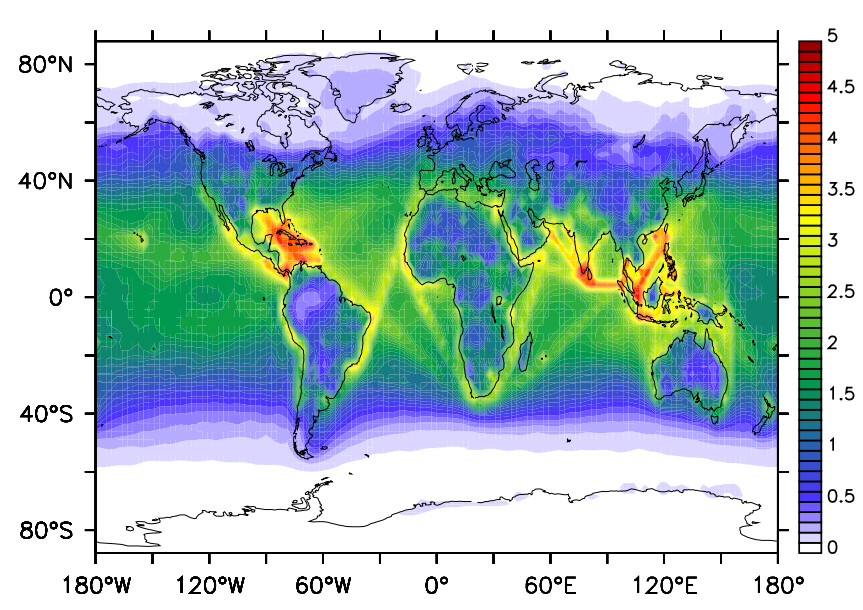

Fig. 16. 5-year average (2000 to 2004) of simulated (S1) diurnal mean $\mathrm{OH}\left(10^{6} \mathrm{~cm}^{-3}\right)$ in the lowest model layer.

(e.g., Lawrence et al., 2003; Fischer et al., 2006) has a correlation of $R^{2}<0.1$ for this same type of comparison to field campaign composites. The tendency of E5/M1 to underestimate the highest mixing ratios in the observations could in part be due to either a deficit of $\mathrm{NO}_{\mathrm{x}}$ sources, or to a too rapid conversion to $\mathrm{HNO}_{3}$ and PAN.

For $\mathrm{HNO}_{3}$, the model also generally reproduces the shape of the vertical profiles and the variability from region to region, as seen in the selected regional profiles in Fig. 15. Overall, there is a tendency to underestimate the mixing ratios slightly in the lower troposphere, and overestimate in the upper troposphere. The latter may be partly because the model does not yet consider the uptake of $\mathrm{HNO}_{3}$ on ice (von Kuhlmann and Lawrence, 2006) and the effects of sedimentation of small ice crystals (Lawrence and Crutzen, 1998). The linear regression between all observed and simulated profiles yields $R^{2}=0.39$, a slope of 0.59 , and an intercept of $57.1 \mathrm{pmol} / \mathrm{mol}$. This is slightly better than the correlation for NO, but the same indications are seen of a tendency to underestimate the highest mixing ratios and the overall variability.

Finally, the comparisons for PAN show a very clear tendency for the model to overestimate the observed mixing ratios (Fig. 15). As for $\mathrm{NO}$ and $\mathrm{HNO}_{3}$, the regression yields a slope of less than one (0.73) and a positive intercept of $190 \mathrm{pmol} / \mathrm{mol}$, indicating an underestimate of the overall variability, though in this case the intercept is large enough that the model statistically overestimates for all mixing ratios up to about $600 \mathrm{pmol} / \mathrm{mol}$. This general tendency to overestimate was also noticed in von Kuhlmann et al. (2003a), in which the MATCH-MPIC model used a very similar chemical scheme for the troposphere to that used here. von Kuhlmann et al. (2003a) considered possible reasons for this overestimate, including a too low dissociation rate, and subgrid chemical effects on the formation of PAN, but were not able to resolve the issue entirely; it will still need to be considered further in future studies, where targeted analyses of individual campaigns are more likely to eventually provide insight into this issue.

For $\mathrm{HNO}_{3}$ and $\mathrm{NH}_{\mathrm{x}}\left(\mathrm{NH}_{3}, \mathrm{NH}_{4}^{+}\right)$, wet deposition is the major sink. Summarising the detailed analyses presented in Tost (2006), a comparison of the wet deposition fluxes shows a good agreement of the model results with observations from several measurement networks (e.g. USA, Europe, East Asia). Nevertheless, analysis of the output from the wet deposition scheme (SCAV) indicates that some improvements with respect to the "effective" and "real" liquid water content (LWC) of the falling precipitation are required. The parameterisation is currently being improved, and preliminary results (not shown) indicate a higher, more realistic precipitation LWC. However, this mainly influences the dissolution of weak acids, e.g. $\mathrm{HCOOH}$ and $\mathrm{CH}_{3} \mathrm{COOH}$, for which the uptake is now more efficient and a greater fraction is scavenged, while for strong acids, e.g. $\mathrm{HNO}_{3}$, the uptake was already almost complete at the low LWC, so that the scavenged fraction does not change much.

\subsection{Hydroxyl radical}

Hydroxyl radical concentrations in the troposphere are computed to be highest in the tropics, as expected. Fig. 16 shows its annual distribution at the surface. Here we see that the highest values are found off the coast of south and southeast Asia and central America, and that ship tracks can be clearly distinguished, coincident with the $\mathrm{NO}_{\mathrm{x}}$ distribution in Fig. 13. Over continental regions, especially the tropical forest, surface layer $\mathrm{OH}$ concentrations tend to be reduced due to reactions with hydrocarbons. The seasonal zonal averages (Fig. 17) are comparable to the distributions computed by other models (Lawrence et al., 2001), although they show a few important differences to the $\mathrm{OH}$ distribution of Spivakovsky et al. (1990). One major difference is that the zonal mean is not symmetric, rather more heavily weighted towards the northern hemisphere. Another difference is that the maximum $\mathrm{OH}$ is located near the surface in the northern hemisphere instead of being centred at about $600 \mathrm{hPa}$ in the tropics as indicated by Spivakovsky et al. (2000). Possible causes for these differences are discussed below.

Traditionally two of the most powerful criteria for evaluating global $\mathrm{OH}$ are the lifetimes of $\mathrm{CH}_{4}$ and methyl chloroform (Krol et al., 1998; Houghton et al., 2001; Prinn et al., 2001; Spivakovsky et al., 1990, 2000). According to Lawrence et al. (2001), we calculated the tropospheric lifetime of methane as

$\tau\left(\mathrm{CH}_{4}\right)=\frac{\sum M_{\mathrm{CH}_{4}}}{\sum\left(k_{\mathrm{CH}_{4}} \times[\mathrm{OH}] \times M_{\mathrm{CH}_{4}}\right)}$

where $k_{\mathrm{CH}_{4}}$ (taken from Atkinson et al., 2005) and $M_{\mathrm{CH}_{4}}$ are the reaction rate coefficient of $\mathrm{CH}_{4}$ with $\mathrm{OH}$ and the gridbox mass of $\mathrm{CH}_{4}$, respectively. $\sum$ denotes the sum over 

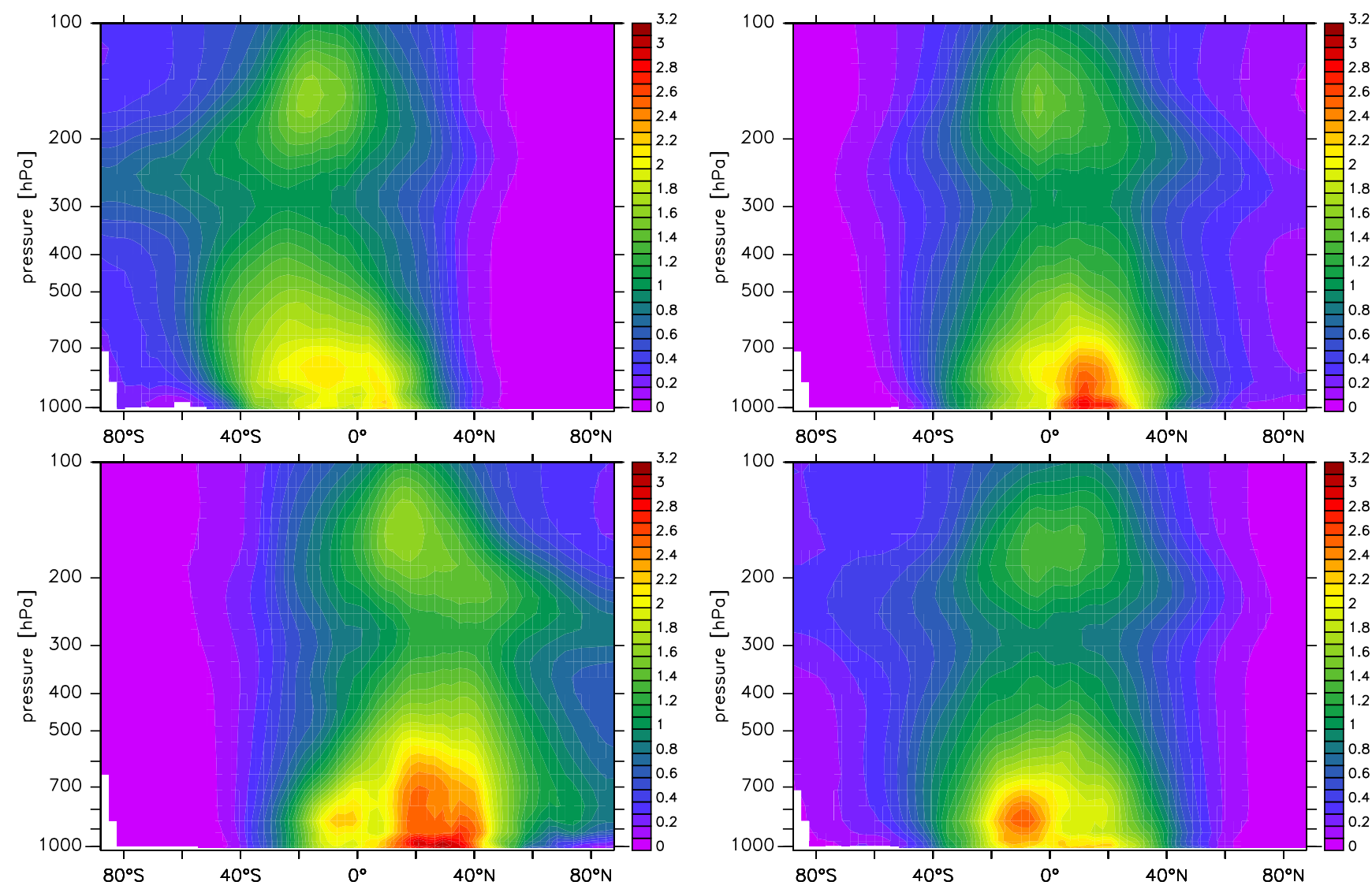

Fig. 17. 5-year averages (2000 to 2004) of simulated (S1) zonal and diurnal mean $\mathrm{OH}\left(10^{6} \mathrm{~cm}^{-3}\right)$ for the 4 seasons (DJF: upper left; MAM: upper right; JJA: lower left; SON: lower right).

tropospheric grid boxes. In the last row of Table 4 we see that $\tau\left(\mathrm{CH}_{4}\right)$ from our model is lower than from Spivakovsky et al. (2000) and von Kuhlmann (2001).

Other estimates in the literature include a global $\tau\left(\mathrm{CH}_{4}\right)$ of $8.67 \pm 1.32$ based on a recent model inter-comparison by Stevenson et al. (2006). Using the same kinetic data as von Kuhlmann (2001), $\tau\left(\mathrm{CH}_{4}\right)$ increases by $2.6 \%$ to about 8.3 years, consistent with a small decrease of global mean (index GM) $\mathrm{OH}_{\mathrm{GM}}\left(\mathrm{CH}_{4}\right)$ from 1.32 to $1.31 \times 10^{6} \mathrm{~cm}^{-3}$. This shows a non-negligible sensitivity to changes in the kinetic parameters, namely the rate constant of the reaction $\mathrm{CH}_{4}+\mathrm{OH}$. The $\tau\left(\mathrm{CH}_{4}\right)$ we calculated is within the range of other models (Stevenson et al., 2006).

To obtain an impression of how well our model calculates $\mathrm{OH}$ we followed Lawrence et al. (2001) and performed an analysis of the $\mathrm{OH}$ field by breaking it down into subdomains using proper weightings that have different dependencies on air mass, air volume and temperature. We also looked at the annual cycle of $\mathrm{OH}$ by sub-domains realizing that the $\mathrm{OH}$ concentration always reaches the maximum value in July and in the northern tropics. The reason for this is that the primary formation of $\mathrm{OH}$ depends on the amount
Table 4. Global average $\mathrm{OH}$ concentration (in $10^{6} \mathrm{~cm}^{-3}$ ) calculated with different weighting factors. Listed are the five-year averages of the reference simulation (S1). The difference between 5 individual annual averages is less than $0.01 \times 10^{6} \mathrm{~cm}^{-3}$. The last row lists the global average methane lifetime $\left(\tau\left(\mathrm{CH}_{4}\right)\right.$ in years).

\begin{tabular}{lrrr}
\hline year & $\begin{array}{r}\mathrm{S} 1 \\
2000-2004\end{array}$ & $\mathrm{~S}^{2000^{\mathrm{a}}}$ & $\mathrm{MATCH}^{\mathrm{b}}$ \\
\hline mass & 1.08 & 1.14 & 0.95 \\
volume & 1.03 & 1.10 & 0.87 \\
$k_{\mathrm{MCF}}$ & 1.28 & 1.29 & 1.16 \\
$k_{\mathrm{CH}}$ & 1.31 & 1.32 & 1.19 \\
\hline$\tau\left(\mathrm{CH}_{4}\right)$ & 8.02 & 8.23 & 9.12 \\
\hline
\end{tabular}

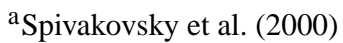

$\mathrm{b}_{\text {von Kuhlmann (2001) }}$

of UV light and water vapour, and the secondary formation depends on $\mathrm{NO}_{\mathrm{x}}$. Therefore the maximum values occur during summer in the most polluted hemisphere (Fig. 17). In 
Table 5. Mass weighted regional average $\mathrm{OH}$ concentration (in $10^{6} \mathrm{~cm}^{-3}$ ) of the reference simulation (S1). The vertical regions are denoted as follows: LT: Below $750 \mathrm{hPa}$; MT: $750-500 \mathrm{hPa}$; UT: 500-250 hPa; UT/TTL: $250 \mathrm{hPa}$ - tropopause.

\begin{tabular}{lrrr}
\hline Region & REF(2000) & S2000 $^{\mathrm{a}}$ & MATCH $^{\mathrm{b}}$ \\
\hline LT, 90 S-30 S & 0.54 & 0.47 & 0.51 \\
LT, 30 S-0 & 1.84 & 1.44 & 1.51 \\
LT, 0-30 N & 2.05 & 1.52 & 1.76 \\
LT, 30 N-90 N & 0.82 & 0.76 & 0.86 \\
MT, 90 S-30 S & 0.55 & 0.72 & 0.46 \\
MT, 30 S-0 & 1.50 & 2.00 & 1.48 \\
MT, 0-30 N & 1.65 & 1.99 & 1.61 \\
MT, 30 N-90 N & 0.70 & 0.88 & 0.72 \\
UT, 90 S-30 S & 0.48 & 0.64 & 0.36 \\
UT, 30 S-0 & 1.01 & 1.43 & 0.82 \\
UT, 0-30 N & 1.07 & 1.36 & 0.96 \\
UT, 30 N-90 N & 0.55 & 0.64 & 0.52 \\
UT/TTL,30 S-0 & 1.12 & & \\
UT/TTL,0-30 N & 1.14 & & \\
Global & 1.07 & 1.14 & 0.95 \\
\hline
\end{tabular}

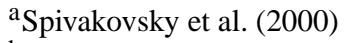

$\mathrm{b}_{\text {von Kuhlmann (2001) }}$

Table 4 the global mean $\mathrm{OH}$ concentrations are shown. At first glance it seems that our model compares well globally with differences ranging from 1 to $5 \%$ with respect to Spivakovsky et al. (2000). However, this is seen to be a cancellation effect between different regions. In Table 5 we see that compared to von Kuhlmann (2001) the global OH distribution in E5/M1 is quite similar, while compared to Spivakovsky et al. (2000) E5/M1 computes higher OH in the lower troposphere (especially in the tropics where differences are about $30 \%$ ) and lower $\mathrm{OH}$ in the upper troposphere (more evenly distributed over latitudes). Possible explanations for these differences are:

- In the lower troposphere (below $750 \mathrm{hPa}$ ) our model setup neglects some important sinks like liquid phase chemistry of $\mathrm{OH}$ (though it includes reactions of $\mathrm{H}_{2} \mathrm{O}_{2}$ and $\mathrm{O}_{3}$ ), $\mathrm{HO}_{\mathrm{x}}$ uptake by aerosols (for a review of these heterogeneous processes see Jacob, 2000), and secondary organic aerosol (SOA) formation. Some evidence in support of this is that the largest differences are in the tropics where VOC emissions from natural sources and humidity are relatively high.

- In the middle and upper troposphere the lower values compared to Spivakovsky et al. (2000) possibly come from the parameterisation of processes that depend strongly on convection like

- the vertical transport of $\mathrm{HO}_{\mathrm{x}}$ precursors (that could also partly account for the positive differences in the lower troposphere),
- $\mathrm{NO}_{\mathrm{x}}$ production by lightning.

- Taking advantage of on-line calculations with short time steps (15 min), our model may actually be computing a more consistent and thus more realistic distribution than using the approach of Spivakovsky et al. (2000) with a photochemical model that uses monthly means of $\mathrm{OH}$ precursors. The latter approach misrepresents non-linear effects, such as transitions between different reaction regimes, which are caused by temporal fluctuations of temperature and of other trace gases.

\subsection{Model comparison with ozone sonde data}

To evaluate the model calculated ozone distribution the compilations of balloon sounding data by Logan (1999) and Thompson et al. (2003a,b) have been used (further denoted as Logan and SHADOZ, respectively). The Logan dataset offers the advantage of a relatively long time series, hence it can be considered a climatology. It covers the period from 1980 to 1993, while our simulation covers the years 1998 to 2005, so that anomalies such as El Niño events and trends may impede the model-data comparison. The SHADOZ measurements, on the other hand, coincide with our model simulation period, although the dataset is smaller and less useful for statistical analyses. The SHADOZ measurements furthermore involve stations primarily in the tropics and the southern hemisphere, whereas the Logan data are more widespread so that the datasets are complementary. From the SHADOZ data we derived a climatological average (1998-2002) for each location, similar to the Logan compilation.

\subsubsection{Vertical profiles}

While the model comparison with TOMS satellite data indicates a slight positive model bias in the column ozone at middle to high latitudes, as discussed in Sect. 4 (Fig. 9), the analysis for the troposphere based on the Logan data gives no evidence of systematic positive or negative biases (Fig. 18).

Upper tropospheric ozone over Lauder in the model seems relatively high, i.e., near the upper bound of the measurement uncertainty range, which is consistent with the bias in total ozone (cf. Fig. 9). In general, the simulated ozone profiles match within one standard deviation of the measurements. Figure 18 also shows that the model calculated variability is typically highest in the upper troposphere, related to the influence of synoptic weather systems on stratospheretroposphere exchange and the stochastic nature of convective outflow, in agreement with the measurement data.

\subsubsection{Annual time series}

The seasonal cycles of ozone in the middle troposphere of the Logan and SHADOZ data along with our model results are shown in Figs. 19 and 20, respectively. 
We focus on $400 \mathrm{hPa}$ because Fig. 18 indicates that model deviations at this level may be most significant. The comparison between the ozone time series in Fig. 19 indicates that the model generally reproduces the observed seasonal dependencies, i.e., well within the standard deviations of both datasets. Moreover, the ozone variability in both model and measurement data are very similar. Over Japan (Kagoshima) our model seems to overestimate ozone mixing ratios in winter, likely related to too strong transport from the stratosphere. Over Alert, the model overestimates ozone in late winter, possibly for the same reason, although the local tropopause mixing ratios fit the data well (Fig. 18), thus indicating that long-distance transport to high northern latitudes might be too strong. Also at Lauder the model seems to be highbiased, although Fig. 18 shows that the agreement improves both at lower and higher altitudes.

Over Hohenpeissenberg our model underestimates free tropospheric ozone in summer, possibly related to a deficiency in the convective transport of precursor gases. An alternative explanation is that the Logan database covers the period 1980-1993, during which the summertime ozone mixing ratios peaked, whereas during subsequent years the ozone levels have decreased at this location. The modeldata comparison for the tropical stations in Fig. 20 generally shows good agreement, although the sparseness of the dataset precludes a detailed model evaluation. Nevertheless, middle tropospheric ozone over Paramaribo ("Param") is clearly too low from June to October. We explain this by a model bias in biomass burning emissions and transport from Brazil in the dry season.

The Taylor diagram in Fig. 21 summarises the comparison of all sonde data at $400 \mathrm{hPa}$ from the Logan climatology. The model-data correlation is high, mostly above 0.6 , suggesting that the seasonal dependency of model calculated ozone is quite realistic. The clustering of the data points around a normalised standard deviation of one furthermore corroborates the absence of systematic model biases. A Taylor diagram for the model comparison with the SHADOZ tropospheric ozone data, averaged to the same pressure levels as in the Logan climatology, is shown in Fig. 22. In spite of several outliers, the points cluster around a normalised standard deviation of one and a correlation coefficient above 0.8 , thus confirming the good agreement.

\section{Middle atmosphere tracers and chemistry}

\subsection{Model comparison with MIPAS data}

\subsubsection{Seasonal distributions}

In this section we compare model calculated $\mathrm{O}_{3}$ and $\mathrm{HNO}_{3}$ with the MIPAS satellite data averaged over the years 2002 and 2003 (Glatthor et al., 2006; Mengistu Tsidu et al., 2005). Nitric acid is included as an example of a reservoir species
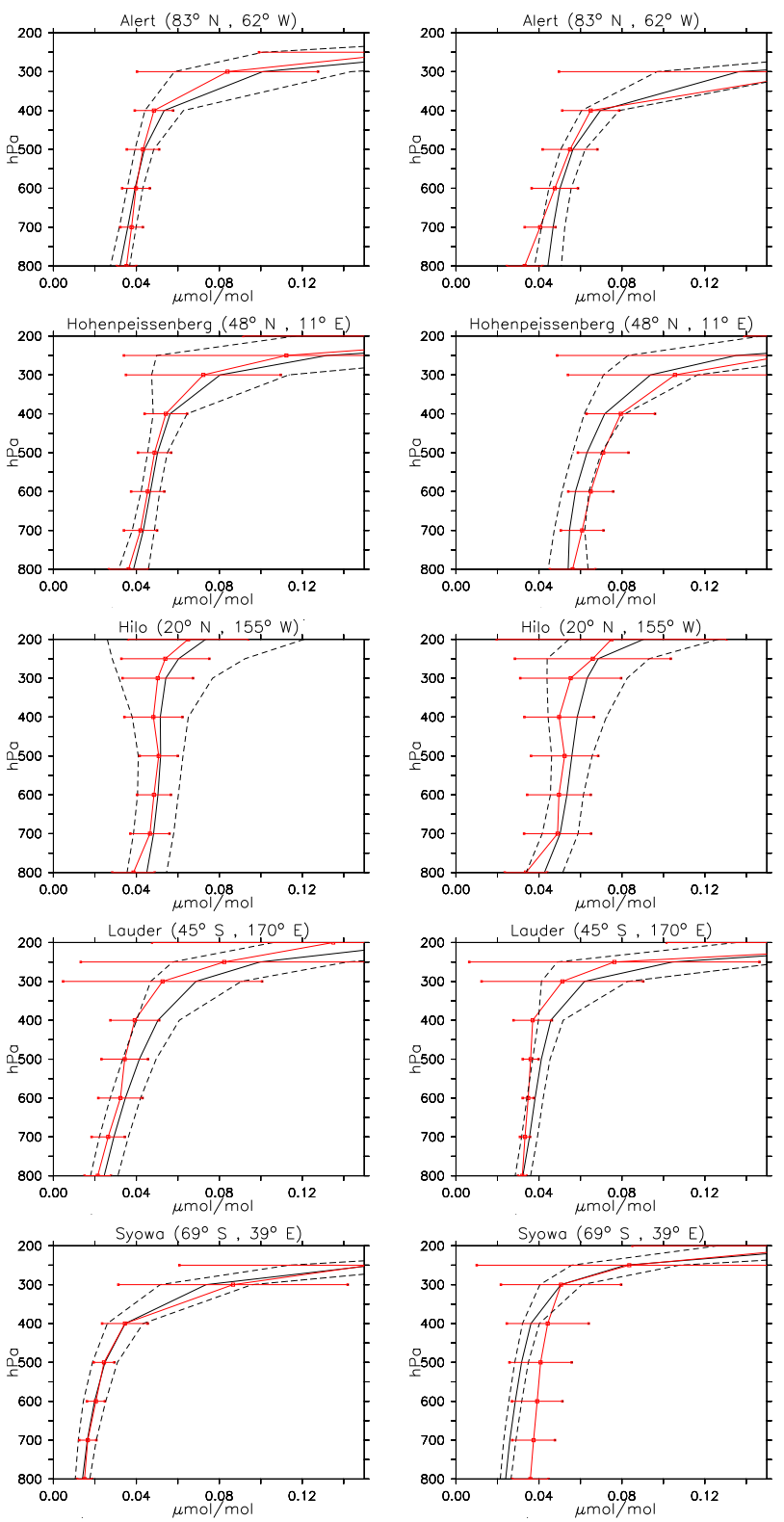

Fig. 18. Vertical profiles of ozone (in $\mu \mathrm{mol} / \mathrm{mol}$ ) in January (left) and June (right) in the free troposphere and tropopause region for selected sites from Logan (1999). Black lines are model results (7-year averages, S1) and red lines are observations. The dashed black lines show the model standard deviations, and the red bars the observed standard deviations.

of ozone destroying gases, being controlled both by transport and chemistry. The northern winter (DJF) and the Antarctic spring season (SON) are shown in Figs. 23 and 24. The model results are typically within the observational error range of about $5 \%\left(\mathrm{O}_{3}\right.$ above about $\left.100 \mathrm{hPa}\right)$ and $10 \%$ $\left(\mathrm{HNO}_{3}\right)$, although the difference graphs in the right panels indicate some deviations. 

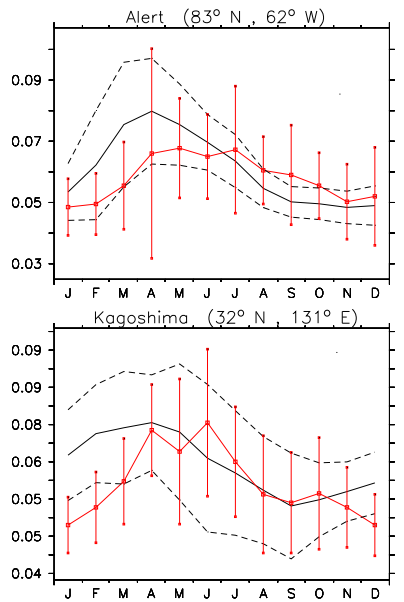
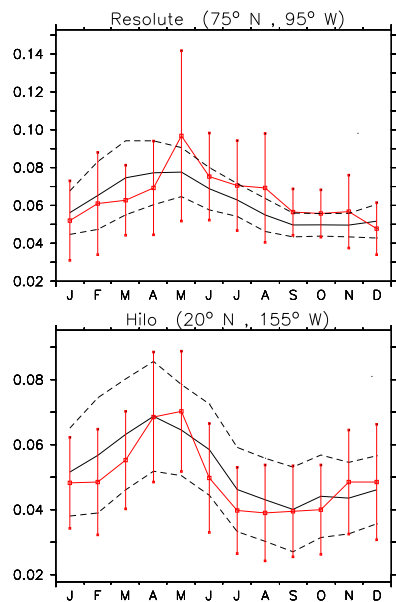
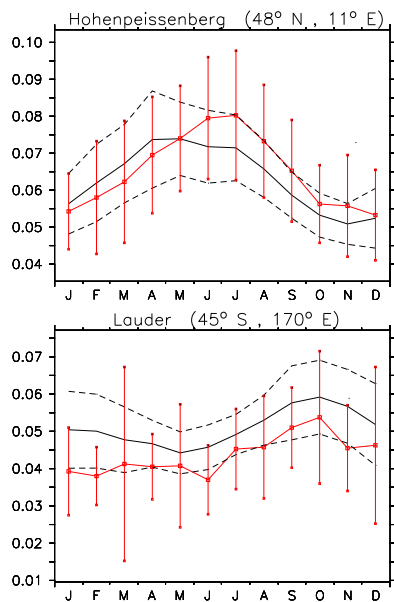
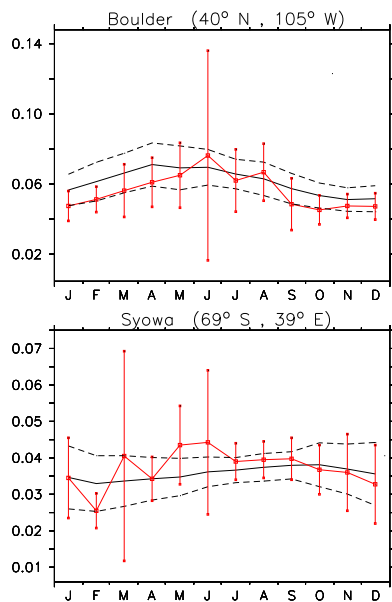

Fig. 19. Seasonal cycle of ozone (in $\mu \mathrm{mol} / \mathrm{mol}$ ) for selected sites from Logan (1999) in the troposphere at $400 \mathrm{hPa}$. Black lines are model results (7-year averages (1998-2004), S1) and red lines are observations. The dashed black lines show the model standard deviations, and the red bars the observed standard deviations.

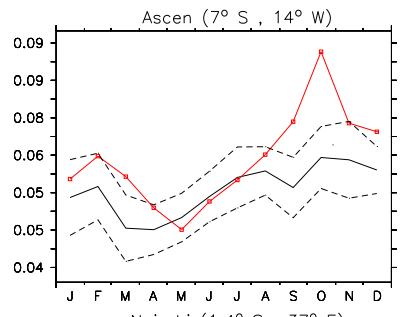

Nairobi $\left(1.4^{\circ} \mathrm{S}, 37^{\circ} \mathrm{E}\right.$

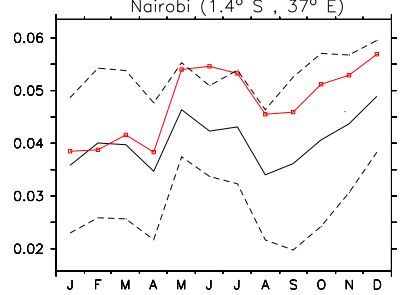

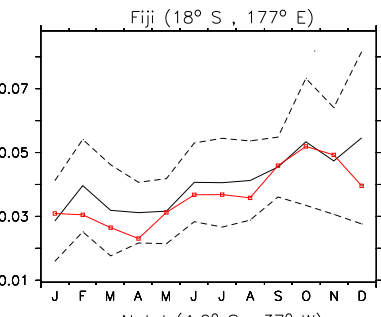

Natal $\left(4.2^{\circ} \mathrm{S}, 37^{\circ} \mathrm{W}\right)$

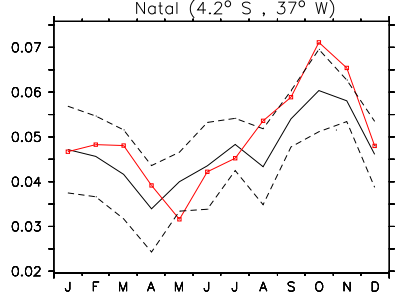

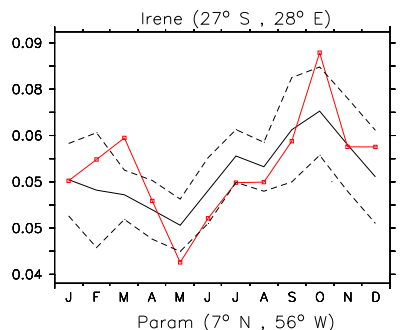
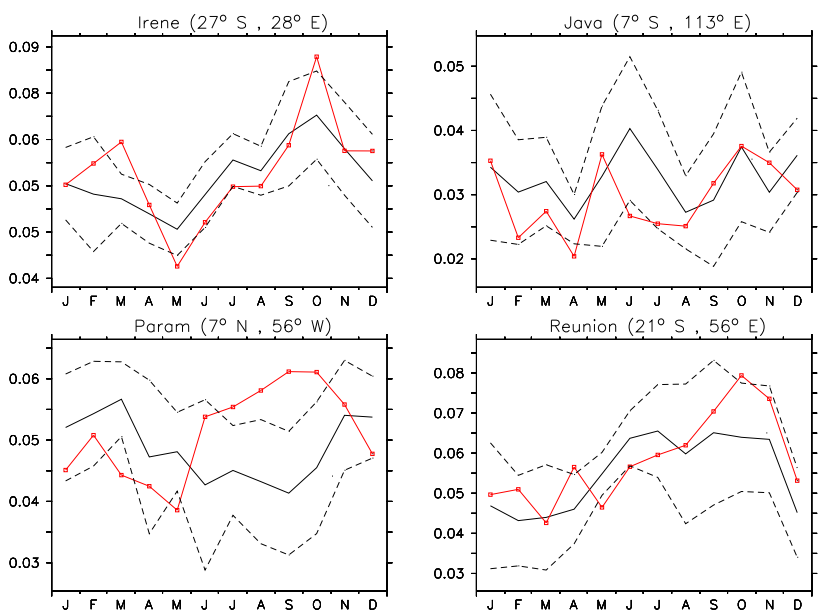

Fig. 20. Seasonal cycle of ozone (in $\mu \mathrm{mol} / \mathrm{mol}$ ) at $400 \mathrm{hPa}$ obtained from the SHADOZ database (red) compared to the 7-year climatology (1998 to 2004) derived from the E5/M1 model simulation S1 (black). The dashed black lines show the model standard deviations.

For ozone, there are two regions with typical difference patterns. The threefold difference structure in the tropical stratosphere points to the sensitivity of ozone to the correct representation of the QBO, in particular because the results improve in the $\mathrm{S} 2$ simulation with reduced nudging and gravity wave forcing, in which the QBO phase shift is diminished as compared to $\mathrm{S} 1$. On the other hand, the higher ozone in the model near the peak at $10 \mathrm{hPa}$ is mostly related to the coarser vertical resolution of the MIPAS data, as indicated by test calculations with model data convolved with the MIPAS averaging kernels (not shown).

In polar latitudes the model tends to underestimate ozone depletion in the lowermost stratosphere, in winter and spring. Because below about $40 \mathrm{hPa}$ the downward transport is too weak (Fig.5), insufficient chlorine and bromine are avail- able, resulting in too little ozone destruction by heterogeneous chemistry on PSCs. In the Antarctic spring the ozone hole below about $30 \mathrm{hPa}$ is well represented though somewhat underestimated below $70 \mathrm{hPa}$. At $30 \mathrm{hPa}$ the reactive chlorine $\mathrm{ClO}_{\mathrm{X}}$ peaks around $3 \mathrm{pmol} / \mathrm{mol}$, which is consistent with values derived from satellite data (e.g., Eyring et al., 2006). $2 \mathrm{pmol} / \mathrm{mol}$ at $70 \mathrm{hPa}$ are too low. In the Arctic in DJF additionally not enough solid PSCs formed because the settings for supersaturation and microphysics were the same as for Antarctica causing an underestimate of halogen activation and denitrification (Buchholz, 2005). The overestimation of ozone around $7 \mathrm{hPa}$ during SON in the Antarctic is a consequence of the lack of $\mathrm{NO}_{\mathrm{y}}$ from downward transport from the thermosphere (Funke et al., 2005a) in the model. 


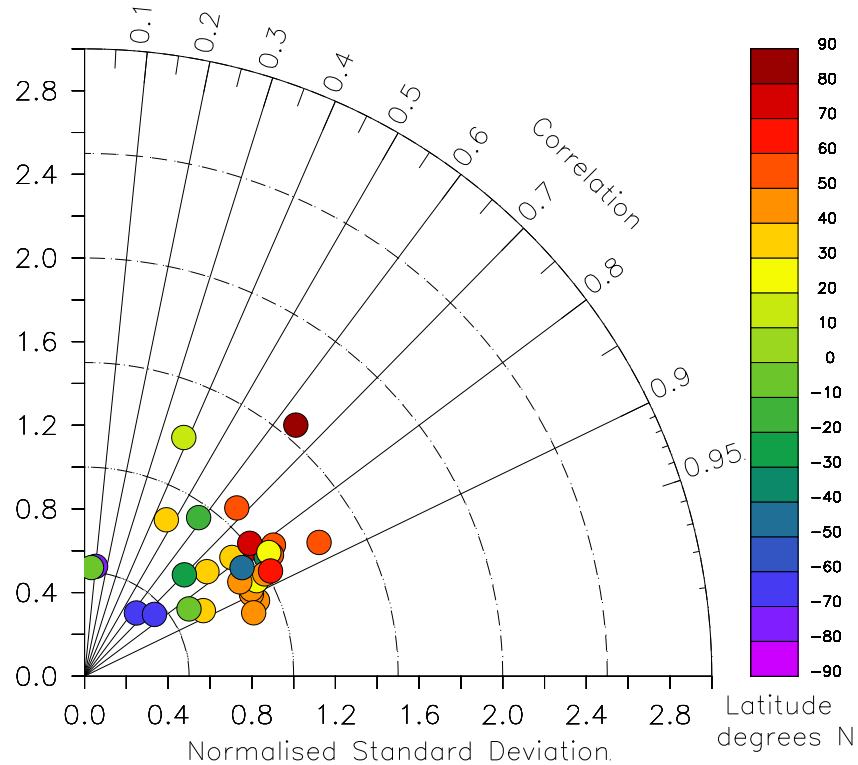

Fig. 21. Taylor plot of the correlation between observations and model results (S1) for the $400 \mathrm{hPa}$ level for all sites from Logan (1999). The correlation has been error weighted (see Appendix D).

Also for $\mathrm{HNO}_{3}$ (Fig. 24) the model reproduces the observed distribution quite well, including the denitrified regions in the Antarctic ozone hole region. The maximum of $\mathrm{HNO}_{3}$ is almost perfectly captured by the model. The slight underestimation of $\mathrm{HNO}_{3}$ throughout the lower stratosphere by the model is attributed to the missing reaction $\mathrm{NO}+\mathrm{HO}_{2} \rightarrow \mathrm{HNO}_{3}$ (Butkovskaya et al., 2005). The dipolar difference pattern in DJF in the Arctic is again due to the too weak downward motion and the underestimated denitrification, whereas the missing $\mathrm{HNO}_{3}$ during SON in the middle and upper stratosphere is related to the solar proton event and enhanced transport of nitrogen oxides from the thermosphere (Stiller et al., 2005; López-Puertas et al., 2005a,b). In the Antarctic the effect of the missing source propagates downward near the vortex edge, the region with the largest downward motion. A more detailed comparison between the model and MIPAS data, including additional reactive nitrogen and chlorine species, will be presented in a follow-up paper with a focus on the stratospheric part of the model domain.

\subsubsection{The 2002 vortex split}

Figure 25 (which is constructed similarly to Fig. 8) shows an underestimate of ozone depletion inside the vortices which is most likely related to an underestimate of activated $\mathrm{ClO}$ below $40 \mathrm{hPa}$ as indicated by satellite data (not shown because it is too noisy). The model also reproduces the observed dehydration and denitrification inside the vortices, shown here with $\mathrm{H}_{2} \mathrm{O}, \mathrm{HNO}_{3}$ and $\mathrm{NO}_{2}$ as examples. These also show

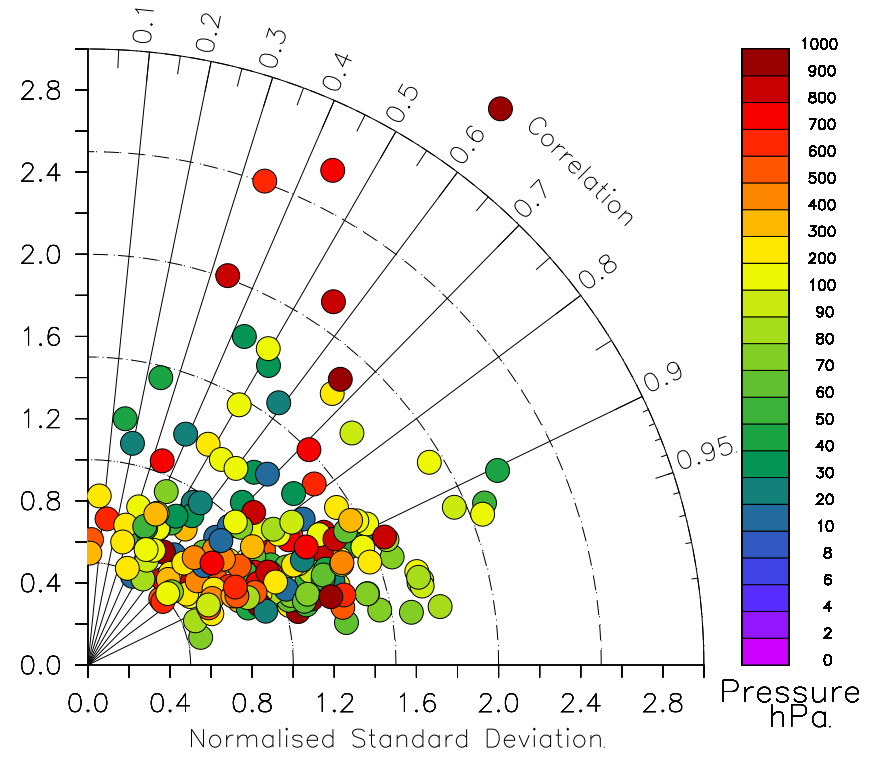

Fig. 22. Taylor plot of $\mathrm{O}_{3}$ correlation between 7-year E5/M1 climatology (S1) and a similar climatology compiled from the SHADOZ database (see Sect. 5.4).

the diurnal cycles of $\mathrm{NO}_{2}$ and ozone, which compare well with the MIPAS observations (Glatthor et al., 2006; Mengistu Tsidu et al., 2005; Funke et al., 2005b). The experimental uncertainty for $\mathrm{NO}_{2}$ for these "snapshots" is about $10 \%$ at night and $20 \%$ at daytime. One has to keep in mind that the comparisons are not done exactly at the same time so that some differences can be caused just by movement of the vortex lobes with their strong gradients. Simulated water vapour has a slight low bias which is consistent with the slightly too cold tropical hygropause in Fig. 4. Further, one has also to keep in mind that MIPAS seems to have a small high bias above $40 \mathrm{~km}$, in particular compared to HALOE data (Milz et al., 2005, Milz et al., validation paper in preparation). Nevertheless, too low water vapour and too high ozone around 30 to $50 \mathrm{hPa}$ outside the vortex are consistent because $\mathrm{HO}_{\mathrm{X}}$ is the most important catalytic ozone sink there.

\subsection{Model comparison with sonde data}

\subsubsection{Vertical profiles}

In Fig. 26 we compare the model results with selected sounding stations from the Logan climatology, being representative of different latitudes.

The agreement is rather good for most locations, both in terms of mixing ratios and variability. The largest discrepancies are found for the middle stratosphere at high latitudes in winter (e.g., Alert), where the model tends to overestimate ozone. This might partly be associated with a time-mismatch and the large inter-annual variability at this location. At the other locations the results are generally within the standard 

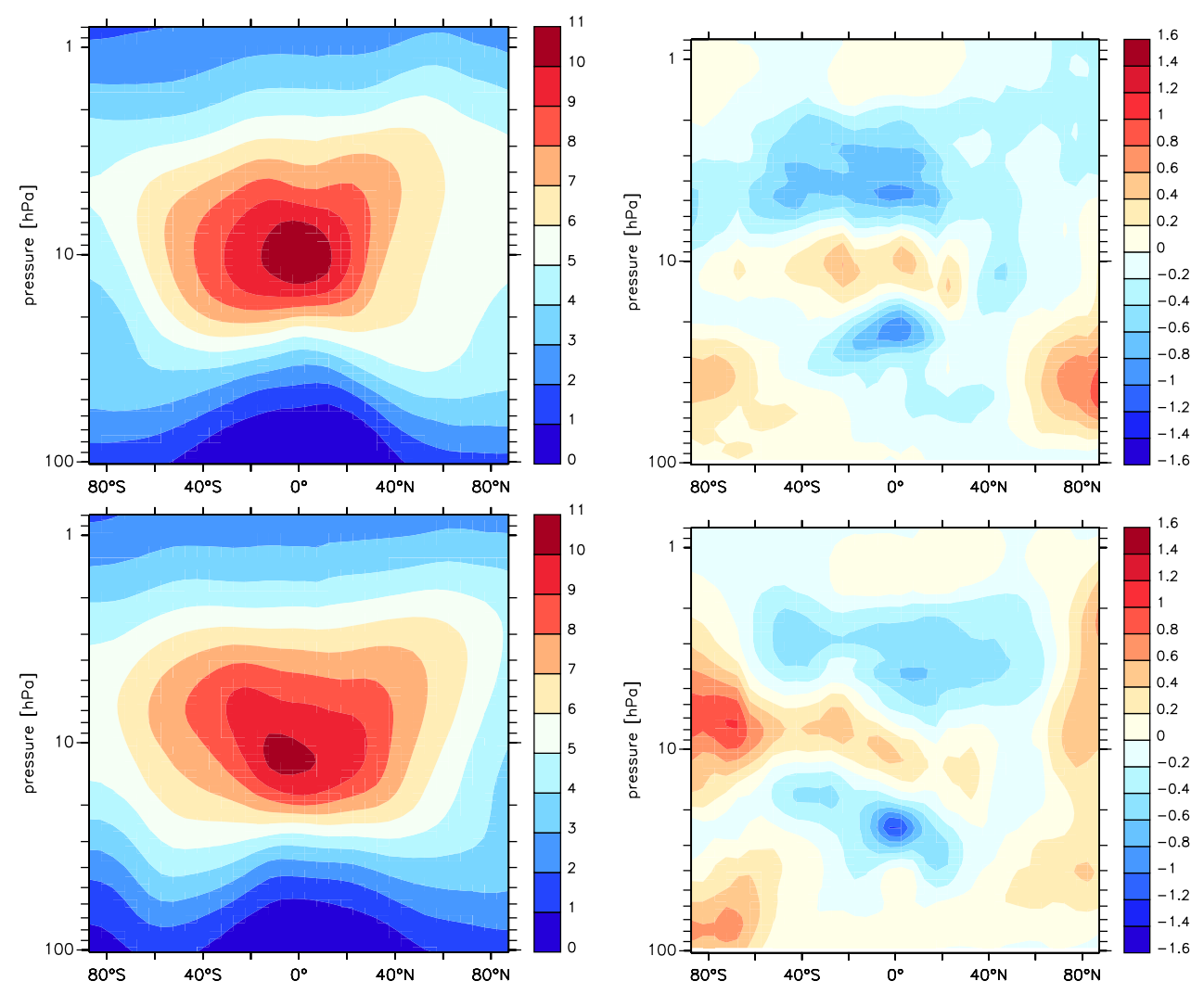

Fig. 23. Left: zonal averages of simulated ozone (in $\mu \mathrm{mol} / \mathrm{mol}$ ). Right: model minus MIPAS observations (in $\mu \mathrm{mol} / \mathrm{mol}$ ). Top: DJF, S1, Bottom SON, S2 with improved QBO. The datasets typically represent 15 days with about 14 orbits each.

deviations. The good agreement with tropical measurement data is confirmed by the comparison with the SHADOZ profiles in Fig. 27.

The stratospheric vertical ozone maxima from the Logan climatology have been collocated with the model results in Fig. 28, showing a very high correlation coefficient $\left(R^{2} \approx 0.9\right)$, and confirming a slight positive bias in the extratropics.

\subsubsection{Annual time series}

In the model results for the extra-tropical stratosphere some deviations with measurement data are found for the pressure altitude around $40 \mathrm{hPa}$. The monthly variation of ozone at this level is compared with selected sonde station data from the Logan climatology in Fig. 29.

The seasonal dependence as well as the variability is very well captured by the model, although a small positive bias up to about $0.5 \mu \mathrm{mol} / \mathrm{mol}$ is apparent for several locations. We speculate that some of the discrepancy might be related to a slight over-prediction of molecular oxygen photodissociation in the stratosphere and an underestimate of the ozone sink due to odd hydrogen related to the low bias of about $0.5 \mu \mathrm{mol} / \mathrm{mol}$ in stratospheric water vapour (cf. Fig. 25,
Lelieveld et al.,2006 ${ }^{4}$ ). The discrepancy seems to be largest at middle latitudes and in winter, associated with relatively rapid transport in the Brewer-Dobson circulation. The overall high correlation between model results and observations, generally above 0.8 , is confirmed by the Taylor diagram in Fig. 30. The clustering around the normalised standard deviation of one supports the impression of good agreement. The few outliers, e.g. in the tropics, represent sparse components of the dataset and should not be overrated. This overall positive picture is reinforced by the comparison with the tropical SHADOZ data in Fig. 31, for which we derive a correlation coefficient of $R=0.8$.

\subsection{Mesospheric ozone}

Vertical profiles of simulated mesospheric ozone (S1) have been compared with observations by the ground based Lindau microwave sounder at $52^{\circ} \mathrm{N} / 10^{\circ} \mathrm{E}$ from December 1998 to November 2000 as shown in Hartogh et al. (2004). The model reproduces the seasonal structure in the lower mesosphere, the winter nighttime maxima at about $73 \mathrm{~km}$ altitude and the summer minima near the upper boundary. We also compared the seasonal and diurnal features for higher latitudes $\left(69^{\circ} \mathrm{N}, 77^{\circ} \mathrm{N}\right)$ and found good agreement. Looking 

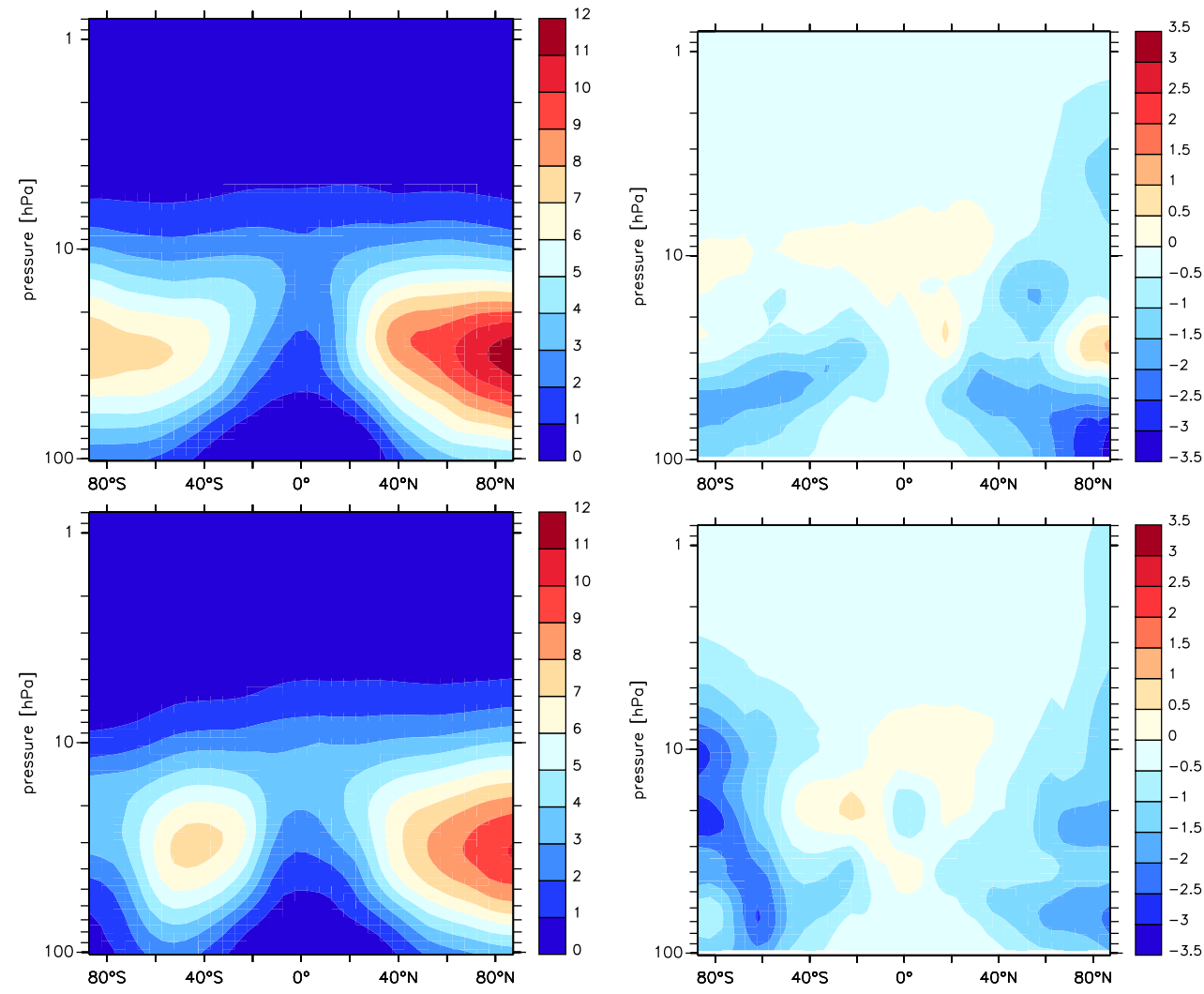

Fig. 24. Left: zonal averages of simulated $\mathrm{HNO}_{3}$ (in nmol/mol). Right: model minus MIPAS observations (in nmol/mol). Top: DJF, S1, Bottom SON, S2. The datasets typically represent 15 days with about 14 orbits each.

for zonal averages at local midnight and solstice, the model captures the tertiary ozone maximum near the terminator at about $71 \mathrm{~km}$ altitude within about $20 \%$ compared to the mesospheric model given in Hartogh et al. (2004), but appears to be somewhat high during polar night. Odd hydrogen species and water vapour are similar to the data presented in Hartogh et al. (2004).

\section{Discussion}

Since for most of the chemical species the observational time series exceeding 20 years which would be necessary for conventional statistics and significance analysis are not available, we applied the nudging technique for tropospheric dynamics which enables point-to-point comparisons with satellite and campaign data. For the middle atmosphere we compared different species and temperature under different dynamical regimes and a time period of 8 years using millions of data points. The selected time period is not perturbed by major volcanoes. Also the halogen concentration changes and the increase in methane are small. We have tested the method for different settings of dynamical forcings by planetary waves (nudging) and gravity waves (S1 and S2). It is shown that the results and the deviations from observations stay robust. Additionally, we performed several tests on sampling and interpolation errors (not shown in detail). Aliasing errors due to the diurnal cycle are reduced by the choice of 5 hourly output.

The sensitivity simulation (S2) with a reduced gravity wave forcing (by 10\%) and a reduced nudging near the tropopause (to $\approx 200 \mathrm{hPa}$ instead of $\approx 100 \mathrm{hPa}$ ) indicates a closer agreement with observations compared to the reference simulation (S1). S2 also has a conceptual advantage, because it is more consistent with the concept of evaluating the free running stratosphere of the model by nudging the tropospheric meteorology towards realistic conditions. Note that the strength of the needed non-orographic gravity wave forcing depends on the chosen nudging height. As shown in the upper panels of Figs. 4 and 5, reducing only the nudging height deteriorates the results in most regions. In S2 the Brewer-Dobson circulation is closer to observations than in $\mathrm{S} 1$, as indicated by upper stratospheric temperatures and the distribution of long-lived tracers. The slower and more realistic Brewer-Dobson circulation in S2 reduces the bias in total ozone at mid and high latitudes and also gives a slightly warmer lowermost tropical stratosphere. As shown in Fig. 7 (also seen in $\mathrm{N}_{2} \mathrm{O}$ and $\mathrm{CH}_{4}$ ), also the representation of the 

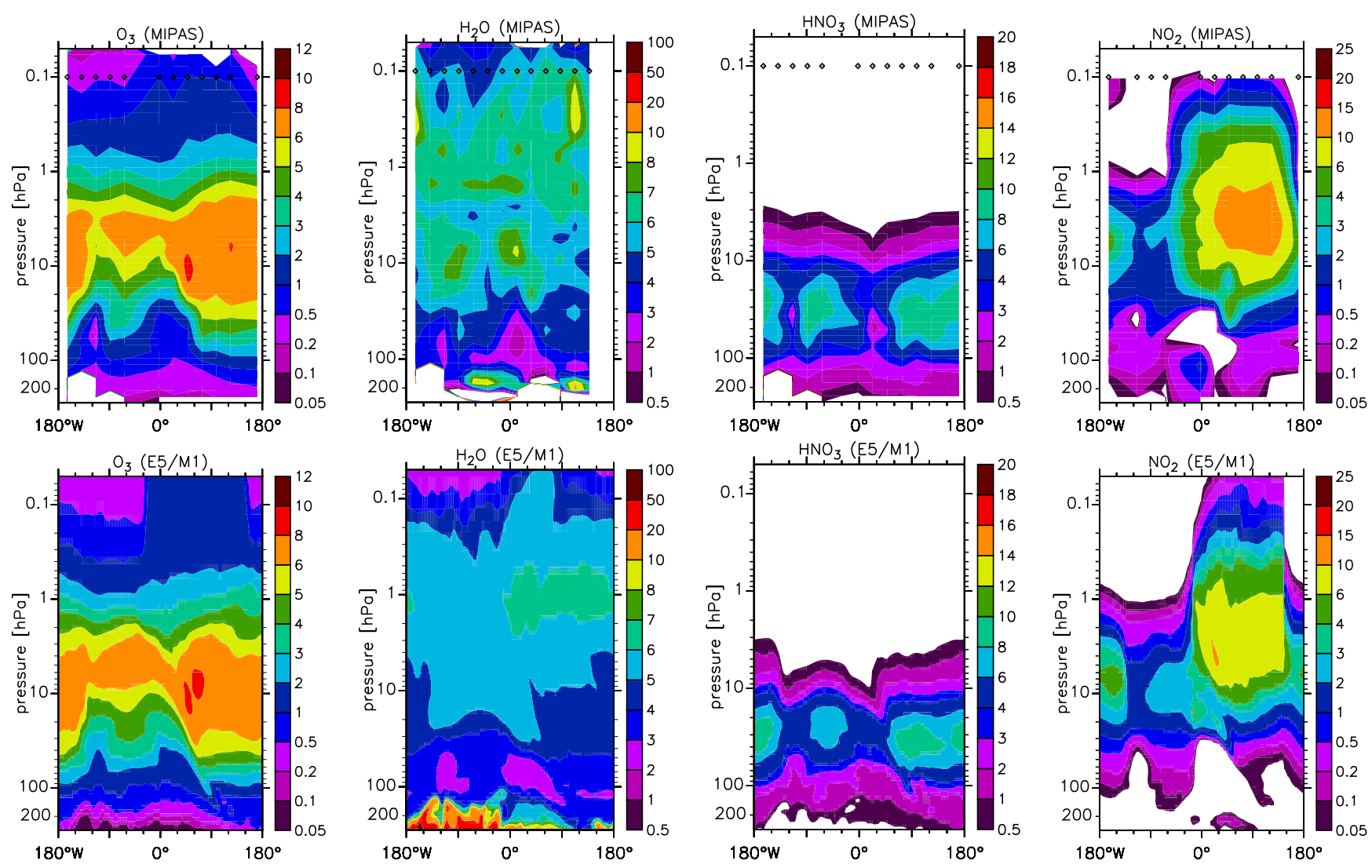

Fig. 25. MIPAS observations (upper row) and model simulations (E5/M1, S2, lower row) of ozone ( $\mu \mathrm{mol} / \mathrm{mol})$, water vapour ( $\mu \mathrm{mol} / \mathrm{mol}$ ), $\mathrm{HNO}_{3}(\mathrm{nmol} / \mathrm{mol})$, and $\mathrm{NO}_{2}(\mathrm{nmol} / \mathrm{mol})$ for 22 September 2002, at $63^{\circ} \mathrm{S}$. Between about $30^{\circ} \mathrm{W}$ and $150^{\circ} \mathrm{E}$ is night. Diamonds mark longitudes of measurements.

vortex split is better in S2 with only tropospheric nudging, possibly pointing to problems in the ECMWF-data in the Antarctic lower stratosphere.

To further improve the model results in the future, we intend to use the S2 setup of the model, though we stress that more research will be needed to optimise the gravity wave forcing in the model. For instance, Fig. 4 indicates that in S2 the reduction of the gravity wave forcing was somewhat too strong.

\section{Summary and conclusions}

We have introduced the new MESSy model, which includes a comprehensive modular description of atmospheric chemistry processes, being straightforward to implement in atmospheric transport and general circulation models through its standardised interface. In the present study MESSy has been coupled to the ECHAM5 general circulation model and applied to analyse the actual atmospheric chemical conditions of the years 1998-2005, a period for which long-term cli- matological atmospheric chemistry data from measurement networks and satellites are available.

The MESSy submodels have been applied with a high degree of complexity including the feedback of chemical to dynamical processes to reach a high level of consistency. To simulate realistic synoptic conditions, we employed a simple data assimilation method, i.e., we nudged the model towards ECMWF meteorological data by Newtonian relaxation. This allows a direct comparison of model output with measurement data. The relaxation coefficients have been chosen to be small, and this weak nudging was limited to the tropospheric part (excluding the boundary layer) of the model domain to allow maximum internal and numerical consistency in the computation of meteorological processes.

Neither the coupling of MESSy, including the feedback between chemistry and dynamics, nor the modifications of ECHAM5, nor the applied nudging technique deteriorate the overall simulation of meteorological processes as compared to the GCM ECHAM5. The representation of key physical parameters influencing the chemistry in the troposphere, such as temperature and moisture is essentially the same in ECHAM5/MESSy1 and ECHAM5. 
Overall, the model consistently reproduces the observed dynamical and chemical state of the atmosphere from the surface to the mesosphere. In particular, the tropospheric wave forcing of the stratospheric circulation has been simulated successfully, as shown by the simulation of a unique major Antarctic stratospheric warming event and the point-to-point correlations with thousands of HALOE profiles covering 8 years.

Simulated temperature distributions in the stratosphere, both statistically and synoptically, have been compared to MIPAS satellite data, and the model results largely agree within the observational uncertainty of about $2 \mathrm{~K}$. Cold biases in the wintertime lower polar stratosphere, notorious in many models, including MAECHAM4/CHEM, have diminished. At higher altitudes $(\approx 25 \mathrm{hPa})$ in the southern hemisphere during winter the model still has a slight warm bias at middle latitudes and a cold bias of a few $\mathrm{K}$ at high latitudes, associated with too weak subsidence within the Antarctic vortex, being confirmed by comparisons of simulated tracer distributions with satellite data $\left(\mathrm{O}_{3}, \mathrm{~N}_{2} \mathrm{O}\right)$.

Detailed comparisons between satellite data and the model results for the Antarctic spring of 2002 show that the model closely reproduces the major stratospheric warming event that caused the extraordinary vortex split in September of that year. Without nudging, i.e., with prescribed sea-surface temperature only, the vortex split was not reproduced, confirming that specific tropospheric synoptic conditions triggered this event.

Overall, the results were most accurate in the S2 setup of the model, i.e., in which the model was left the largest degree of freedom in simulating the middle atmosphere. Further investigations to explain and optimise the model setup are nevertheless required.

Our model analysis of tropospheric tracers focused on $\mathrm{CO}$ and reactive nitrogen compounds, being central in the photochemistry of global ozone and oxidation processes. The comparison of simulated $\mathrm{CO}$ with in situ measurements at ground-based background stations shows good agreement, although steep mixing ratio gradients near polluted areas are difficult to capture with the T42 resolution. The comparison of model results with MOPITT satellite CO data suggests that global and regional $\mathrm{CO}$ distributions are well captured, while the simulated biomass burning $\mathrm{CO}$ source in Africa may be somewhat too strong. The model underestimates $\mathrm{CO}$ emissions from boreal fires in the summer of 2003, though not in other years, which shows that it would be desirable to more realistically represent the inter-annual variability of biomass burning emissions.

The model results for reactive nitrogen species have been evaluated with a focus on $\mathrm{NO}, \mathrm{HNO}_{3}$ and PAN. The model accurately reproduces the characteristic $\mathrm{C}$-shaped altitude profiles of NO in polluted regions as well as the low boundary layer mixing ratios typical for the remote oceans. The model also captures $\mathrm{HNO}_{3}$ profiles as measured by aircraft, although in several cases upper tropospheric mixing ratios
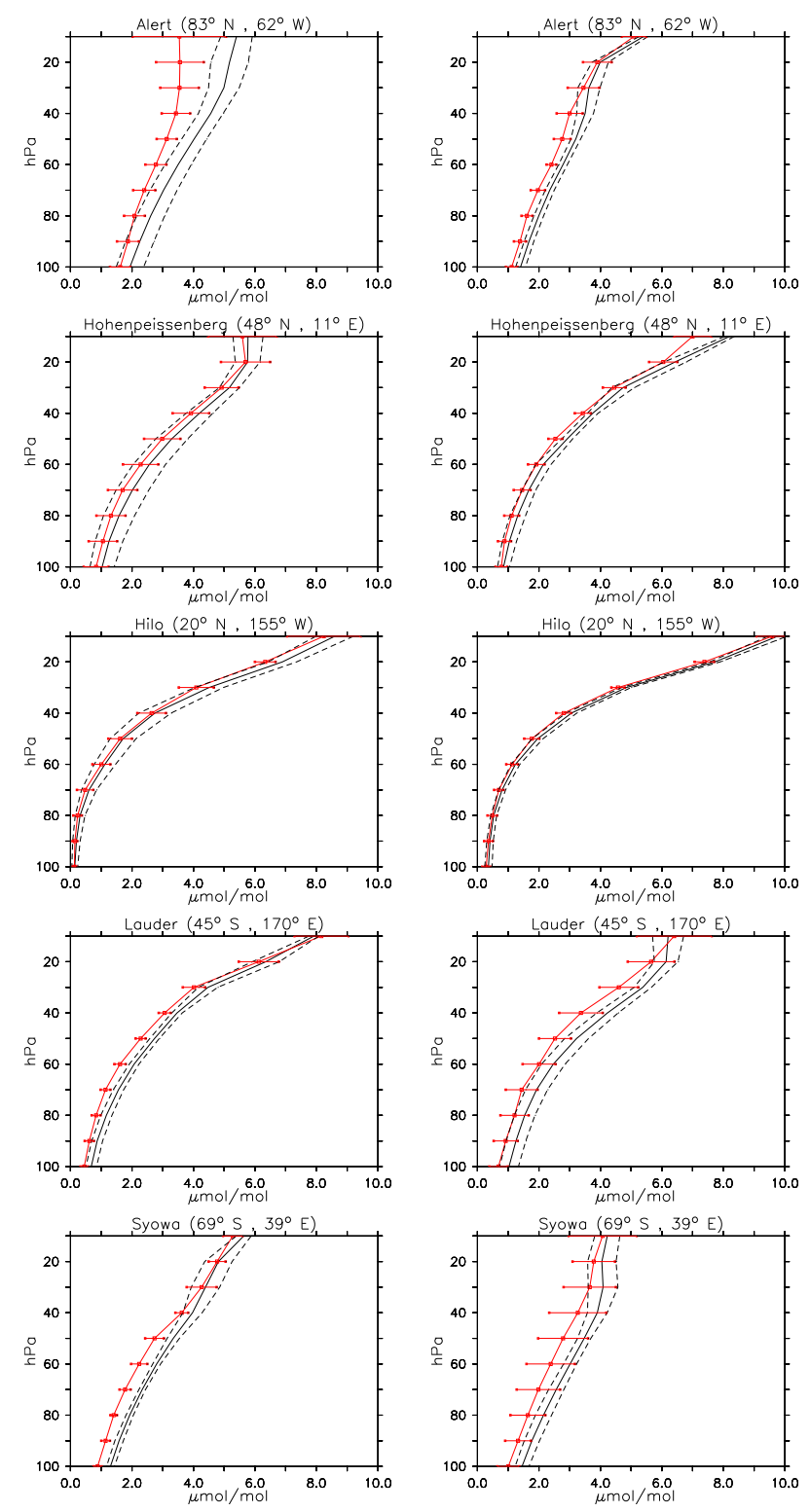

Fig. 26. Observed and simulated (S1) vertical profiles of ozone (in $\mu \mathrm{mol} / \mathrm{mol}$ ) for January (left) and June (right) in the stratosphere for selected sites from Logan (1999). Colours and line styles as in Fig. 18.

are overestimated, probably because $\mathrm{HNO}_{3}$ removal through the sedimentation of ice particles is neglected. PAN mixing ratios are systematically overestimated, possibly related to the parameterisation of chemical reactions between nitrogen oxides and organic compounds, although the shape of the altitude distribution seems well captured.

Global $\mathrm{OH}$ distributions have been tested by comparing with other models and by contrasting the lifetime of methane with empirical data. Although the lifetime is quite comparable with earlier estimates, we find that especially the 

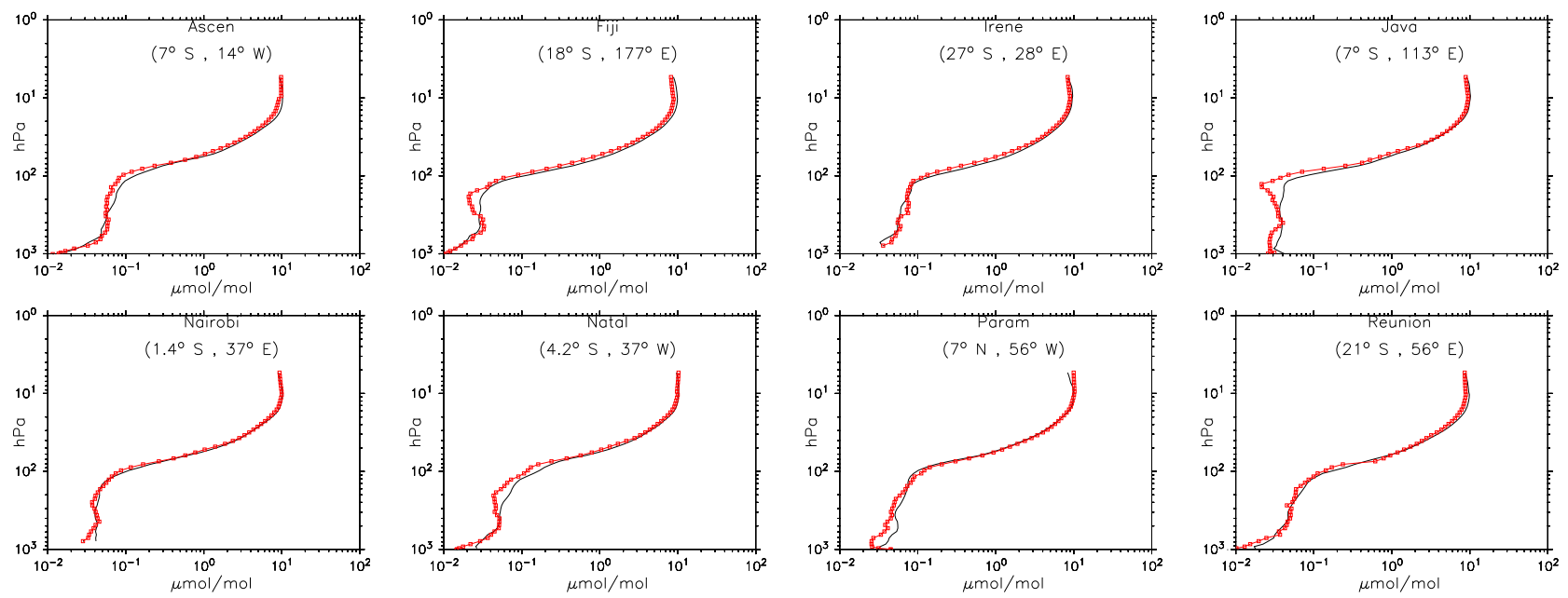

Fig. 27. Vertical profiles of ozone (in $\mu \mathrm{mol} / \mathrm{mol}$ ) for January for the sites from the SHADOZ database. Model climatology (S1) in black and measured climatology in red.

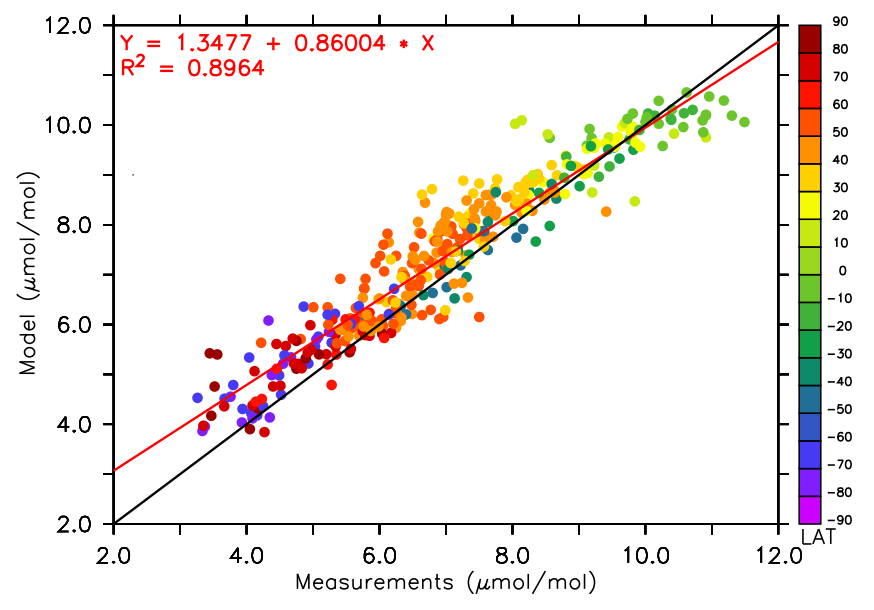

Fig. 28. Comparison of simulated (E5/M1, S1) and observed (Logan, 1999) vertical maximum $\mathrm{O}_{3}$ mixing ratio (in $\mu \mathrm{mol} / \mathrm{mol}$ ). The colour code denotes the latitude.

computed vertical $\mathrm{OH}$ distributions can differ substantially compared to earlier work. We suppose that the advancements in our model with respect to the consistency and comprehensiveness of convection, emissions (e.g. $\mathrm{NO}_{\mathrm{x}}$ from lightning), multiphase chemistry and deposition processes have improved the simulations of global $\mathrm{OH}$. However, the ultimate test is still pending, and we will need to substantiate this through more detailed analyses of individual measurement campaigns.

The computed profiles and distributions of ozone in the troposphere and stratosphere have been tested by comparing with climatological datasets from $\mathrm{O}_{3}$ soundings and satellite observations. In general, the simulated mean ozone distri- bution and variability seem to be captured very well by the model. In the middle and upper extra-tropical stratosphere the poleward transport might be slightly too rapid, giving rise to a small high-bias in ozone, although the model-data comparison further improves in the $\mathrm{S} 2$ sensitivity simulation. In the polar lower stratosphere ozone destruction by reactive chlorine and bromine species is slightly underestimated, associated with too weak subsidence and delayed downward transport of these species within the vortex. The model reproduces the observed $\mathrm{HNO}_{3}$ distribution, including the effect of denitrification by sedimenting PSC particles over the poles.

We conclude that our global atmospheric chemistry GCM, ECHAM5/MESSy1, consistently simulates the photochemical and dynamical processes that determine ozone in the lower and middle atmosphere up to $0.01 \mathrm{hPa}$. To our knowledge this is the first time that a free running model, albeit with weak nudging towards ECMWF meteorological analyses in the troposphere, reproduces the steep ozone gradients across the tropopause, both in the tropics and extratropics, without artificial boundary conditions between layers (such as for instance prescribed ozone at the tropopause for the downward transport). This is a strong indication that stratosphere-troposphere coupling processes are simulated accurately, even though over some regions, notably over Japan in winter, the downward flux of $\mathrm{O}_{3}$ may be too strong. We expect, though, that this will improve at higher resolutions. Our results corroborate the importance of the QBO in simulating vertical ozone distributions in the stratosphere. Especially in the S2 simulation the comparison with satellite observations is very good, indicating that this model setup is particularly well-suited to simulate stratospheric processes and stratosphere - troposphere interactions. 

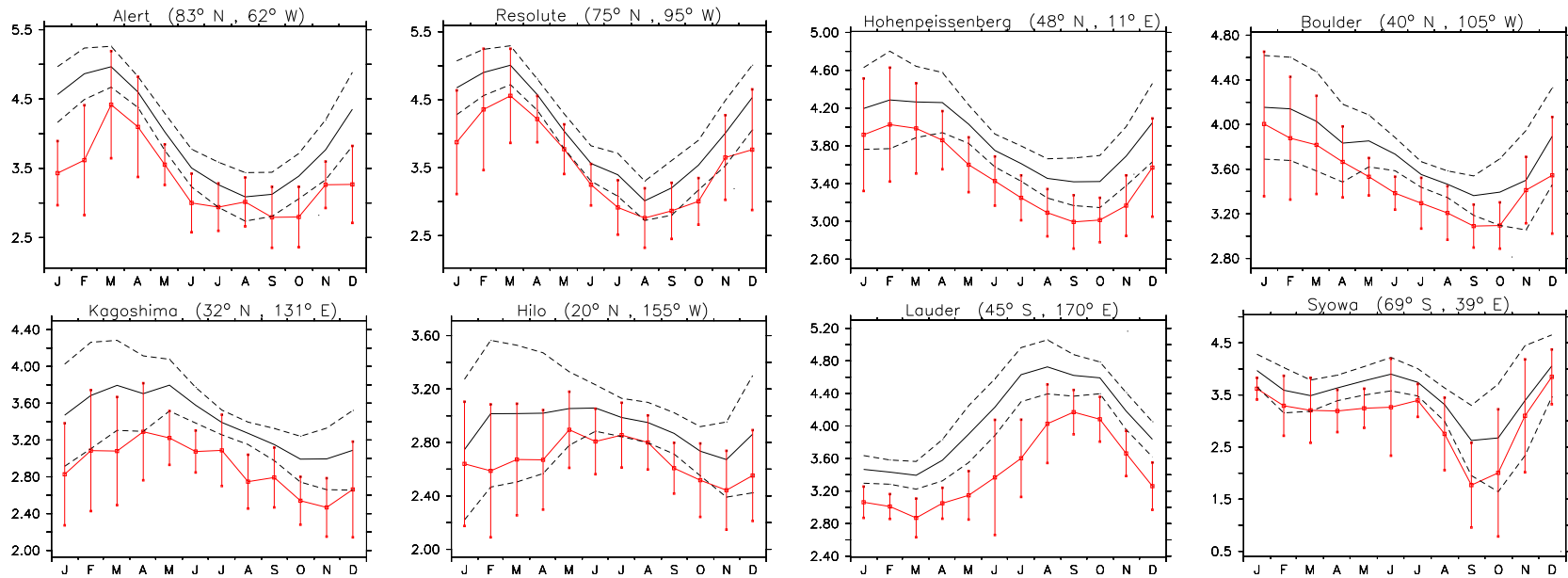

Fig. 29. Seasonal cycle of ozone (in $\mu \mathrm{mol} / \mathrm{mol}$ ) for selected sites from Logan (1999) in the stratosphere at $40 \mathrm{hPa}$. The model results (S1, black) represent a 7-year average.

\section{Outlook}

In the present study we focused only on $\mathrm{CO}$ as the most relevant carbonated species in global atmospheric photochemistry. Since hydrocarbons are also important in this respect, the multitude of species and reactions involved will be done justice by presenting the results in a separate publication (Pozzer et al., 2006a ${ }^{7}$ ).

The MESSy modules and the 8-year output are available on request through the internet address http://www. messy-interface.org, which also provides a user-friendly web-based graphics tool to select data for geographical regions and time periods, and to download or plot the data in different coordinates. We hope that colleagues will use the model results, compare them with measurement data and report possible virtues and shortcomings. It must be emphasised, though, that the model was applied at $\mathrm{T} 42$ resolution and 90 layers up to $0.01 \mathrm{hPa}$, being most suited for simulations of the stratosphere and the tropopause region. For detailed comparisons with measurements in the troposphere a higher resolution may be desirable. For example, for a model setup with a focus on the troposphere a higher horizontal and vertical resolution can be selected, and the computation of stratospheric processes can be scaled down by using the results presented here to constrain the model above the tropopause. The present resolution has been chosen as a compromise between model accuracy and CPU time efficacy.

The present dataset serves as a benchmark for simulations with reduced model complexity and the model in its full com-

7 Pozzer, A., Jöckel, P., Tost, H., Sander, R., Ganzeveld, L., Kerkweg, A., and Lelieveld, J.: Simulating organic species with the global atmospheric chemistry general circulation model ECHAM5/MESSy1: a comparison of model results with observations, Atmos. Chem. Phys. Discuss., in preparation, 2006a.

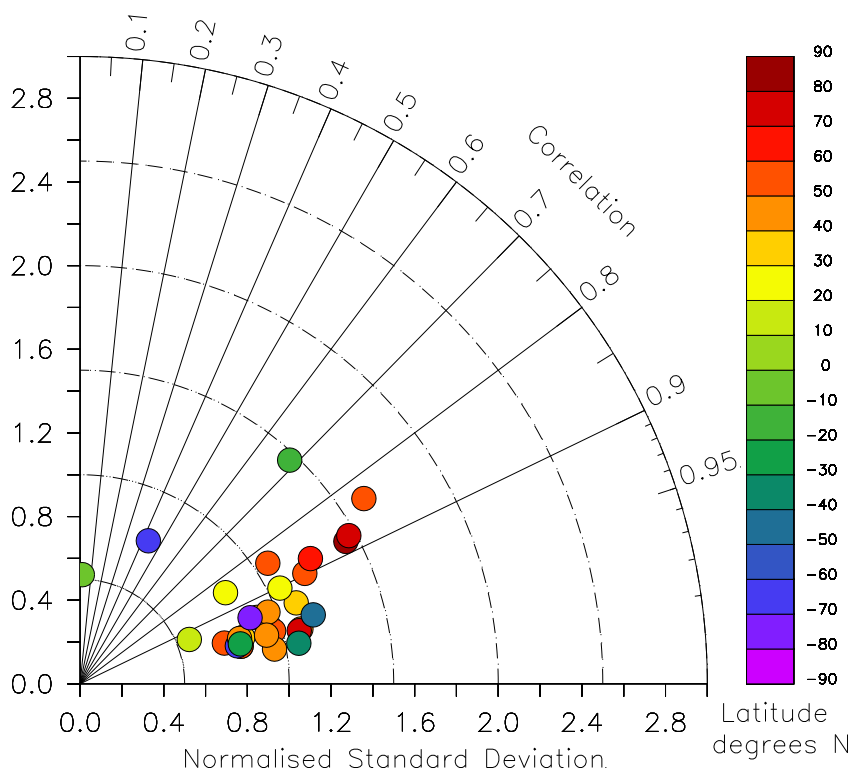

Fig. 30. Taylor plot of the correlation between observations and model results (S1) for the $40 \mathrm{hPa}$ level for all sites from Logan (1999). The correlation has been error weighted (see Appendix D).

plexity as a reference model for key processes in the upper troposphere/lower stratosphere which are most critical for chemistry climate feedbacks. Thus, ECHAM5/MESSy1 can be applied not only to analyse, but also to predict the actual atmospheric chemical conditions, or as a "free-running" chemistry-climate model (CCM). Note that the nudging technique applied in this study solely for an efficient and direct evaluation using observations does not significantly change the model physics. The dynamical part of the model 

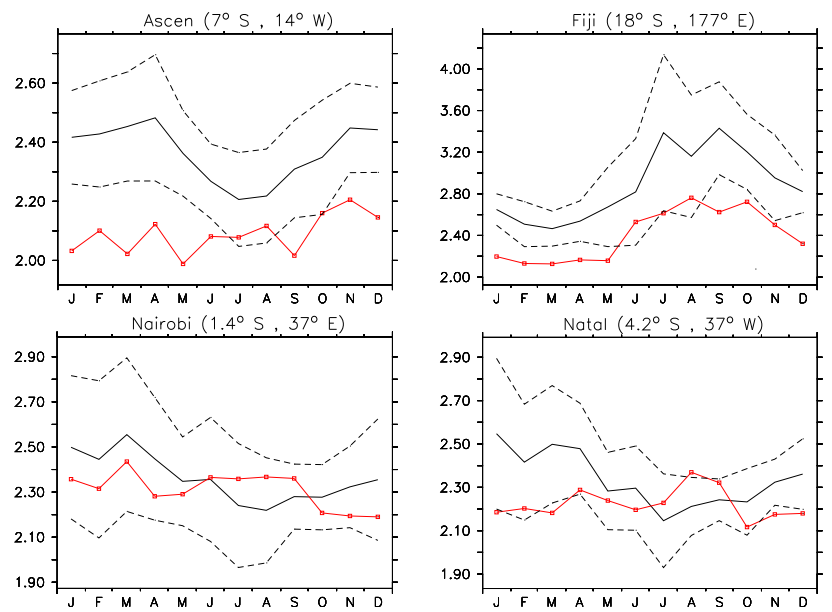
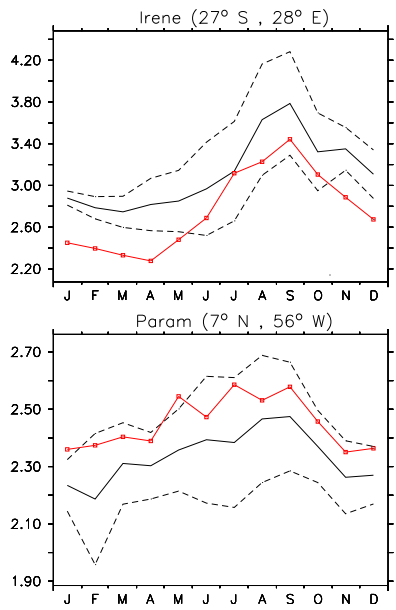
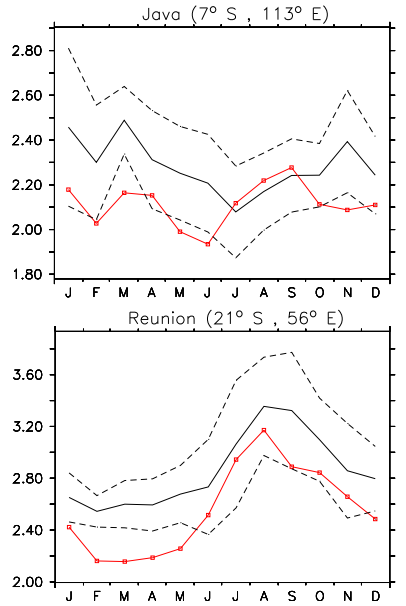

Fig. 31. Seasonal cycle of ozone (in $\mu \mathrm{mol} / \mathrm{mol}$ ) at $40 \mathrm{hPa}$ obtained from the SHADOZ database (red) compared to the 7-year climatology (1998 to 2004) derived from the E5/M1 model simulation S1 (black).

(ECHAM5) has already been extensively evaluated in a recent special issue of the Journal of Climate. Long-term integrations in CCM mode, however, may require concessions with respect to the level of complexity applied in view of computational costs. In this respect the modular structure of MESSy is of advantage.

MESSy can easily be extended with new modules, either to improve and test existing ones, or to further develop the system into an Earth system model. Model setups can be changed by selecting modules and parameter settings in the namelists of the computer programme, which implies that different setups can be used in sensitivity studies with the same executable, i.e., under identical numerical conditions.

\section{Appendix A}

The following modifications and additions have been applied to ECHAM5:

- The nudging routines have been fully vectorised and parallelised to allow the application of the nudging technique without further restrictions w.r.t. the technical setup of the model. Nudging can now be applied in any ECHAM5 supported domain decomposition (parallelisation) and vector length (vectorisation) combination.

- The calculation of the initial values in the vertical diffusion scheme have been modified, to be consistent with the applied leapfrog time integration scheme and filter (Asselin, 1972).

- Convection, cloud, and radiation subroutines have been replaced by the MESSy submodels CONVECT, CLOUD, and RAD4ALL, respectively. In the present study, the MESSy submodels give identical results to the original ECHAM5 routines. The recoding serves the straightforward implementation of alternative process descriptions, including the option to test the submodels under identical numerical conditions by using the same executable (e.g., CONVECT, Tost, 2006; Tost et al., 2006b), and/or the implementation of additional couplings between processes (e.g., radiation-aerosol, cloud-aerosol) in the future.

- The convective tracer transport of ECHAM5 has been modified to guarantee positive definite results (Brinkop and Sausen, 1996). Note that for the present study the convective tracer transport has been calculated with the submodel CVTRANS, which is a convection-scheme independent implementation.

- The ECHAM5 output routines have been expanded to allow the output of time average and standard deviation, as an alternative to the output of instantaneous fields. Furthermore, the data representations SCALAR, COLUMN, and ARRAY1D have been added.

- The build process (configure/gmake) for user-friendly compilation of the source code has been revised.

\section{Appendix B}

The following MESSy submodels (in alphabetical order) have been applied in the present study; the corresponding namelists are contained in the electronic supplement (http://www.atmos-chem-phys.net/6/5067/2006/ acp-6-5067-2006-supplement.zip):

CLOUD contains the original cloud process and cover routines from ECHAM5 in a modularised, MESSy-conform structure and calculates the cloud microphysics, cloud distribution, and precipitation. 
CONVECT calculates the process of convection. Different convection schemes can be selected. At present the original ECHAM5 convection routines (Tiedtke, 1989; Nordeng, 1994) with three types of closure (Nordeng, Tiedtke, Hybrid) are implemented. In this study, we exclusively apply the Tiedtke - Nordeng configuration, which is the default for the ECHAM5 model. The CONVECT submodel also includes an update for positive definite tracer transport (Brinkop and Sausen, 1996), which is, however, not used in this study, since convective tracer transport is calculated by the submodel CVTRANS.

CVTRANS calculates the transport of tracers as caused by convection. It uses a monotonic, positive definite and mass conserving algorithm following the bulk approach as described in Lawrence and Rasch (2005).

DRYDEP (Kerkweg et al., 2006a) calculates gas phase and aerosol tracer dry deposition according to the big leaf approach.

H2O defines $\mathrm{H}_{2} \mathrm{O}$ as a tracer, provides its initialisation in the stratosphere and mesosphere from satellite data, and controls the feedback with specific humidity of the basemodel. The water vapour source of methane oxidation in the stratosphere (and mesosphere) can be accounted for by using the water vapour tendency of a chemistry submodel (e.g., MECCA, as applied in the present study), or by using a satellite climatology (UARS/HALOE) of methane together with monthly climatological conversion rates pre-calculated from a MAECHAM4/CHEM simulation (Steil et al., 2003).

HETCHEM calculates heterogeneous reaction rates on stratospheric nitric acid trihydrate (NAT), ice, super-cooled ternary solutions (STS), and on stratospheric and tropospheric (sulfate) aerosols. It can easily be coupled by namelist to aerosol modules, which then provide the aerosol parameters. Monthly climatologies of stratospheric $\mathrm{H}_{2} \mathrm{SO}_{4}$ mixing ratios for the years 1960 to 1999 (derived from the Stratospheric Aerosol and Gas Experiment (SAGE) data) and tropospheric sulfate aerosol surface for present day conditions (Kerkweg, 2005) are provided, so that HETCHEM can be used in a minimum configuration to simulate reactions on sulfate aerosol (e.g. $\mathrm{N}_{2} \mathrm{O}_{5}+\mathrm{H}_{2} \mathrm{O} \rightarrow 2 \mathrm{HNO}_{3}$ ). In the present study the $\mathrm{H}_{2} \mathrm{SO}_{4}$ climatology (monthly averages) of the year 1999 has also been used for 2000-2005 in the stratosphere. Note: The reaction rates in the polar stratosphere are similar to the rates calculated by the PSC submodel. In case PSC (see below) is switched on, HETCHEM calculates the reaction rates only outside the PSC region.

JVAL, following Landgraf and Crutzen (1998), provides online calculations of photolysis rate coefficients (J-values) using cloud water and ice content, cloudiness calculated by the basemodel, and climatological aerosol. For ozone the prognostic tracer $\mathrm{O}_{3}$ is used, but it is also possible to run the module with prescribed climatological ozone. A delta-twostream-method is used for 8 spectral intervals in the UV and visible spectrum together with pre-calculated effective crosssections (partially temperature and pressure dependent) for more than 50 tropospheric and stratospheric species. If used for the mesosphere, Ly-alpha radiation is also included. Optionally the rates of heating through solar UV-C absorption by ozone and oxygen are calculated. This feature, however, has not been applied in this study.

LNOX is used to calculate the $\mathrm{NO}_{\mathrm{x}}$ production resulting from lightning activity. The submodel comprises two alternative parameterisations of lightning $-\mathrm{NO}_{\mathrm{x}}$ production (Grewe et al., 2001; Price and Rind, 1994). The latter is applied in the present study. Both approaches can be combined with the vertical C-shape distribution of Pickering et al. (1998) stretched or squeezed to the depth of the convective column, with separate parameters for continental and marine convective columns. The total lightning- $\mathrm{NO}_{\mathrm{x}}$ production scales with the flash frequency and the amount of produced $\mathrm{NO}_{\mathrm{x}}$ per single flash. In the present simulation, these parameters have been scaled to achieve a global lightning$\mathrm{NO}_{\mathrm{x}}$ production of $\approx 2 \mathrm{Tg}(\mathrm{N}) /$ year.

MECCA, the Module Efficiently Calculating the Chemistry of the Atmosphere (Sander et al., 2005), calculates tropospheric and stratospheric chemistry. The KPP (Kinetic Preprocessor) software (Sandu and Sander, 2006) is used for the integration of the set of stiff differential equations. KPP provides a variety of solver algorithms. For the simulations in this study we have chosen a 3rd order Rosenbrock solver with automatic time stepping. The selected mechanism consists of 104 gas phase species (including $\mathrm{H}_{2} \mathrm{O}$ defined by the submodel $\mathrm{H} 2 \mathrm{O}$ ) and 245 reactions. It comprises the $\mathrm{O}_{3}$ related chemistry of the troposphere, including non-methanehydrocarbons (NMHCs) up to isoprene (von Kuhlmann et al., 2003b). For the stratosphere, the main chlorine (Steil et al., 1998) and bromine (Meilinger, 2000) reactions are considered. Details of the selected chemical mechanism (including reaction rate coefficients and references) can be found in the electronic supplement (http://www.atmos-chem-phys.net/6/ 5067/2006/acp-6-5067-2006-supplement.zip). The chosen set of ordinary differential equations (ODEs) describing the chemical mechanism has been integrated in the entire model domain, i.e., consistently from the surface to the mesosphere. MECCA uses heterogeneous rate coefficients calculated by HETCHEM and photolysis rates calculated by JVAL.

OFFLEM (Kerkweg et al., 2006b) reads surface emission fluxes (2-D), multi-layer emission fluxes (Nx2-D) and volume emission fluxes (3-D) from prescribed data files via the MESSy data import interface (Jöckel, 2006), and either calculates tracer tendencies (2-D, 3-D, Nx2-D) or modifies the vertical diffusive flux boundary condition of the respective species at the surface (2-D only). Furthermore, OFFLEM is used to import data (Jöckel, 2006) for use in other submodels (e.g., TNUDGE). For the present study the emissions of $\mathrm{NO}, \mathrm{CO}, \mathrm{C}_{2} \mathrm{H}_{4}, \mathrm{C}_{2} \mathrm{H}_{6}$, $\mathrm{C}_{3} \mathrm{H}_{6}, \mathrm{C}_{3} \mathrm{H}_{8}, \mathrm{C}_{4} \mathrm{H}_{10}, \mathrm{CH}_{3} \mathrm{CHO}, \mathrm{CH}_{3} \mathrm{COCH}_{3}, \mathrm{CH}_{3} \mathrm{COOH}$, $\mathrm{CH}_{3} \mathrm{OH}, \mathrm{HCHO}, \mathrm{HCOOH}$, methyl ethyl ketone (MEK), $\mathrm{SO}_{2}$, and $\mathrm{NH}_{3}$ are distributed as multi-layer emissions onto 6 levels $(45,140,240,400,600,800 \mathrm{~m})$. The 
emissions comprise the anthropogenic emissions from the EDGAR3.2FT 2000 ("fast-track") 8 database and additional biogenic emissions as described in Ganzeveld et al. (2006). The aircraft NO emissions (1995) (Schmitt and Brunner, 1997) are distributed as volume emissions.

ONLEM (Kerkweg et al., 2006b) calculates surface emission fluxes for gas-phase (and optionally aerosol) tracers and either calculates tracer tendencies, or modifies the vertical diffusive flux boundary condition of the respective species at the surface. With the latter approach, emissions of DMS from the ocean, isoprene from plants, and NO from soils have been calculated. For the present simulations, the isoprene and soil NO emission fluxes have been scaled by a factor of 0.6 to achieve total net emissions of approximately $315 \operatorname{Tg}(\mathrm{C}) /$ year and $7 \operatorname{Tg}(\mathrm{N}) /$ year, respectively. Note: The parameterisations have been originally developed for a different model (cf. Kerkweg et al., 2006b; Ganzeveld et al., 2006, and references therein). The additional scaling factors adapt the parameterisations in order to achieve realistic mixing ratios of isoprene in the boundary layer, whereas the soil-biogenic $\mathrm{NO}_{\mathrm{x}}$ emission flux is similar to the estimates provided by IPCC (Houghton et al., 2001).

PSC, the Polar Stratospheric Cloud submodel (Buchholz, 2005), simulates micro-physical processes that lead to the formation of super-cooled ternary solutions (STS), nitric acid trihydrate (NAT), and ice particles in the polar stratosphere, as well as heterogeneous chemical reaction coefficients of halogens and $\mathrm{N}_{2} \mathrm{O}_{5}$ on liquid and solid aerosol particles. Denitrification and dehydration due to sedimenting solid PSC particles are calculated for each grid box depending on particle size, pressure and temperature. PSC defines the additional tracer $\mathrm{HNO}_{3}$ nat. Note: PSC calculates the reaction coefficients only in the PSC region, and HETCHEM (see above) outside the PSC region.

PTRAC is used to define and initialise additional tracers which are not part of the chemical mechanism. In the present study we defined $\mathrm{SF}_{6}$ for the evaluation of the upper troposphere/lower stratosphere (UTLS) transport, and $\mathrm{SO}_{4}^{(\mathrm{cs})}$ as a pseudo aerosol tracer (coarse mode, soluble) for closure of the SCAV mass balance.

QBO is a submodel for the assimilation of quasi-biennial oscillation (QBO) zonal wind observations (Giorgetta and Bengtsson, 1999; Naujokat, 1986). The QBO submodel can be used to enforce artificially the QBO in a GCM that does not simulate the QBO by internal forcing, or to synchronise an internally generated QBO with an external QBO time series. Here, the QBO submodel was used to initialise the QBO during the first year of the simulation.

RAD4ALL is a re-implementation of the ECHAM5 radiation code according to the MESSy standard. New and extended features are: (1) Choice between standard ECHAM5 radiation and RAD4ALL; (2) All input quantities are now

\footnotetext{
${ }^{8}$ http://www.mnp.nl/edgar/model/v32ft2000edgar/ docv $32 \mathrm{ft} 2000$
}

controlled via the user interface; (3) Online coupling of radiation with trace gases; (4) All input quantities (except aerosols in the current version) can be read from external climatologies. In the present study, RAD4ALL is coupled to the prognostic cloud cover, cloud water, and cloud ice (all from CLOUD), to the prognostic specific humidity, and to the prognostic trace gases $\mathrm{CO}_{2}, \mathrm{CH}_{4}, \mathrm{O}_{3}, \mathrm{~N}_{2} \mathrm{O}, \mathrm{CFCl}_{3}$, and $\mathrm{CF}_{2} \mathrm{Cl}_{2}$. For the aerosol-radiation interaction, the standard ECHAM5 aerosol climatology (Tanre et al., 1984) has been applied.

SCAV simulates the processes of wet deposition and liquid phase chemistry in clouds and precipitation. It considers gas phase and aerosol species in large-scale as well as in convective clouds and precipitation events. A detailed description can be found in Tost et al. (2006a). In the present study the chemical mechanism comprises 6 additional species and 41 reactions. These chemical reactions are decoupled from the comprehensive gas phase chemical reaction set of the MECCA submodel, because for some applications a relatively comprehensive and computationally expensive solver for the stiff set of ODEs is required. Details of the selected aqueous phase chemical mechanism (including reaction rate coefficients and references) can be found in the electronic supplement (http://www.atmos-chem-phys.net/6/5067/2006/ acp-6-5067-2006-supplement.zip). In this study a 3rd order Rosenbrock solver with automatic time stepping has been used to solve the SCAV ODE system.

SEDI calculates sedimentation of aerosol particles and their components (Kerkweg et al., 2006a). The submodel comprises a zero-order scheme (used in this study), and a first order trapezoid scheme with corrections above/below local extrema. Both schemes are mass conserving and allow non-monotonic redistribution, as required for a correct representation of particle sedimentation.

TNUDGE (Kerkweg et al., 2006b) is used for the relaxation (nudging) of user-defined tracers with arbitrary userdefined fields (e.g., imported via OFFLEM). In the present study, TNUDGE is used to prescribe the lower boundary conditions of $\mathrm{N}_{2} \mathrm{O}, \mathrm{CH}_{4}, \mathrm{CFCl}_{3}, \mathrm{CF}_{2} \mathrm{Cl}_{2}, \mathrm{CH}_{3} \mathrm{CCl}_{3}, \mathrm{CCl}_{4}$, $\mathrm{CH}_{3} \mathrm{Cl}, \mathrm{CH}_{3} \mathrm{Br}, \mathrm{CF}_{2} \mathrm{ClBr}, \mathrm{CF}_{3} \mathrm{Br}, \mathrm{H}_{2}, \mathrm{CO}_{2}$, and $\mathrm{SF}_{6}$ from observed mixing ratios using the AGAGE database (Prinn et al., 2000). As in Steil et al. (2003) other source gases contributing to stratospheric chlorine, such as $\mathrm{C}_{2} \mathrm{~F}_{3} \mathrm{Cl}_{3}, \mathrm{CHF}_{2} \mathrm{Cl}$ and $\mathrm{C}_{2} \mathrm{H}_{3} \mathrm{FCl}_{2}$, are added to $\mathrm{CF}_{2} \mathrm{Cl}_{2}$ taking into account their chlorine atom number. The pseudo-fluxes resulting from the nudging tendency are diagnosed. The nudging is applied every model time step with a nudging time coefficient for all species of $3 \mathrm{~h}$.

TRACER is a generic MESSy submodel and handles the data and meta-data for chemical species. Note that the current implementation is independent from a similar approach contained in ECHAM5. TRACER contains two additional sub-submodels, TRACER_FAMILY for transporting userdefined tracer-sets as tracer families, and TRACER_PDEF to force positive definite tracer mixing ratios including tracer 
mass diagnostics. In the present study, the following tracer families have been transported:

$$
\begin{aligned}
& -\mathrm{ClO}_{\mathrm{X}}=\mathrm{Cl}+\mathrm{ClO}+\mathrm{HOCl}+\mathrm{OClO}+2 \mathrm{Cl}_{2} \mathrm{O}_{2}+2 \mathrm{Cl}_{2} \\
& -\mathrm{BrO}_{\mathrm{X}}=\mathrm{Br}+\mathrm{BrO}+\mathrm{HOBr}+\mathrm{BrCl}+2 \mathrm{Br}_{2} \\
& -\mathrm{NO}_{\mathrm{Z}}=\mathrm{N}+\mathrm{NO}+\mathrm{NO}_{2}+\mathrm{NO}_{3}+2 \mathrm{~N}_{2} \mathrm{O}_{5} .
\end{aligned}
$$

Note: In the present simulations, the family members are only advected as families, all other tendencies (e.g., chemical tendencies) are calculated for the individual tracers.

TROPOP diagnoses the tropopause according to various definitions. In the present study the tropopause is defined according to the WMO definition (WMO, 1992) based on the temperature lapse rate for latitudes equatorward of $30^{\circ}$, and as the potential vorticity iso-surface of 3.5 PVU at latitudes poleward of $30^{\circ}$. Moreover, TROPOP diagnoses the height of the planetary boundary layer for several applications.

\section{Appendix C}

The following submodels are also part of MESSy version 1.1, but have not been used in this study:

AIRSEA (Pozzer et al., 2006) calculates the exchange of chemical tracers between the ocean and atmosphere using a two-layer approach. The submodel simulates in particular the bi-directional transport of volatile organic compounds and their oxidation products. The successful use of this submodel is dependent on the availability of observations of the distribution of organic tracers in seawater.

EMDEP (Ganzeveld et al., 2006) combines the calculations of online emissions (VOC, NO, DMS, sea-salt, dust, and organic and black carbon), and the dry deposition of gases and aerosols following the "big-leaf"-approach. It is the developer implementation of the emission and deposition routines, and formed the basis for the submodels ONLEM and DRYDEP.

M7 (Vignati et al., 2004; Stier et al., 2005) is an aerosol dynamics model that redistributes the particle numbers and masses between 7 modes and from the gas to the aerosol phase (for each mode), by nucleation, condensation and coagulation.

MECCA_MBL is a sub-submodel of MECCA for calculating the aerosol chemistry in the marine boundary layer.

PHOTO is the developer implementation of the fast online photolysis rate calculation scheme which formed the basis for JVAL. It is closer to the original code of Landgraf and Crutzen (1998), but less general than JVAL.

\section{Appendix D}

Following are the statistical methods employed in this study: $m_{i}$ is the simulated (model) and $o_{i}$ the observed value. The absolute errors are $\delta_{i}^{m}$ and $\delta_{i}^{o}$, respectively. The model "error" is the standard deviation from the averaged output values, and the measurement error is a combination of instrumental errors and variance. The difference is defined as:

$d_{i}=m_{i}-o_{i}$.

Any classical statistical calculation can be weighted using $1 / \epsilon_{i}$ as a weighting factor, where

$\epsilon_{i}=\sqrt{\delta_{i}^{m 2}+\delta_{i}^{o 2}}$

is the geometric average of observed and simulated "error".

This allows an independent statistical analysis, whereby each value is scaled with the geometrical average of the errors. We use the following statistical functions:

- standard deviations:

$$
\sigma_{m}=\left[\frac{1}{N} \sum_{i=1}^{N}\left(\frac{m_{i}-\bar{m}}{\epsilon_{i}}\right)^{2}\right]^{1 / 2}
$$

$$
\sigma_{o}=\left[\frac{1}{N} \sum_{i=1}^{N}\left(\frac{o_{i}-\bar{o}}{\epsilon_{i}}\right)^{2}\right]^{1 / 2}
$$

- Root Mean Square (RMS)

$$
E=\left[\frac{1}{N} \sum_{i=1}^{N}\left(\frac{m_{i}-o_{i}}{\epsilon_{i}}\right)^{2}\right]^{1 / 2}=\left[\frac{1}{N} \sum_{i=1}^{N}\left(\frac{d_{i}}{\epsilon_{i}}\right)^{2}\right]^{1 / 2}
$$

- Correlation coefficient

$$
R=\frac{\frac{1}{N} \sum_{i=1}^{N}\left(\frac{\left(m_{i}-\bar{m}\right)\left(o_{i}-\bar{o}\right)}{\epsilon_{i}^{2}}\right)}{\sigma_{m} \sigma_{o}}
$$

- Centred pattern RMS difference

$$
E^{\prime}=\left[\frac{1}{N} \sum_{i=1}^{N}\left[\left(\frac{m_{i}-\bar{m}}{\epsilon_{i}}\right)-\left(\frac{o_{i}-\bar{o}}{\epsilon_{i}}\right)\right]^{2}\right]^{1 / 2}
$$

To apply this approach to the Taylor diagrams (Taylor, 2001), the basic relationship between the variables $E^{\prime}, \sigma_{m}, \sigma_{o}$ and $R$ must hold:

$E^{\prime 2}=\sigma_{m}^{2}+\sigma_{o}^{2}-2 \sigma_{m} \sigma_{o} R$.

Using the definitions (D3) to (D6) yields:

$$
\begin{gathered}
\frac{1}{N}\left[\sum_{i=1}^{N}\left(\frac{m_{i}-\bar{m}}{\epsilon_{i}}\right)^{2}+\sum_{i=1}^{N}\left(\frac{o_{i}-\bar{o}}{\epsilon_{i}}\right)^{2}\right. \\
\left.-2 \sum_{i=1}^{N}\left(\frac{m_{i}-\bar{m}}{\epsilon_{i}}\right)\left(\frac{o_{i}-\bar{o}}{\epsilon_{i}}\right)\right]= \\
\frac{1}{N}\left[\sum_{i=1}^{N}\left[\left(\frac{m_{i}-\bar{m}}{\epsilon_{i}}\right)-\left(\frac{o_{i}-\bar{o}}{\epsilon_{i}}\right)\right]^{2}\right] .
\end{gathered}
$$


Hence from Eq. (D9):

$\frac{1}{N} \sum_{i=1}^{N}\left(\frac{d_{i}-\bar{d}}{\epsilon_{i}}\right)^{2}=E^{\prime 2}$ as in Eq. (D7).

This approach can be applied in different types of data analysis, like time-series or vertical profile analysis.

The average and RMS are dimensionless (normalised to $\epsilon_{i}$ ). To obtain a non-normalised value, the statistic functions have to be multiplied by the average of the weighting factor:

$\widehat{\bar{\epsilon}}=\left[\frac{1}{N} \sum_{i=1}^{N} \epsilon_{i}^{2}\right]^{1 / 2}=\left[\frac{1}{N} \sum_{i=1}^{N}\left(\delta_{i}^{m 2}+\delta_{i}^{o 2}\right)\right]^{1 / 2}$

Acknowledgements. The authors wish to thank E. Roeckner and the model development team at the MPI for Meteorology for the ECHAM5 development, M. Giorgetta (MPI for Meteorology) for the 90-layer version and helpful suggestions, E. Manzini (INGV, Bologna) for helpful suggestions on the gravity wave parameterisation, C. Kurz, A. Lauer, V. Grewe, M. Dameris, R. Sausen (DLR Oberpfaffenhofen) for useful discussions, H. Lederer and his team (Max-Planck Computer Centre in Garching near Munich) for their support, P. Zimmermann and T. Butler for help with creating the emission dataset, the EU (Projects SCOUT-O3, QUANTIFY) and the BMBF (Projects KLIMEX, HGF-ENVISAT) for funding, the International Max Planck Research School for Atmospheric Chemistry and Physics for support, D. Stevenson (School of Geosciences, University of Edinburgh) for providing the results from the model inter-comparison project. The authors further wish to acknowledge the use of the Ferret program for analysis and graphics in this paper. Ferret is a product of NOAA's Pacific Marine Environmental Laboratory (information is available at http://ferret.pmel.noaa.gov/Ferret/). And finally the comments of three anonymous referees are gratefully acknowledged.

Edited by: M. Dameris

\section{References}

Asselin, R.: Frequency filter for time integrations, Mon. Wea. Rev., 100, 487-490, 1972.

Atkinson, R., Baulch, D. L., Cox, R. A., Crowley, J. N., Hampson, Jr., R. F., Hynes, R. G., Jenkin, M. E., Kerr, J. A., Rossi, M. J., and Troe, J.: Summary of evaluated kinetic and photochemical data for atmospheric chemistry: Web version March 2005, http: //www.iupac-kinetic.ch.cam.ac.uk/, 2005.

Austin, J., Shindell, D., Beagley, S. R., Brühl, C., Dameris, M., Manzini, E., Nagashima, T., Newman, P., Pawson, S., Pitari, G., Rozanov, E., Schnadt, C., and Shepherd, T. G.: Uncertainties and assessments of chemistry-climate models of the stratosphere, Atmos. Chem. Phys., 3, 1-27, 2003,

http://www.atmos-chem-phys.net/3/1/2003/.

Brinkop, S. and Sausen, R.: A modified mass-flux scheme for convection which maintains positive tracer concentrations, Tech. Rep. 67, Institut für Physik der Atmosphäre DLR, 1996.

Brühl, C. and Crutzen, P. J.: $\mathrm{NO}_{\mathrm{x}}$-catalyzed ozone destruction and $\mathrm{NO}_{\mathrm{x}}$ activation at midlatitudes to high latitudes as a main cause of the spring to fall ozone decline in the Northern Hemisphere, J. Geophys. Res., 105, 12 163-12 168, 2000.
Buchholz, J.: Simulations of physics and chemistry of polar stratospheric clouds with a general circulation model, Ph.D. thesis, University of Mainz, Germany, http://nbn-resolving.de/urn/ resolver.pl?urn=urn:nbn:de:hebis:77-8187, 2005.

Butkovskaya, N. I., Kukui, A., Pouvesle, N., and Le Bras, G.: Formation of nitric acid in the gas-phase $\mathrm{HO}_{2}+\mathrm{NO}$ reaction: Effects of temperature and water vapor, J. Phys. Chem. A, 109, 6509-6520, 2005.

Courant, R., Friedrichs, K., and Lewy, H.: Über die partiellen Differenzengleichungen der mathematischen Physik, Mathematische Annalen, 100, 32-74, 1928.

Crutzen, P. J. and Brühl, C.: Catalysis by $\mathrm{NO}_{\mathrm{x}}$ as the main cause of the spring to fall stratospheric ozone decline in the Northern Hemisphere, J. Phys. Chem., 105-A, 1579-1582, 2001.

Deeter, M. N., Emmons, L. K., Francis, G. L., Edwards, D. P., Gille, J. C., Warner, J. X., Khattatov, B., Ziskin, D., Lamarque, J.-F., Ho, S. P., Yudin, V., Attie, J.-L., Packman, D., Chen, J., Mao, D., Drummond, J. R., Novelli, P., and Sachse, G.: Evaluation of operational radiances for the Measurements of Pollution in The Troposphere (MOPITT) instrument CO thermal band channels, J. Geophys. Res., 109, D03308, doi:10.1029/2003JD003970, 2004.

Emmons, L. K., Hauglustaine, D. A., Müller, J.-F., Carroll, M. A., Brasseur, G. P., Brunner, D., Staehelin, J., Thouret, V., and Marenco, A.: Data composites of airborne observation of tropospheric ozone and its precursor, J. Geophys. Res., 105, $20497-$ 20 538, 2000.

Endemann, M., Garé, P., Langen, J., Nett, H., and Readings, C. J.: MIPAS - An Envisat Instrument for Atmospheric Chemistry and Climate Research, Tech. rep., ESA, ESA bulletin 101, http://www.esa.int/esapub/bulletin/bullet101_.htm, 2000.

Eyring, V., Butchart, N., Waugh, D. W., Akiyoshi, H., Austin, J., Bekki, S., Bodeker, G. E., Boville, B. A., Brühl, C., Chipperfield, M. P., Cordero, E., Dameris, M., Deushi, M., Fioletov, V. E., Frith, S. M., Garcia, R. R., Gettelman, A., Giorgetta, M. A., Grewe, V., Jourdain, L., Kinnison, D. E., Mancini, E., Manzini, E., Marchand, M., Marsh, D. R., Nagashima, T., Newman, P. A., Nielsen, J. E., Pawson, S., Pitari, G., Plummer, D. A., Rozanov, E., Schraner, M., Shepherd, T. G., Shibata, K., Stolarski, R. S., Struthers, H., Tian, W., and Yoshiki, M.: Assessment of coupled chemistry-climate models: Evaluation of dynamics, transport, and ozone, J. Geophys. Res., in press, 2006.

Fischer, H., Lawrence, M. G., Gurk, C., Hoor, P., Lelieveld, J., Hegglin, M. I., Brunner, D., and Schiller, C.: Model simulations and aircraft measurements of vertical, seasonal, and latitudinal $\mathrm{O}_{3}$ and $\mathrm{CO}$ distributions over Europe, Atmos. Chem. Phys., 6, 339348, 2006, http://www.atmos-chem-phys.net/6/339/2006/.

Funke, B., López-Puertas, M., Gil-López, S., von Clarmann, T., Stiller, G. P., Fischer, H., and Kellmann, S.: Downward transport of upper atmospheric $\mathrm{NO}_{\mathrm{x}}$ into the polar stratosphere and lower mesosphere during the Antarctic 2003 and Arctic 2002/2003 winters, J. Geophys. Res., 110, D24308, doi:10.1029/2005JD006463, 2005a.

Funke, B., López-Puertas, M., von Clarmann, T., Stiller, G. P., Fischer, H., Glatthor, N., Grabowski, U., Höpfner, M., Kellmann, S., Kiefer, M., Linden, A., Mengistu Tsidu, G., Milz, M., Steck, T., and Wang, D. Y.: Retrieval of stratospheric $\mathrm{NO}_{\mathrm{x}}$ from 5.3 and $6.2 \mu \mathrm{m}$ nonlocal thermodynamic equilibrium emissions 
measured by Michelson Interferometer for Passive Atmospheric Sounding (MIPAS) on Envisat, J. Geophys. Res., 110, D09302, doi:10.1029/2004JD005225, 2005b.

Ganzeveld, L. N., van Aardenne, J., Butler, T. M., Lawrence, M. G., Metzger, S. M., Stier, P., Zimmermann, P., and Lelieveld, J.: Technical Note: Anthropogenic and natural offline emissions and the online EMissions and dry DEPosition (EMDEP) submodel of the Modular Earth Submodel System (MESSy), Atmos. Chem. Phys. Discuss., 6, 5457-5483, 2006,

http://www.atmos-chem-phys-discuss.net/6/5457/2006/.

Giorgetta, M. A. and Bengtsson, L.: The potential role of the quasibiennial oscillation in the stratosphere-troposphere exchange as found in water vapour in general circulation model experiments, J. Geophys. Res., 104, 6003-6019, 1999.

Giorgetta, M. A., Manzini, E., and Roeckner, E.: Forcing of the quasi-biennial oscillation from a broad spectrum of atmospheric waves, Geophys. Res. Lett., 29, 1245, doi:10.1029/2002GL014756, 2002.

Giorgetta, M. A., Manzini, E., Roeckner, E., Esch, M., and Bengtsson, L.: Climatology and forcing of the quasi-biennial oscillation in the MAECHAM5 model, J. Climate, 19, 3882-3901, 2006.

Glatthor, N., von Clarmann, T., Fischer, H., Funke, B., Grabowski, U., Höpfner, M., Kellmann, S., Kiefer, M., Linden, A., Milz, M., Steck, T., Stiller, G. P., Mengistu Tsidu, G., and Wang, D. Y.: Mixing processes during the Antarctic vortex split in September/October 2002 as inferred from source gas and ozone distributions from ENVISAT-MIPAS, J. Atmos. Sci., 62, 787-800, 2005.

Glatthor, N., von Clarmann, T., Fischer, H., Funke, B., Gil-López, S., Grabowski, U., Höpfner, M., Kellmann, S., Linden, A., López-Puertas, M., Mengistu Tsidu, G., Milz, M., Steck, T., Stiller, G. P., and Wang, D. Y.: Retrieval of stratospheric ozone profiles from MIPAS/ENVISAT limb emission spectra: a sensitivity study, Atmos. Chem. Phys., 6, 2767-2781, 2006, http://www.atmos-chem-phys.net/6/2767/2006/.

Grewe, V., Brunner, D., Dameris, M., Grenfell, J. L., Hein, R., Shindell, D., and Staehelin, J.: Origin and variability of upper tropospheric nitrogen oxides and ozone at northern mid-latitudes, Atmos. Environ., 35, 3421-3433, 2001.

Hagemann, S., Arpe, K., and Roeckner, E.: Evaluation of the hydrological cycle in the ECHAM5 model, J. Climate, 19, 3810-3827, 2006.

Hall, T. M., Waugh, D. W., Boering, K. A., and Plumb, R. A.: Evaluation of transport in stratospheric models, J. Geophys. Res., 104, 18 815-18 839, 1999.

Hartogh, P., Jarchow, C., Sonnemann, G. R., and Grygalashvyly, M.: On the spatiotemporal behavior of ozone within the upper mesosphere/mesopause region under nearly polar night conditions, J. Geophys. Res., 109, D18303, doi:10.1029/2004JD004576, 2004.

Hervig, M. E., Russell III, J. M., Gordley, L. L., Drayson, S. R., Stone, K., Thompson, R. E., Gelman, M. E., McDermid, I. S., Hauchecorne, A., Keckhut, P., McGee, T. J., Singh, U. N., and Gross, M. R.: Validation of temperature measurements from the Halogen Occultation Experiment, J. Geophys. Res., 101, $10277-$ $10286,1996$.

Hines, C. O.: Doppler spread parameterization of gravity wave momentum deposition in the middle atmosphere. Part I: Basic formulation, J. Atmos. Solar. Terr. Phys., 59, 371-386, 1997a.
Hines, C. O.: Doppler spread parameterization of gravity wave momentum deposition in the middle atmosphere. Part II: Broad and quasi monochromatic spectra and implementation, J. Atmos. Solar. Terr. Phys., 59, 387-400, 1997b.

Houghton, J. T., Ding, Y., Griggs, D. J., Nouger, M., van der Linden, P. J., Dai, X., Maskell, K., and Johnson, C. A.: IPCC - Climate Change 2001: The Scientific Basis. Contribution of Working Group I to the third Assessment Report of the Intergovernmental Panel on Climate Change, Cambridge University Press, 2001.

Jacob, D. J.: Heterogeneous chemistry and tropospheric ozone, Atmos. Environ., 34, 2131-2159, 2000.

Jeuken, A. B. M., Siegmund, P. C., Heijboer, L. C., Feichter, J., and Bengtsson, L.: On the potential of assimilating meteorological analyses in a global climate model for the purpose of model validation, J. Geophys. Res., 101, 16 939-16950, 1996.

Jöckel, P.: Technical Note: Recursive rediscretisation of geoscientific data in multiple dimensions in the Modular Earth Submodel System (MESSy) data import interface, Atmos. Chem. Phys., 6, 3557-3562, 2006,

http://www.atmos-chem-phys.net/6/3557/2006/.

Jöckel, P., Sander, R., Kerkweg, A., Tost, H., and Lelieveld, J.: Technical Note: The Modular Earth Submodel System (MESSy) - a new approach towards Earth System Modeling, Atmos. Chem. Phys., 5, 433-444, 2005,

http://www.atmos-chem-phys.net/5/433/2005/.

Jöckel, P., Tost, H., Pozzer, A., Brühl, C., Buchholz, J., Ganzeveld, L., Hoor, P., Kerkweg, A., Lawrence, M. G., Sander, R., Steil, B., Stiller, G., Tanarhte, M., Taraborrelli, D., van Aardenne, J., and Lelieveld, J.: The atmospheric chemistry general circulation model ECHAM5/MESSy1: consistent simulation of ozone from th surface to the mesosphere, Atmos. Chem. Phys. Discuss., 6, 6957-7050, 2006, http://www.atmos-chem-phys-discuss.net/6/6957/2006/.

Kerkweg, A.: Global Modelling of Atmospheric Halogen Chemistry in the Marine Boundary Layer, Ph.D. thesis, University of Bonn, Germany, http://hss.ulb.uni-bonn.de/diss_online/math nat_fak/2005/kerkweg_astrid/, 2005.

Kerkweg, A., Buchholz, J., Ganzeveld, L., Pozzer, A., Tost, H., and Jöckel, P.: Technical Note: An implementation of the dry removal processes DRY DEPosition and SEDImentation in the Modular Earth Submodel System (MESSy), Atmos. Chem. Phys., 6, 4617-4632, 2006a.

Kerkweg, A., Sander, R., Tost, H., and Jöckel, P.: Technical Note: Implementation of prescribed (OFFLEM), calculated (ONLEM), and pseudo-emissions (TNUDGE) of chemical species in the Modular Earth Submodel System (MESSy), Atmos. Chem. Phys., 6, 3603-3609, 2006b.

Krol, M., van Leeuwen, P. J., and Lelieveld, J.: Global OH trend inferred from methylchloroform measurements, J. Geophys. Res., 103, 10 697-10 711, 1998.

Landgraf, J. and Crutzen, P. J.: An efficient method for online calculations of photolysis and heating rates, J. Atmos. Sci., 55, 863878, 1998.

Lawrence, M. G. and Crutzen, P. J.: The impact of cloud particle gravitational settling on soluble trace gas distributions, Tellus, 50B, 263-289, 1998.

Lawrence, M. G. and Rasch, P. J.: Tracer transport in deep convective updrafts: plume ensemble versus bulk formulations, J. 
Atmos. Sci., 62, 2880-2894, 2005.

Lawrence, M. G., Jöckel, P., and von Kuhlmann, R.: What does the global mean $\mathrm{OH}$ concentration tell us?, Atmos. Chem. Phys., 1, 37-49, 2001, http://www.atmos-chem-phys.net/1/37/2001/.

Lawrence, M. G., Rasch, P. J., von Kuhlmann, R., Williams, J., Fischer, H., de Reus, M., Lelieveld, J., Crutzen, P. J., Schultz, M., Stier, P., Huntrieser, H., Heland, J., Stohl, A., Forster, C., Elbern, H., Jakobs, H., and Dickerson, R. R.: Global chemical weather forecasts for field campaign planning: predictions and observations of large-scale features during MINOS, CONTRACE, and INDOEX, Atmos. Chem. Phys., 3, 267-289, 2003, http://www.atmos-chem-phys.net/3/267/2003/.

Lin, S.-J. and Rood, R.: Multi-dimensional flux-form semiLagrangian transport schemes, Mon. Wea. Rev., 124, 20462070, 1996.

Logan, J. A.: An analysis of ozone-sonde data for the troposphere: Recommendations for testing 3-D models and development of a gridded climatology for tropospheric ozone, J. Geophys. Res., 104, 16 115-16 149, 1999.

Logan, J. A., Prather, M. J., Wofsy, S. C., and McElroy, M. B.: Tropospheric chemistry: A global perspective, J. Geophys. Res., 86, 7210-7254, 1981.

López-Puertas, M., Funke, B., Gil-López, S., von Clarmann, T., Stiller, G. P., Höpfner, M., Kellmann, S., Mengistu Tsidu, G., Fischer, H., and Jackman, C. H.: $\mathrm{HNO}_{3}$, $\mathrm{N}_{2} \mathrm{O}_{5}$, and $\mathrm{ClONO}_{2}$ enhancements after the October-November 2003 solar proton events, J. Geophys. Res., 110, A09S44, doi:10.1029/2005JA011051, 2005a.

López-Puertas, M., Funke, B., Gil-López, S., von Clarmann, T., Stiller, G. P., Kellmann, S., Fischer, H., and Jackman, C. H.: Observation of $\mathrm{NO}_{\mathrm{x}}$ enhancement and ozone depletion in the Northern and Southern Hemispheres after the OctoberNovember 2003 solar proton events, J. Geophys. Res., 110, A09S43, doi:10.1029/2005JA011050, 2005b.

Manney, G. L., Sabutis, J. L., Allen, D. R., Lahoz, W. A., Scaife, A. A., Randall, C., Pawson, S., Naujokat, B., and Swinbank, R.: Simulations of dynamics and transport during the September 2002 Antarctic major warming, J. Atmos. Sci., 62, 690-707, 2005.

Manzini, E. and McFarlane, N. A.: The effect of varying the source spectrum of a gravity wave parameterization in a middle atmosphere general circulation model, J. Geophys. Res., 103, $31523-$ 31539, 1998.

Manzini, E., Giorgetta, M. A., Esch, M., Kornblueh, L., and Roeckner, E.: The influence of sea surface temperatures on the northern winter stratosphere: Ensemble simulations with the MAECHAM5 model, J. Climate, 19, 3863-3881, 2006.

Meilinger, S. K.: Heterogeneous Chemistry in the Tropopause Region: Impact of Aircraft Emissions, Ph.D. thesis No. 13819, ETH Zürich, Switzerland, http://e-collection.ethbib.ethz.ch/ show?type=diss \&nr=13819, 2000.

Mengistu Tsidu, G., Stiller, G. P., von Clarmann, T., Funke, B., Höpfner, M., Fischer, H., Glatthor, N., Grabowski, U., Kellmann, S., Kiefer, M., Linden, A., López-Puertas, M., Milz, M., Steck, T., and Wang, D. Y.: $\mathrm{NO}_{\mathrm{y}}$ from Michelson Interferometer for Passive Atmospheric Sounding on Environmental Satellite during the Southern Hemisphere polar vortex split in September/October 2002, J. Geophys. Res., 110, D11301,
doi:10.1029/2004JD005322, 2005.

Milz, M., von Clarmann, T., Fischer, H., Glatthor, N., Grabowski, U., Höpfner, M., Kellmann, S., Kiefer, M., Linden, A., Mengistu Tsidu, G., Steck, T., and Stiller, G. P.: Water vapor distribution measured with the Michelson Interferometer for Passive Atmospheric Sounding on board Envisat (MIPAS/ENVISAT), J. Geophys. Res., 110, D24307, doi:10.1029/2005JD005973, 2005.

Naujokat, B.: An update of the observed quasi-biennial oscillation of the stratospheric winds over the tropics, J. Atmos. Sci., 43, 1873-1877, 1986.

Nordeng, T. E.: Extended versions of the convective parametrization scheme at ECMWF and their impact on the mean and transient activity of the model in the tropics, Tech. rep., ECWMF, 1994.

Novelli, P. C., Masarie, K. A., and Lang, P. M.: Distributions and recent changes in carbon monoxide in the lower troposphere, J. Geophys. Res., 103, 19015-19033, 1998.

Pawson, S., Kodera, K., Hamilton, K., Shepherd, T. G., Beagley, S. R., Boville, B. A., Farrara, J. D., Fairlie, T. D. A., Kitoh, A., Lahoz, W. A., Langematz, U., Manzini, E., Rind, D. H., Scaife, A. A., Shibata, K., Simon, P., Swinbank, R., Takacs, L., Wilson, R. J., Al-Saadi, J. A., Amodei, M., Chiba, M., Coy, L., de Grandpre, J., Eckman, R. S., Fiorino, M., Grose, W. L., Koide, H., Koshyk, J. N., Li, D., Lerner, J., Mahlman, J. D., McFarlane, N. A., Mechoso, C. R., Molod, A., O'Neill, A., Pierce, R. B., Randel, W. J., Rood, R. B., and Wu, F.: The GCM-reality intercomparison project for SPARC (GRIPS): Scientific issues and initial results, Bull. Am. Met. Soc., 81, 781-796, 2000.

Pickering, K. E., Wang, Y., Tao, W.-K., Price, C., and Müller, J.F.: Vertical distribution of lightning $\mathrm{NO}_{\mathrm{x}}$ for use in regional and chemical transport models, J. Geophys. Res., 103, 31203 $31216,1998$.

Pozzer, A., Jöckel, P., Sander, R., Ganzeveld, L., and Lelieveld, J.: Technical Note: The MESSy-submodel AIRSEA calculating the air-sea exchange of chemical species, Atmos. Chem. Phys. Discuss., 6, 8189-8214, 2006, http://www.atmos-chem-phys-discuss.net/6/8189/2006/.

Price, C. and Rind, D.: Modeling Global Lightning Distributions in a General Circulation Model, Mon. Wea. Rev., 122, 1930-1939, 1994.

Prinn, R. G., Weiss, R. F., Fraser, P. J., Simmonds, P. G., Cunnold, D. M., Alyea, F. N., O’Doherty, S., Salameh, P., Miller, B. R., Huang, J., Wang, R. H. J., Hartley, D. E., Harth, C., Steele, L. P., Sturrock, G., Midgley, P. M., and McCulloch, A.: A history of chemically and radiatively important gases in air deduced from ALE/GAGE/AGAGE, J. Geophys. Res., 105, 17 751-17 792, 2000.

Prinn, R. G., Huang, J., Weiss, R. F., Cunnold, D. M., Fraser, P. J., Simmonds, P. G., McCulloch, A., Harth, C., Salameh, P., O’Doherty, S., Wang, R. H. J., Porter, L., and Miller, B. R.: Evidence for substantial variations of atmospheric hydroxyl radicals in the past two decades, Science, 292, 1882-1888, 2001.

Riese, M., Spang, P., Preusse, P., Ern, M., Jarisch, M., Offermann, D., and Grossmann, K. H.: Cryogenic Infrared Spectrometer and Telescopes for the Atmosphere (CRISTA) data processing and atmospheric temperature and trace gas retrieval, J. Geophys. Res., 104, 16349-16367, 1999.

Roeckner, E., Bäuml, G., Bonaventura, L., Brokopf, R., Esch, M., Giorgetta, M., Hagemann, S., Kirchner, I., 
Kornblueh, L., Manzini, E., Rhodin, A., Schlese, U., Schulzweida, U., and Tompkins, A.: The atmospheric general circulation model ECHAM5. PART I: Model description, Tech. rep., Max Planck Institute for Meteorology, MPI-Report 349, http://www.mpimet.mpg.de/fileadmin/ publikationen/Reports/max_scirep_349.pdf, 2003.

Roeckner, E., Brokopf, R., Esch, M., Giorgetta, M., Hagemann, S., Kornblueh, L., Manzini, E., Schlese, U., and Schulzweida, U.: The atmospheric general circulation model ECHAM5. PART II: Sensitivity of Simulated Climate to Horizontal and Vertical Resolution, Tech. rep., Max Planck Institute for Meteorology, MPI-Report 354, http://www.mpimet.mpg.de/fileadmin/ publikationen/Reports/max_scirep_354.pdf, 2004.

Roeckner, E., Brokopf, R., Esch, M., Giorgetta, M., Hagemann, S., Kornblueh, L., Manzini, E., Schlese, U., and Schulzweida, U.: Sensitivity of simulated climate to horizontal and vertical resolution in the ECHAM5 atmosphere model, J. Climate, 19, 3771-3791, 2006.

Roelofs, G.-J. and Lelieveld, J.: Model study of the influence of cross-tropopause $\mathrm{O}_{3}$ transports on tropospheric $\mathrm{O}_{3}$ levels, Tellus, 49B, 38-55, 1997.

Roelofs, G.-J. and Lelieveld, J.: Tropospheric ozone simulation with a chemistry general circulation model: Influence of higher hydrocarbon chemistry, J. Geophys. Res., 105, 22 697-22 712, 2000.

Roesch, A. and Roeckner, E.: Assessment of snow cover and surface albedo in the ECHAM5 general circulation model, J. Climate, 19, 3828-3843, 2006.

Russell III, J. M., Gordley, L. L., Park, J. H., Drayson, S. R., Hesketh, W. D., Cicerone, R. J., Tuck, A. F., Frederick, J. E., Harries, J. E., and Crutzen, P. J.: The Halogen Occultation Experiment, J. Geophys. Res., 98, 10777-10 797, 1993.

Sander, R., Kerkweg, A., Jöckel, P., and Lelieveld, J.: Technical Note: The new comprehensive atmospheric chemistry module MECCA, Atmos. Chem. Phys., 5, 445-450, 2005, http://www.atmos-chem-phys.net/5/445/2005/.

Sandu, A. and Sander, R.: Technical Note: Simulating chemical systems in Fortran90 and Matlab with the kinetic preprocessor KPP-2.1, Atmos. Chem. Phys., 6, 187-195, 2006, http://www.atmos-chem-phys.net/6/187/2006/.

Schmitt, A. and Brunner, B.: Emissions from aviation and their development over time, in: Pollutants from air traffic - results of atmospheric research 1992-1997. Final Report on the BMBF Verbundprogramm "Schadstoffe in der Luftfahrt", Tech. report, DLR-Mitteilung 97-04, pp. 1-301, 1997.

Spivakovsky, C. M., Yevich, R., Logan, J. A., Wofsy, S. C., McElroy, M. B., and Prather, M. J.: Tropospheric $\mathrm{OH}$ in a threedimensional chemical tracer model: An assessment based on observations of $\mathrm{CH}_{3} \mathrm{CCl}_{3}$, J. Geophys. Res., 95, 18 441-18 471, 1990.

Spivakovsky, C. M., Logan, J. A., Montzka, S. A., Balkanski, Y. J., Foreman-Fowler, M., Jones, D. B. A., Horowitz, L. W., Fusco, A. C., Brenninkmeijer, C. A. M., Prather, M. J., Wofsy, S. C., and McElroy, M. B.: Three-dimensional climatological distribution of tropospheric $\mathrm{OH}$ : Update and evaluation, J. Geophys. Res., 105, 8931-8980, 2000.

Steil, B., Dameris, M., Brühl, C., Crutzen, P. J., Grewe, V., Ponater, M., and Sausen, R.: Development of a chemistry module for GCMs: First results of a multiannual integration, Ann. Geophys.,
16, 205-228, 1998,

http://www.ann-geophys.net/16/205/1998/.

Steil, B., Brühl, C., Manzini, E., Crutzen, P., Lelieveld, J., Rasch, P. J., Roeckner, E., and Krüger, K.: A new interactive chemistry climate model. I: Present day climatology and interannual variability of the middle atmosphere using the model and 9 years of HALOE/UARS data, J. Geophys. Res., 108, 4290, doi:10.1029/2002JD002971, 2003.

Stevenson, D. S., Dentener, F. J., Schultz, M. G., Ellingsen, K., van Noije, T. P. C., Wild, O., Zeng, G., Amann, M., Atherton, C. S., Bell, N., Bergmann, D. J., Bey, I., Butler, T., Cofala, J., Collins, W. J., Derwent, R. G., Doherty, R. M., Drevet, J., Eskes, H. J., Fiore, A. M., Gauss, M., Hauglustaine, D. A., Horowitz, L. W., Isaksen, I. S. A., Krol, M. C., Lamarque, J.-F., Lawrence, M. G., Montanaro, V., Müller, J.-F., Pitari, G., Prather, M. J., Pyle, J. A., Rast, S., Rodriguez, J. M., Sanderson, M. G., Savage, N. H., Shindell, D. T., Strahan, S. E., Sudo, K., and Szopa, S.: Multimodel ensemble simulations of present-day and near-future tropospheric ozone, J. Geophys. Res., 111, D08301, doi:10.1029/2005JD006338, 2006.

Stier, P., Feichter, J., Kinne, S., Kloster, S., Vignati, E., Wilson, J., Ganzeveld, L., Tegen, I., Werner, M., Balkanski, Y., Schulz, M., Boucher, O., Minikin, A., and Petzold, A.: The aerosolclimate model ECHAM5-HAM, Atmos. Chem. Phys., 5, 11251156, 2005, http://www.atmos-chem-phys.net/5/1125/2005/.

Stiller, G. P., Mengistu Tsidu, G., von Clarmann, T., Glatthor, N., Höpfner, M., Kellmann, S., Linden, A., Ruhnke, R., Fischer, H., López-Puertas, M., Funke, B., and Gil-López, S.: An enhanced $\mathrm{HNO}_{3}$ second maximum in the Antarctic midwinter upper stratosphere 2003, J. Geophys. Res., 110, D20303, doi:10.1029/2005JD006011, 2005.

Tanre, D., Geleyn, J.-F., and Slingo, J. M.: First results of the introduction of an advanced aerosol-radiation interaction in the ECMWF low resolution global model, in: Aerosols and their climatic effects, edited by: Gerber, H. and Deepak, A., pp. 133177, A. Deepak, Hampton, VA, 1984.

Taylor, K. E.: Summarizing multiple aspects of model performance in a single diagram, J. Geophys. Res., 106, 7183-7192, 2001.

Thompson, A. M., Witte, J. C., McPeters, R. D., Oltmans, S. J., Schmidlin, F. J., Logan, J. A., Fujiwara, M., Kirchhoff, V. W. J. H., Psny, F., Coetzee, G. J. R., Hoegger, B., Kawakami, S., Ogawa, T., Johnson, B. J., Vömel, H., and Labow, G.: Southern Hemisphere Aditional Ozonesondes SHADOZ 1998-2000 tropical ozone climatology: Comparison with Total Ozone Mapping Spectrometer (TOMS) and ground-based measurements, J. Geophys. Res., 108, 8238, doi:10.1029/2001JD000967, 2003a.

Thompson, A. M., Witte, J. C., Oltmans, S. J., Schmidlin, F. J., Logan, J. A., Fujiwara, M., Kirchhoff, V. W. J. H., Posny, F., Coetzee, G. J. R., Hoegger, B., Kawakami, S., Ogawa, T., Fortuin, J. P. F., and Kelder, H. M.: Southern Hemisphere Aditional Ozonesondes SHADOZ 1998-2000 tropical ozone climatology: 2. Tropospheric variability and the zonal wave-one, J. Geophys. Res., 108, 8241, doi:10.1029/2002JD002241, 2003 b.

Tiedtke, M.: A comprehensive mass flux scheme for cumulus parametrization in large-scale models, Mon. Wea. Rev., 117, 1779-1800, 1989.

Tost, H.: Global Modelling of Cloud, Convection and Precipitation Influences on Trace Gases and Aerosols, Ph.D. thesis, University 
of Bonn, Germany, http://hss.ulb.uni-bonn.de/diss_online/math_ nat_fak/2006/tost_holger/, 2006.

Tost, H., Jöckel, P., Kerkweg, A., Sander, R., and Lelieveld, J.: Technical Note: A new comprehensive SCAVenging submodel for global atmospheric chemistry modelling, Atmos. Chem. Phys., 6, 565-574, 2006a.

Tost, H., Jöckel, P., and Lelieveld, J.: Influence of different convection parameterisations in a GCM, Atmos. Chem. Phys. Discuss., 6, 9213-9257, 2006b.

van Aalst, M. K., van den Broek, M. M. P., Bregman, A., Brühl, C., Steil, B., Toon, G. C., Garcelon, S., Hansford, G. M., Jones, R. L., Gardiner, T. D., Roelofs, G.-J., Lelieveld, J., and Crutzen, P. J.: Trace gas transport in the 1999/2000 Arctic; comparison of nudged GCM runs with observations, Atmos. Chem. Phys., 4, 81-93, 2004,

http://www.atmos-chem-phys.net/4/81/2004/.

van Aardenne, J. A., Dentener, F., Olivier, J. G. G., Peters, J. A. H. W., and Ganzeveld, L. N.: The EDGAR3.2 Fast Track 2000 dataset (32FT2000), Tech. rep., Joint Research Centre, Institute for Environment and Sustainability (JRC-IES), Climate Change Unit, TP280, 21020, Ispra (Va), Italy, http://www.mnp.nl/edgar/ model/v32ft2000edgar/docv32ft2000/, 2005.

van Noije, T. P. C., Eskes, H. J., Dentener, F. J., Stevenson, D. S., Ellingsen, K., Schultz, M. G., Wild, O., Amann, M., Atherton, C. S., Bergmann, D. J., Bey, I., Boersma, K. F., Butler, T., Cofala, J., Drevet, J., Fiore, A. M., Gauss, M., Hauglustaine, D. A., Horowitz, L. W., Isaksen, I. S. A., Krol, M. C., Lamarque, J.F., Lawrence, M. G., Martin, R. V., Montanaro, V., Müller, J.F., Pitari, G., Prather, M. J., Pyle, J. A., Richter, A., Rodriguez, J. M., Savage, N. H., Strahan, S. E., Sudo, K., Szopa, S., and van Roozendael, M.: Multi-model ensemble simulations of tropospheric $\mathrm{NO}_{2}$ compared with GOME retrievals for the year 2000, Atmos. Chem. Phys., 6, 2943-2979, 2006,

http://www.atmos-chem-phys.net/6/2943/2006/.

Vignati, E., Wilson, J., and Stier, P.: M7: An efficient size-resolved aerosol microphysics module for large-scale aerosol transport models, J. Geophys. Res., 109, D22 202, doi:10.1029/2003JD004485, 2004.

von Clarmann, T., Chidiezie Chineke, T., Fischer, H., Funke, B., García-Comas, M., Gil-López, S., Glatthor, N., Grabowski, U., Höpfner, M., Kellmann, S., Kiefer, M., Linden, A., LópezPuertas, M., López-Valverde, M. Á., Mengistu Tsidu, G., Milz, M., Steck, T., and Stiller, G. P.: Remote Sensing of the Middle Atmosphere with MIPAS, in: Remote Sensing of Clouds and the Atmosphere VII, Proceedings of SPIE Vol. 4882, SPIE, Bellingham, WA, USA, edited by: Schäfer, K., Lado-Bordowsky, O., Comerón, A., and Picard, R. H., pp. 172-183, 2003 a. von Clarmann, T., Glatthor, N., Grabowski, U., Höpfner, M., Kellmann, S., Kiefer, M., Linden, A., Mengistu Tsidu, G., Milz, M., Steck, T., Stiller, G. P., Wang, D. Y., Fischer, H., Funke, B., Gil-López, S., , and López-Puertas, M.: Retrieval of temperature and tangent altitude pointing from limb emission spectra recorded from space by the Michelson Interferometer for Passive Atmospheric Sounding (MIPAS), J. Geophys. Res., 108, 4736, doi:10.1029/2003JD003602, 2003b.

von Kuhlmann, R.: Photochemistry of Tropospheric Ozone, its Precursors and the Hydroxyl radical: A 3D-Modeling Study Considering Non-Methane Hydrocarbons, PhD, University of Mainz, Germany, 2001.

von Kuhlmann, R. and Lawrence, M. G.: The impact of ice uptake of nitric acid on atmospheric chemistry, Atmos. Chem. Phys., 6, 225-235, 2006,

http://www.atmos-chem-phys.net/6/225/2006/.

von Kuhlmann, R., Lawrence, M. G., Crutzen, P. J., and Rasch, P. J.: A model for studies of tropospheric ozone and non-methane hydrocarbons: Model evaluation of ozone related species, J. Geophys. Res., 108, 4729, doi:10.1029/2002JD003348, 2003a.

von Kuhlmann, R., Lawrence, M. G., Crutzen, P. J., and Rasch, P. J.: A model for studies of tropospheric ozone and nonmethane hydrocarbons: Model description and ozone results, J. Geophys. Res., 108(D9), 4294, doi:10.1029/2002JD002893, 2003b.

Wang, D. Y., von Clarmann, T., Fischer, H., Funke, B., Gil-López, S., Glatthor, N., Grabowski, U., Höpfner, M., Kaufmann, M., Kellmann, S., Kiefer, M., Koukouli, M. E., Linden, A., LópezPuertas, M., Mengistu Tsidu, G., Milz, M., Steck, T., Stiller, G. P., Simmons, A. J., Dethof, A., Swinbank, R., Marquardt, C., Jiang, J. H., Romans, L. J., Wickert, J., Schmidt, T., Russell III, J., and Remsberg, E.: Validation of stratospheric temperatures measured by Michelson Interferometer for Passive Atmospheric Sounding MIPAS on Envisat, J. Geophys. Res., 110, D08301, doi:10.1029/2004JD005342, 2005.

Wild, M. and Roeckner, E.: Radiative fluxes in the ECHAM5 general circulation model, J. Climate, 19, 3792-3809, 2006.

WMO: International meteorological vocabulary, ISBN: 92-6302182-1, 1992. 